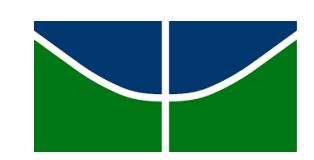

INIVERSIDADE DE BRASÍLIA

INSTITUTO DE FÍSICA

PROGRAMA DE PÓS-GRADUAÇÃO EM FÍSICA

DISSERTAÇÃO DE MESTRADO

Estudo das propriedades estruturais e magnéticas da ferrita de Cobalto-Alumínio 


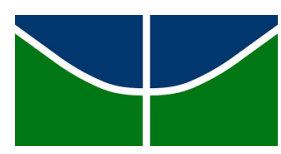

INIVERSIDADE DE BRASÍLIA

INSTITUTO DE FÍSICA

PROGRAMA DE PÓS-GRADUAÇÃO EM FÍSICA

\title{
Estudo das propriedades estruturais e magnéticas da ferrita de Cobalto-Alumínio
}

\author{
Ítalo Sanglard Borel Ferraz
}

Orientador: Prof. Dr. Sebastião William da Silva

Dissertação apresentada ao Programa de Pós-Graduação em Física, do Instituto de Física da Universidade de Brasília, como parte dos requisitos necessários à obtenção do título de Mestre em Física.

BRASÍLIA - DF

Outubro de 2016 


\title{
"Estudo das propriedades estruturais e magnéticas da ferrita de Cobalto-Alumínio."
}

\author{
Por \\ Ítalo Sanglard Borel Ferraz.
}

Dissertação submetida ao Instituto de Física da Universidade de Brasília como parte dos requisitos para a obtenção do grau de Mestre em Física.

Aprovada por:

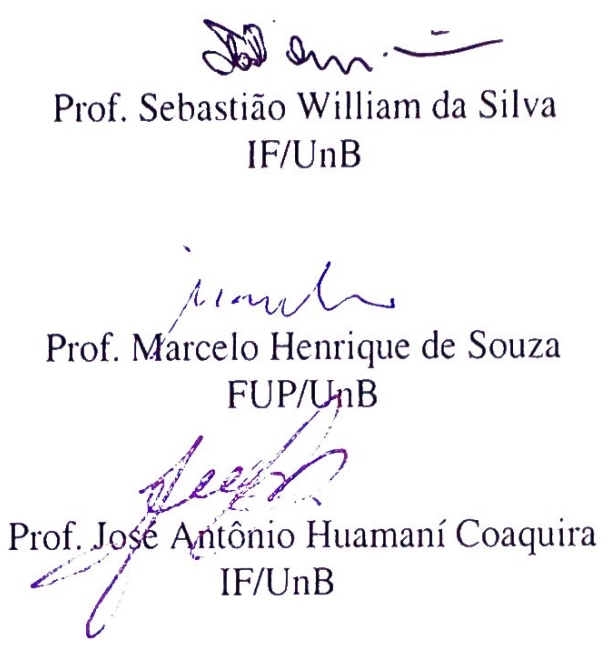

Prof. Dr. Fernando de Oliveira Albuquerque

Coordenador de Pós-Graduação

Instituto de Física 


\section{Dedicatória}

A meu querido avô Emílio Borel, mestre das ciências "ocurtas".

Meu exemplo de persistência. 


\section{AGRADECIMENTOS}

A minha família, principalmente ao meu irmão, Isaac, que desde sempre ouviu tudo que tinha a dizer, mesmo que não fosse tão interessante assim. A minha querida Lidiane (futura Lady Sanglard), por seu amor, paciência e companheirismo.

Ao meu orientador, Prof. Dr. Sebastião William da Silva, por seus ensinamentos inestimáveis, sábios conselhos e pela inexplicável paciência. Ao "mestre" Tiago Castro (Obiwan). Sem sua ajuda este trabalho não teria se concretizado. Ao professor Dr. Adolfo Franco Júnior (Universidade de Goiás), e seu grupo, pela síntese das amostras.

Aos professores Júnio Márcio R. Cruz, Dr. Pedro Augusto M. Rodrigues e Dr. José Antônio Coaquira pelo incentivo e valiosas discussões. Aos professores Dr. Vijayendra Kumar Gard e Dr. Aderbal Carlos de Oliveira pelas medidas de Espectroscopia Mössbauer e ao meu querido amigo Prof. Ademir Santana (condutor da carroça fotônica), por ter me ensinado o que o elétron realmente significa.

Aos meus amigos físicos: Carmem, Thaís, Guilherme, Tathianne "Thati”, Gustavo, Luiz Fernando "Zé” e Gabriel “manco", Juliano "Julis” e Gabriel Nagamine “Japa”. Aos meus amigos da "caverna do dragão": Alan "o abençoado", Arlon "o falastrão", Antônio "o bondoso", Tom “o lindão", Artur "o simpático", Rennan "o habilidoso" e Jack “o eficiente".

A todos os meus amigos não físicos, em especial os participantes da "colegaiada". Aos meus irmãos de coração, Rafael Everson, Gustavo Mesquita, Eduardo Henrique, Guilherme Monteiro e Osmar Júnior.

A CAPES pela concessão da bolsa de estudos. 
"...the problem is not so much, to see what nobody has yet seen, but rather to think concerning that which everybody sees, what nobody has yet thought." (Arthur Schopenhauer) 


\section{RESUMO}

Ferritas de cobalto $\left(\mathrm{CoFe}_{2} \mathrm{O}_{4}\right)$ têm sido estudados extensivamente nos últimos anos devido a suas notáveis propriedades físicas. Estas propriedades fazem dele um bom candidato para a fabricação de sensores magnéticos, sistemas de carreamento de fármacos, diagnóstico médico, gravação magnética de alta densidade, etc. Suas propriedades magnéticas, que são comuns à maioria das ferritas de estrutura espinélio, são explicadas pela intensa interação de supertroca entre os cátions localizados nos sítios A e B. Assim, pode ser possível ajustar o momento magnético, substituindo os cátions de ferro na estrutura espinélio por algum outro elemento não-magnético, enfraquecendo a interação de supertroca, abrindo a possibilidade de um ajuste magnético fino de maneira a atender a aplicação tecnológica visionada. Um possível bom candidato para substituição é o alumínio. Ele tem zero momento magnético e também a vantagem econômica de baixo custo de aquisição. As ferritas de cobalto-alumínio $\left(\mathrm{CoAl}_{\mathrm{x}} \mathrm{Fe}_{2}\right.$ ${ }_{\mathrm{x}} \mathrm{O}_{4}$ ) trazem algumas alterações importantes nas propriedades estruturais e magnéticas do $\mathrm{CoFe}_{2} \mathrm{O}_{4}$, expandindo as possíveis áreas de aplicação. Neste trabalho, foi utilizado a espectroscopia Mössbauer e Difração de raios X (DRX) para investigar a distribuição de cátions no $\mathrm{CoAl}_{\mathrm{x}} \mathrm{Fe}_{2-\mathrm{x}} \mathrm{O}_{4}$ sintetizado pelo método de reação de combustão, com teor de Alumínio (x) variando entre 0,00 e 2,00. A estrutura de fase única espinélio foi verificada por DRX e confirmada por espectroscopia de Raman. Os modos Raman foram deslocados para o azul com o aumento no teor de alumínio. Além disso, observou-se que a intensidade dos picos de difração nos padrões de DRX varia em função da distribuição catiônica de alumínio substitucional. Fazendo uso destes resultados foi possível determinar, com ajuda do método de refinamento de Rietveld e da espectroscopia Mössbauer, a distribuição catiônica das amostras de $\mathrm{CoAl}_{\mathrm{x}} \mathrm{Fe}_{2-\mathrm{x}} \mathrm{O}_{4}$. Além do mais, medidas de magnetização mostraram uma queda geral da magnetização de saturação e magnetização remanescente com o aumento no teor de Alumínio, indicando um enfraquecimento das interações de supertroca.

Palavras-chave: Ferrita de Cobalto-Alumínio. Ferrita espinélio. Espectroscopia Mössbauer. Método de Rietveld. 


\begin{abstract}
Cobalt ferrites $\left(\mathrm{CoFe}_{2} \mathrm{O}_{4}\right)$ have been extensively studied in the past few years due to their remarkable physical properties. They have been quoted as one of the best candidates for high density magnetic recording. These properties make it also a good candidate for its use in magnetic sensors, drug delivery systems, medical diagnosis, etc . Their magnetic properties, that are common to most of the spinel ferrite materials, are explained by the super-exchange interactions between A- and B-sites cations. Thus, it may be possible to tune the magnetic moment by replacing the iron cation in the spinel structure by some other non-magnetic element, weakening the super-exchange interaction, opening the possibility of magnetic fine adjustment as the technological application may require. One possible good candidate for substitution is aluminium. It has zero magnetic moment and also the economic advantage of low cost of purchase. The aluminium substituted cobalt ferrites $\left(\mathrm{CoAl}_{\mathrm{x}} \mathrm{Fe}_{2-\mathrm{x}} \mathrm{O}_{4}\right)$ brings some important changes in the structural and magnetic properties of $\mathrm{CoFe}_{2} \mathrm{O}_{4}$, expanding the fields of possible applications. In this work, we use X-Ray Difraction and Mössbauer spectroscopy to investigate the cation distribution on the $\mathrm{CoAl}_{\mathrm{x}} \mathrm{Fe}_{2-\mathrm{x}} \mathrm{O}_{4}$ with $\mathrm{x}$ varying composition from 0,00 to 2,00 synthesized by combustion reaction method. The formation of a single phase spinel structure was verified by X-ray diffraction (XRD) and confirmed by Raman spectroscopy. The Raman modes were blue-shifted with increase on aluminum content. In addition, it was observed that the intensity of the diffraction peaks changed as the aluminium content distribution was varied. Using those observations it was possible, with the help of the Rietveld refinement method and Mössbauer spectroscopy, to calculate the cation distribution in A- and B-sites of the spinel structure. Also, magnetization measurements showed an overall decay of the saturation magnetization and remanent magnetization with increase in aluminium content, indicating the weakening of the super-exchange interactions.
\end{abstract}

Keywords: Aluminium substituted cobalt ferrites. Spinel ferrite. Mössbauer spectroscopy. Rietveld analysis. 


\section{LISTA DE TABELAS}

Tabela 5.1 : Parâmetros obtidos por meio do refinamento Rietveld dos espectrogramas de DRX das amostras de $\mathrm{CoAl}_{\mathrm{x}} \mathrm{Fe}_{2-\mathrm{x}} \mathrm{O}_{4}$ 66

Tabela 5.2 : Fatores de espalhamento atômico dos íons constituintes da ferrita de $\mathrm{CoAl}_{\mathrm{x}} \mathrm{Fe}_{2-}$ ${ }_{\mathrm{x}} \mathrm{O}_{4}$

Tabela 5.3 : Distribuição de cátions obtidas por meio das técnicas de espectroscopias Mössbauer e DRX (Refinamento de Rietiveld). M representa o íon Co/Al não diferenciados na espectroscopia Mössbauer. A medida de erro $\xi^{2}$ foi obtido por meio do refinamento dos padrões de DRX pelo método o de Rietveld. 72

Tabela 5.4 : Parâmetros obtidos através de histerese magnética das amostras de $\mathrm{CoAl}_{\mathrm{x}} \mathrm{Fe}_{2-\mathrm{x}} \mathrm{O}_{4}$ a temperatura ambiente. $M_{S}$ : magnetização de saturação, $H_{C}$ : campo coercivo, $K_{e f f}$ : anisotropia magnetocristalina efetiva). 90 


\section{LISTA DE FIGURAS}

Fig. 2.2: Espectro Raman característico da molécula de $\mathrm{CCl}_{4}$. Modos vibracionais deslocadas do espalhamento Rayleigh para maiores números de onda (energia) são chamados modos antiStokes. Modos deslocados para menores números de onda em relação ao espalhamento Rayleigh são chamados modos Stokes. Adaptada de [14]. 21

Fig. 2.3: Hand mit Ringen (Mão com aliança). Primeiro imagem negativa realizada por absorção de Raio X da história, tirado por Wilhelm Röntgen da mão de sua esposa em dezembro de 1895.[15].

Fig. 2.4: Espectros de raios $\mathrm{X}$ de um anodo de molibdênio em função da voltagem aplicada. Adaptada de [16]. 26

Fig. 2.5: Descrição do efeito do estresse homogêneo e não homogêneo nos picos de difração. Adaptada de [17]. 30

Fig. 2.6: Representação das bandas de emissão e absorção nuclear entre núcleos Mössbauer.

Fig. 2.7: Intensidade total e intensidade relativa em espectros Mössbauer (singleto). 34

Fig. 2.8: Desvio isomérico no espectro Mössbauer (singleto). (a) Correção nas energias causada pela diferença entre o raio atômico no estado fundamental $E_{o}$ e estado excitado $E_{S}$, tanto para o absorvedor quanto para a fonte. (b) Desvio isomérico no espectro Mössbauer...37 Fig. 2.9: Possíveis espectros Mössbauer e o efeito das possíveis interações nos níveis energéticos. Adaptada de [19]. 39

Fig. 3.1: Representação e classificação dos diferentes tipos de materiais magnéticos. Adaptada de $[20]$

Fig. 3.2: Célula unitária da estrutura espinélio cúbica. A estrutura mostrada se repete em áreas de mesma cor. Adaptada de [22]. 
Fig. 3.3: Sítio de coordenação tetraédrica na estrutura espinélio cúbica. Adaptada de [22].... 43 Fig. 3.4: Sítio de coordenação octaédrica na estrutura espinélio cúbica e detalhe da vizinhança. Adaptada de [22]. 44

Fig. 3.5: Detalhe da vizinhança do oxigênio na estrutura espinélio cúbica. Adaptada de [22].

Fig. 3.6: Modos vibracionais da estrutura espinélio atribuidas por Verble [36]. 50

Fig. 4.1: Chamas produzidas durante reação de combustão [11]. 55

Fig. 5.1: Espectros Mössbauer das amostras de $\mathrm{CoAl}_{\mathrm{x}} \mathrm{Fe}_{2-\mathrm{x}} \mathrm{O}_{4}$ obtidos à temperatura de $77 \mathrm{~K}$ em geometria de transmissão. As linhas verticais pontilhadas são apenas guia para os olhos. 60 Fig. 5.2: Dependência dos Parâmetros hiperfinos em função do teor de Al substitucional, obtidos para as amostras de $\mathrm{CoAl}_{\mathrm{x}} \mathrm{Fe}_{2-\mathrm{x}} \mathrm{O}_{4}$ : (a) Campo Hiperfino HF, (b) Desvio Isométrico IS, (c) Desvio Quadrupolar QS e (d) população percentual de Fe nos sítios A e B. Os círculos cheios estão relacionados aos sítios tetraédricos, enquanto os vazios aos sítios octaédricos. As linhas pontilhadas são apenas guia para os olhos. 61

Fig. 5.3: (a) Padrões de difração de raios $\mathrm{X}$ das amostras de $\mathrm{CoAl}_{\mathrm{x}} \mathrm{Fe}_{2-\mathrm{x}} \mathrm{O}_{4} \operatorname{com} x=0,0-$ 2,0 . 64

Fig. 5.4: (a) Refinamento Rietveld do padrão de DRX da amostra com $x=0,20$. A inserção mostra detalhes do ajuste em torno do pico (311). (b) Parâmetro de rede das amostras de $\mathrm{CoAl}_{\mathrm{x}} \mathrm{Fe}_{2-\mathrm{x}} \mathrm{O}_{4} \operatorname{com} x=0,0-2,0$ obtido por meio do refinamento Rietveld. 65

Fig. 5.5: Variação das intensidades dos planos (220) (a) e (c), (400) (b) e (d), (222) (e) e (331) (f) em função do teor de Alumínio substitucional no sítio tetraédrico $A l($ sítio A). As áreas de todos os espectrogramas foram normalizados a unidade. 70

Fig. 5.6: Simulação: razão entre as intensidades dos picos (220) (400) obtidos para a ferrita de $\mathrm{CoAl}_{\mathrm{x}} \mathrm{Fe}_{2-\mathrm{x}} \mathrm{O}_{4} \operatorname{com} x=0,30,1,00$ e 2,00 em função do teor de Alumínio substitucional no sítio tetraédrico $A l($ sítio $A)$. 71 
Fig. 5.7: Espectros Raman das amostras de $\mathrm{CoAl}_{\mathrm{x}} \mathrm{Fe}_{2-\mathrm{x}} \mathrm{O}_{4} \operatorname{com} x=0,00$ - 2,00. Os principais modos vibracionais previstos para as ferrita de Cobalto $(x=0,00)$ e Cobalto Azul $(x=2,00)$ estão indicados por retas tracejadas e pontilhadas, respectivamente. As curvas vermelhas representam o melhor ajuste. 76

Fig. 5.8: Detalhes dos espectros Raman das amostras de. $\mathrm{CoFe}_{2} \mathrm{O}_{4}$ (a) e $\mathrm{CoAl}_{2} \mathrm{O}_{4}$. (b) Deslocamentos dos modos vibracionais (c) $E_{g}$, (d) $F_{2 g}(3)$, (e) $F_{2 g}(2)$ e (f) $A_{1 g}$ em função do teor de $A l(x)$ substitucional.

Fig. 5.9: Curvas de histerese, $M$ vs $H$, das amostras de $\mathrm{CoAl}_{\mathrm{x}} \mathrm{Fe}_{2-\mathrm{x}} \mathrm{O}_{4}$ com teor de $\operatorname{Al}(x)$ no intervalo $0,00-2,00$. Detalhe das curvas $x=1,50$ e $x=2,00$.. 80

Fig. 5.10: Comparação entre os valores de magnetização de saturação $M s$ experimentais, obtidos para as amostras de $\mathrm{CoAl}_{\mathrm{x}} \mathrm{Fe}_{2-\mathrm{x}} \mathrm{O}_{4}$ (em vermelho) e teóricos, obtidos por meio da equação (5.2) e da distribuição de cátions mostradas na Tabela 5.3 (em preto). As linhas pontilhadas servem apenas como guia para os olhos. 81

Fig. 5.11: Primeiro quadrante da curva $M v s H$ para as amostras $x=0,20$ e $\mathrm{x}=1,50$ a $5 \mathrm{~K}$ (vermelho) e a $300 \mathrm{~K}$ (preto). 84

Fig. 5.12: Curvas ZFC(preto)-FC(vermelho) das amostras de $\mathrm{CoAl}_{\mathrm{x}} \mathrm{Fe}_{2-\mathrm{x}} \mathrm{O}_{4}$ para $x=$ $0,00,0,20,1,50$ e 2,00 . 87 


\section{SUMÁRIO}

CAPÍTULO 1: INTRODUÇÃO .....................................................................................15

CAPÍTULO 2: TÉCNICAS DE CARACTERIZAÇÃO ..........................................................19

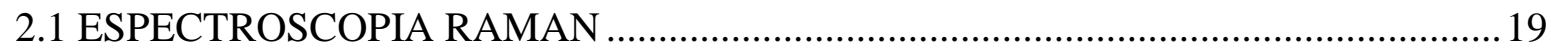

2.1.1 Introdução ao efeito Raman.................................................................................. 19

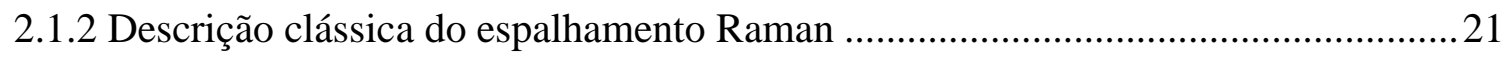

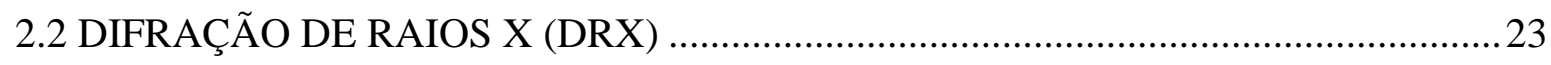

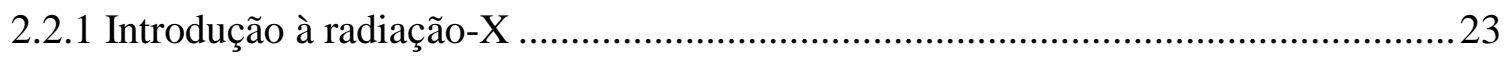

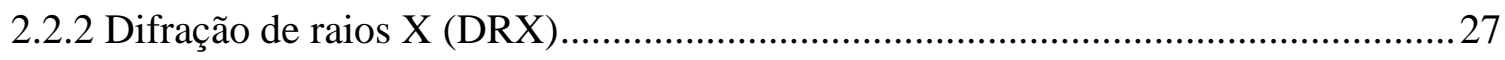

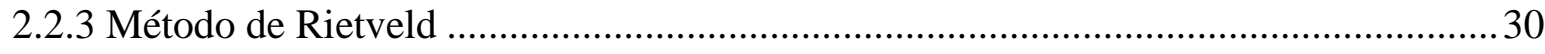

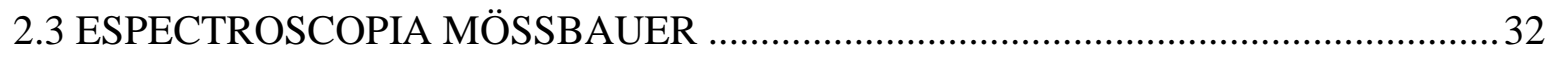

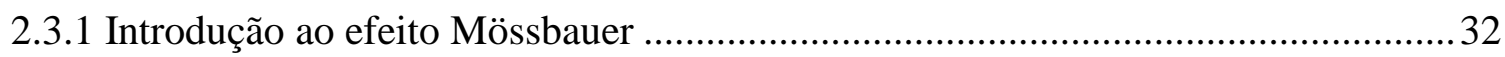

2.3.2 Principais propriedades dos espectros Mössbauer................................................. 33

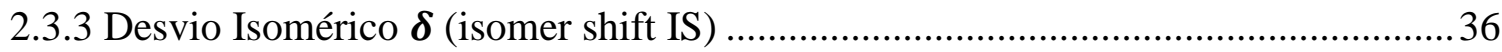

2.3.4 Desdobramento quadrupolar (quadrupole spliting QS) ...................................... 37

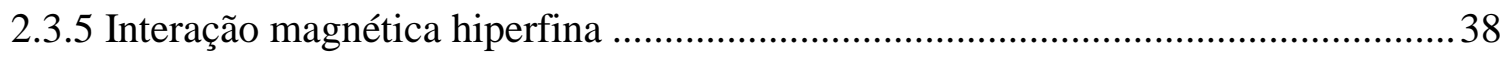

CAPÍTULO 3: REVISÃO SOBRE FERITAS ESPINÉLIO.................................................40

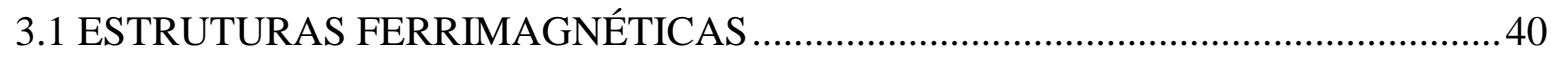

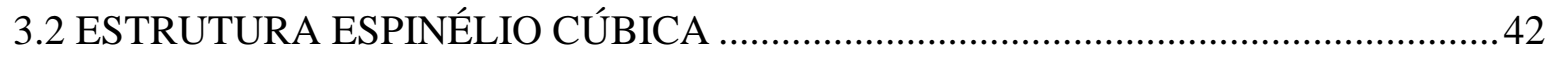

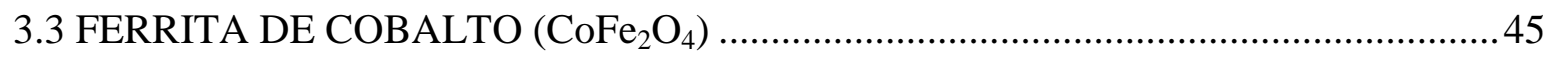

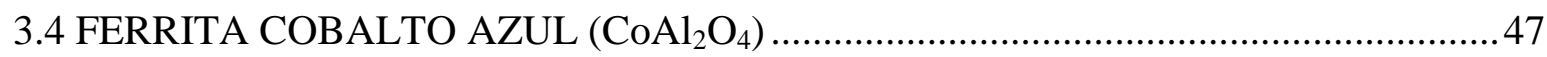

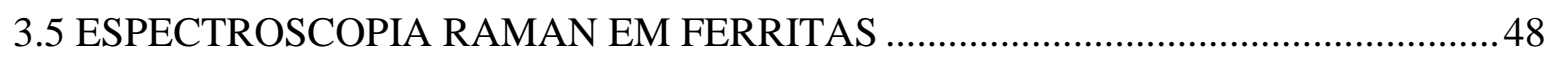


4.1 PREPARAÇÃO DAS AMOSTRAS 54

4.2 ESPECTROSCOPIA RAMAN 56

4.3 ESPECTROSCOPIA MÖSSBAUER 56

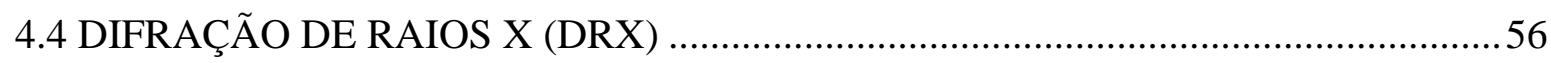

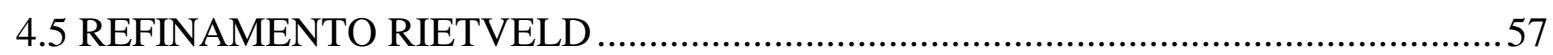

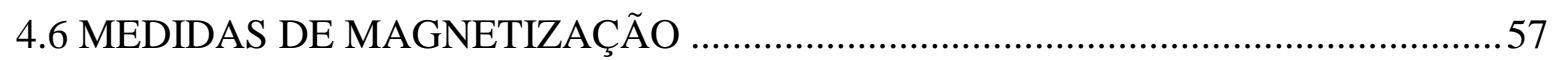

CAPÍTULO 5: RESULTADOS E DISCUSSÕES ..................................................................58

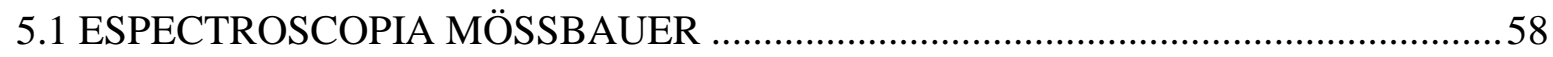

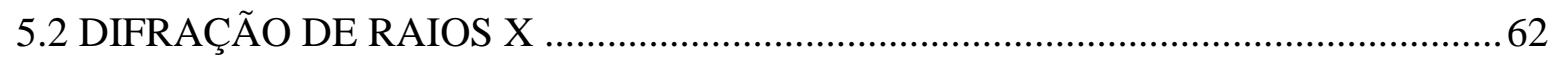

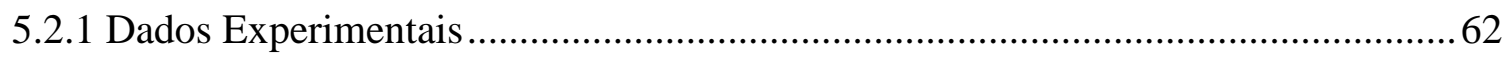

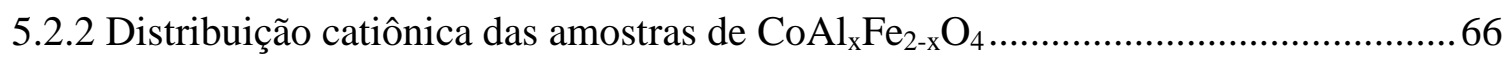

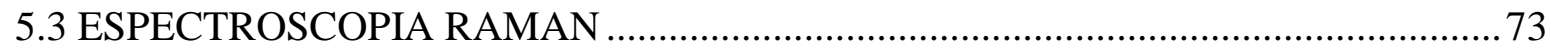

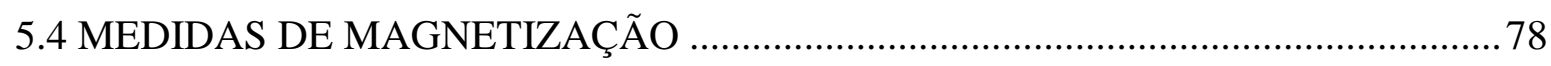

CAPÍTULO 6: CONCLUSÕES E PERSPECTIVAS FUTURAS ......................................91

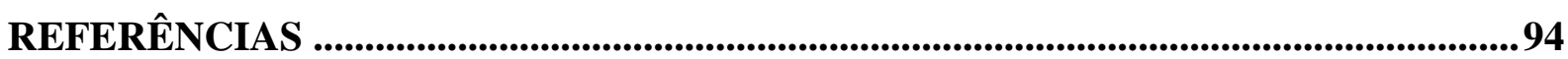




\section{CAPÍULO 1: INTRODUÇÃO}

Materiais magnéticos nanoparticulados têm sido intensivamente investigados devido à sua grande aplicabilidade em diversas áreas do conhecimento. Dentre esses materiais, as nanopartículas magnéticas à base de óxidos de ferro têm se destacado, uma vez que são largamente utilizadas como material base em uma grande variedade de aplicações tecnológicas e biotecnológicas, tais como: gravação magnética em alta densidade, catalisadores e sistemas de vetorização de fármacos ("drug delivery") [1], entre outras. Em qualquer uma destas aplicações requer-se que as nanopartículas bem como as moléculas a elas funcionalizadas possuam propriedades bem definidas. Contudo, suas propriedades físicas e químicas são criticamente dependentes dos íons envolvidos bem com das condições de síntese e técnicas/processos de preparação [2].

Devido aos vários graus de liberdade da estrutura cristalina, tem-se a possibilidade do controle e modificação de suas propriedades físicas. Essas modificações podem ser alcançadas de várias formas: controlando sua estequiometria no processo de síntese, tratando termicamente as amostras, aplicando campos magnéticos intensos, etc. Pode-se também sintetizar ferritas mistas, introduzindo íons não magnéticos como o alumínio, por exemplo. Dessa forma as propriedades magnéticas podem ser controladas por meio da substituição dos íons na estrutura cristalina do material [3].

Um dos integrantes da família dos óxidos metálicos mais interessantes é a ferrita de cobalto $\left(\mathrm{CoFe}_{2} \mathrm{O}_{4}\right)$, que possui estrutura espinélio inversa [4]. Estudos mostram que ela possui alta magnetorrestritividade devido à alta anisotropia magnetocristalina, o que por sua vez é governada pela presença dos íons de Co nos sítios octaédricos da estrutura [3].

Um dos fatores responsáveis pelas propriedades magnéticas da ferrita de cobalto pura é a forte interação de supertroca entre os cátions nos sítios tetraédricos (sítio A) e octaédricos 
(sítio B). Para esse composto a força da interação de supertroca varia com a ocupação dos íons $\mathrm{Co}^{2+}$ nos sítios $\mathrm{A}$, pois a interação entre $\mathrm{Fe}^{3+}(\mathrm{A})-\mathrm{Fe}^{3+}(\mathrm{B})$ é mais forte que a interação entre $\mathrm{Co}^{2+}(\mathrm{A})-\mathrm{Fe}^{3+}(\mathrm{B})$. Esta diferença é atribuída as diferentes superposições das funções de onda dos elétrons $d$, o que leva a integrais de troca distintas para cada distribuição de cátions entre os sítios A-B, como reportado por Sawatzky et al $[5,6]$. Sendo assim, muitos grupos têm controlado as propriedades magnéticas da ferrita de cobalto substituindo cátions magnéticos ou não magnéticos nos sítios A e B. Dessa forma pode-se ter um controle fino dessas propriedades, o que é essencial às aplicações tecnológicas. Em particular, alguns estudos foram realizados sobre os efeitos da substituição do íon ferro por íon alumínio na estrutura da ferrita de cobalto [3, 7, 8]. Várias aplicações interessantes emergem da substituição do cátion trivalente (magnético) pelo alumínio (não magnético). Esse novo composto chamado ferrita de cobalto-alumínio $\mathrm{CoAl}_{\mathrm{x}} \mathrm{Fe}_{2-\mathrm{x}} \mathrm{O}_{4}$ tem mostrado novas propriedades, dentre as quais destacam-se: ajuste fino do coeficiente magnetostrictivo e da sensibilidade ao estresse (strain sensitivity), controle da magnetização de saturação e coercividade, essenciais a aplicação em novos dispositivos eletrônicos [7].

Outros fatores com grande influência nas propriedades magnéticas da ferrita de cobalto-alumínio são: método de síntese escolhido e a temperatura de recozimento nos tratamentos térmicos das amostras. Estudos como o de Kumar et al. [8] mostram que a cristalinidade das amostras cresce com a temperatura de recozimento, bem como o tamanho médio dos nanocristais. Também foi mostrado que para amostras sintetizadas pelo método citrato precursor (citrate precursor method), as amostras tratadas termicamente a $400{ }^{\circ} \mathrm{C}$ estão na faixa de domínio único, enquanto as tratadas a $800{ }^{\circ} \mathrm{C}$ estão na faixa de domínios múltiplos. Foi mostrado que a coercividade aumenta com o tamanho da região de domínio único. Entretanto, ela decresce para amostras na faixa de multidomínios. 
Embora existam alguns trabalhos investigando as propriedades da ferrita de cobaltoalumínio, ainda não se tem um consenso sobre como se dá a substituição do Al nos sítios tetraédrico e octaédrico. No trabalho de Kumar et al. [9] é sugerido que para $x<0,20$ não existe sítio preferencial para a substituição, de forma que o alumínio substitui o ferro tanto no sítio A quanto no B. Apenas para $x>0,20$ surgiria uma preferência pela substituição do ferro no sítio octaédrico. Em sua maioria, esses trabalhos determinam a ocupação dos sítios por meio do refinamento de medidas de difração de raios $\mathrm{X}$ (DRX) [3], [8]. Até o presente momento, apenas um trabalho foi encontrado na literatura [10] em que foram feitas medidas de espectroscopia Mössbauer com o objetivo de calcular a distribuição catiônica de amostras de ferrita de Cobalto-Alumínio. Além disso, não foram encontrados até o momento estudos detalhados utilizando espectroscopia Raman para investigar a ferrita de $\mathrm{CoAl}_{\mathrm{x}} \mathrm{Fe}_{2-\mathrm{x}} \mathrm{O}_{4}$.

Diferentes técnicas têm sido utilizadas na síntese da ferrita de cobalto-alumínio, como por exemplo: citrato-gel, rota aerossol, citrato precursor, autocombustão sol-gel, reação de combustão, etc. Dentre estas, a reação de combustão apresenta processo de síntese simples e relativamente barato, permitindo possível produção em grande escala. O método de reação por combustão é rápido, não utiliza reagentes tóxicos e não envolve passos intermediários de decomposição. Além disso, permite facilmente o controle da estequiometria, que por sua vez tem relação direta com as propriedades magnéticas e estruturais [11]. O processo ocorre através de uma reação química exotérmica entre os nitratos metálicos em solução aquosa e um combustível orgânico, geralmente ureia, resultando em um aglomerado cristalino seco, homogêneo e de alta pureza. A reação é induzida através do aquecimento dos reagentes até certa temperatura de ignição característica, onde se inicia uma reação exotérmica autossustentável durante um pequeno intervalo de tempo, produzindo assim o nanocomposto desejado [12]. 
Neste trabalho são investigadas as propriedades estruturais e magnéticas da ferrita de cobalto-alumínio $\mathrm{CoAl}_{\mathrm{x}} \mathrm{Fe}_{2-\mathrm{x}} \mathrm{O}_{4}$, sintetizada pelo método de reação de combustão, fazendo uso das seguintes técnicas de caracterização: espectroscopia Raman, espectroscopia Mossbauer, difração de raios $\mathrm{X}$. 


\section{CAPÍTULO 2: TÉCNICAS DE CARACTERIZAÇÃO}

\subsection{ESPECTROSCOPIA RAMAN}

\subsubsection{Introdução ao efeito Raman}

Espectros de espalhamento Raman, assim como os de infravermelho, tem origem na interação entre a radiação eletromagnética e o movimento vibracional dos núcleos atômicos. Enquanto a radiação infravermelha é relacionada a processos ressonantes com espalhamentos elásticos, o espalhamento Raman é relacionado a espalhamentos inelásticos, ocorrendo na região do visível. As frequências vibracionais são dadas então pela diferença de energias das radiações incidente e espalhada. Embora os dois espectros se relacionem a modos vibracionais, seus mecanismos de produção não são os mesmos. Para determinado modo vibracional ser Raman ativo, deve haver variação na polarizabilidade da molécula durante a vibração. Já no caso do espectro infravermelho, é necessário que haja variação no momento dipolar da molécula. Adolf Gustav Stephan Smekal (1895-1959) foi quem, em 1923 previu o espalhamento inelástico de fótons. Entretanto, somente em 1928 o efeito seria detectado experimentalmente por Chandrasekhara Venkata Raman (1988-1970) e por seu aluno de doutorado Kariamanickam Srinivasa Krishnan. O espalhamento inelástico foi descoberto independentemente em cristais por Grigory Landsberg, também em 1928, mas acabou sendo nomeado em homenagem a Raman. Devido ao impacto de sua descoberta, recebeu em 1930 o prêmio Nobel de Física [13].

Para moléculas simples, duas possibilidades existem para o fóton incidente: ser espalhado elasticamente, efeito conhecido como espalhamento Rayleigh, ou ser espalhado inelasticamente (espalhamento Raman). No caso de cristais, fótons podem ser espalhados por 
fônons da rede cristalina. Neste caso, a energia recebida ou perdida pelo fóton corresponde à excitação ou desexcitação de algum nível energético da rede (níveis energéticos dos fônons). Se o fóton incidente induz a criação de um fônon, o fóton espalhado terá energia mais baixa que o incidente. Por outro lado, se a absorção induz a aniquilação de um fônon, o fóton espalhado terá energia maior que o incidente.

A Fig. 2.1 ilustra as possíveis transições energéticas da rede induzidas pelo fóton incidente: O espalhamento gerado com criação de fônons, chamado espalhamento Stokes, e o gerado com aniquilação de fônons, chamado espalhamento anti-Stokes. A energia do fóton incidente é dada por $h v_{0}$ enquanto $E_{0}+h v_{m}$ corresponde à energia do estado excitado de vibração. A Fig. 2.2 mostra um espectro Raman característico. Em geral, o espectro é dado em função da diferença do número de onda relativo à linha do laser (primeira escala da Fig. 2.2).

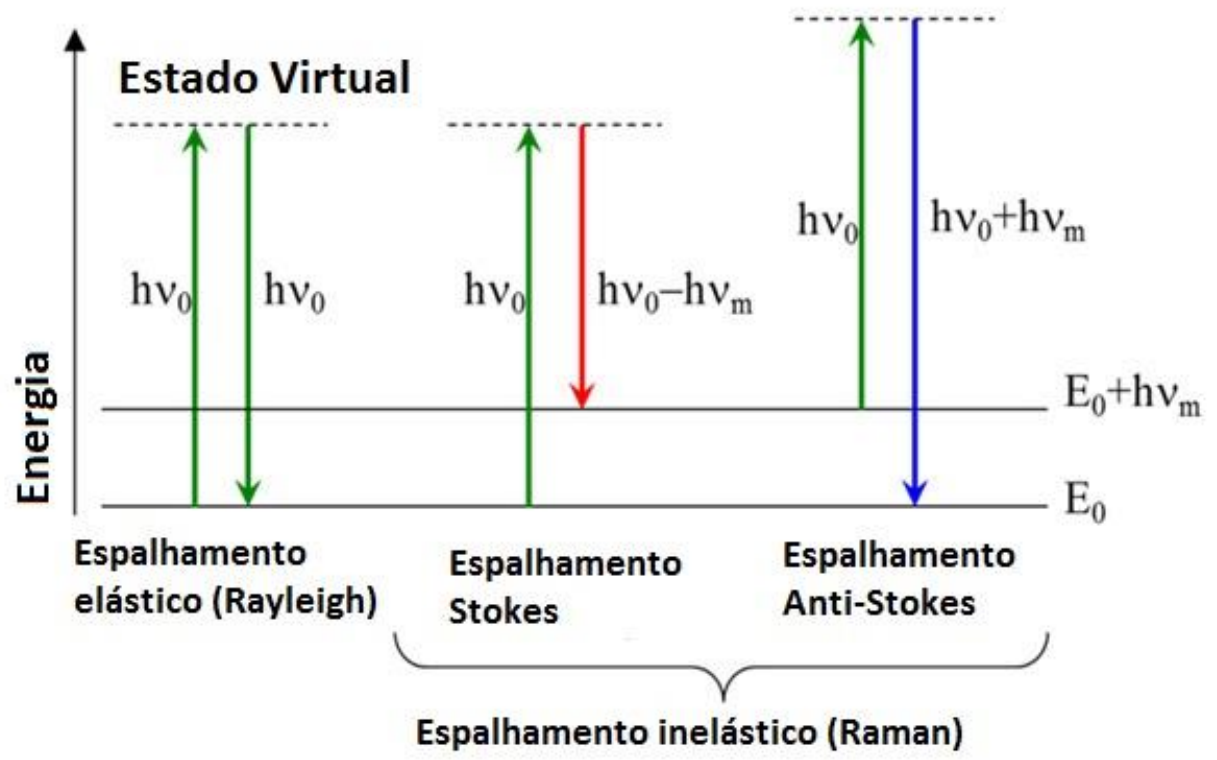

Fig. 2.1: Descrição das possíveis transições induzidas na rede pelo fóton incidente. $\boldsymbol{E}_{\mathbf{0}}$ corresponde ao estado fundamental de vibração enquanto $\boldsymbol{E}_{\mathbf{0}}+\boldsymbol{h} \boldsymbol{v}_{\boldsymbol{m}}$ corresponde ao estado excitado. Adaptada de [14]. 


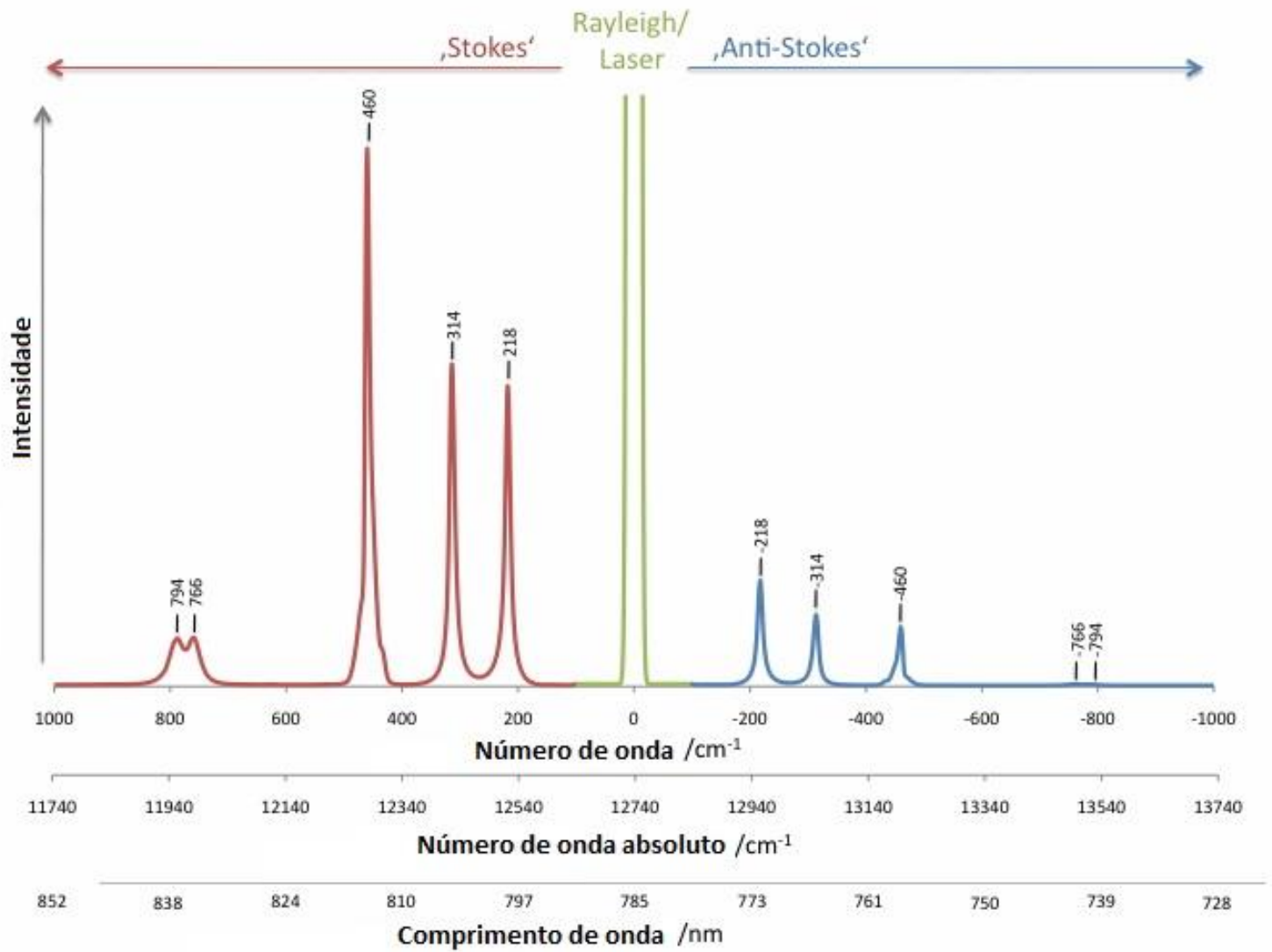

Fig. 2.2: Espectro Raman característico da molécula de $\mathrm{CCl}_{4}$. Modos vibracionais deslocadas do espalhamento Rayleigh para maiores números de onda (energia) são chamados modos anti-Stokes. Modos deslocados para menores números de onda em relação ao espalhamento Rayleigh são chamados modos Stokes. Adaptada de [14].

\subsubsection{Descrição clássica do espalhamento Raman}

A origem da radiação espalhada no efeito Raman está relacionada ao surgimento de momentos de dipolo elétrico induzido pela radiação incidente. A presença de um campo elétrico externo gera uma distorção da nuvem eletrônica, dando origem a momentos de dipolo induzidos na rede cristalina. $\mathrm{Na}$ aproximação de campos de baixa intensidade, o momento de dipolo induzido pode ser descrito pela seguinte equação 


$$
\vec{p}=\overleftrightarrow{\alpha} \cdot \vec{E}
$$

no qual $\overleftrightarrow{\alpha}$ é chamado tensor de polarizabilidade e $\vec{E}$ é o campo elétrico externo,

$$
\vec{E}=\overrightarrow{E_{0}} \cos \left(2 \pi v_{0} t\right)
$$

O movimento dos núcleos da rede cristalina causado pela absorção dos fótons pode ser descrito de forma simplificada pela seguinte equação

$$
\vec{q}=\overrightarrow{q_{0}} \cos \left(2 \pi v_{m} t\right)
$$

onde $q_{0}$ representa a amplitude do movimento e $v_{m}$ sua frequência de oscilação. Para pequenas amplitudes, o tensor de polarizabilidade pode ser escrito como uma função linear do vetor deslocamento

$$
\overleftrightarrow{\alpha}=\overleftrightarrow{\alpha_{0}}+\overleftrightarrow{\left(\frac{\partial \alpha}{\partial q}\right)_{0}} \vec{q}+\cdots
$$

onde a derivada é tomada na posição de equilíbrio. Considerando as equações $(2.1)-(2.4)$ pode-se escrever o momento de dipolo como

$$
\vec{p}=\overleftrightarrow{\alpha_{0}} \overrightarrow{E_{0}} \cos \left(2 \pi v_{0} t\right)+\overleftrightarrow{\left(\frac{\partial \alpha}{\partial q}\right)_{0}} \overrightarrow{q_{0}} \cdot \overrightarrow{E_{0}} \cos \left(2 \pi v_{0} t\right) \cos \left(2 \pi v_{m} t\right)+\cdots
$$

ou de forma simplificada 


$$
\begin{gathered}
p=\alpha_{0} E_{0} \cos \left(2 \pi v_{0} t\right)+ \\
\frac{1}{2}\left(\frac{\partial \alpha}{\partial q}\right)_{0} q_{0} E_{0}\left[\cos \left\{2 \pi\left(v_{0}+v_{m}\right) t\right\}+\cos \left\{2 \pi\left(v_{0}-v_{m}\right) t\right\}\right]
\end{gathered}
$$

O primeiro termo da equação acima corresponde ao espalhamento elástico, que como pode ser visto tem a mesma frequência de oscilação que a do campo incidente, $v_{0}$. Os espalhamentos inelásticos que compõem o espalhamento Raman são descritos pelo segundo termo, com frequências $v_{0}+v_{m}$ (anti-Stokes) e $v_{0}-v_{m}$ (Stokes). A dependência do espalhamento Raman com a variação da polarizabilidade fica explicita no segundo termo, onde só existe

intensidade de espalhamento inelástico quando $\left(\frac{\partial \alpha}{\partial q}\right) \neq 0$. Logo, se a polarizabilidade da rede não mudar durante a vibração, não haverá sinal Raman. A diferença de intensidades entre o sinal Stokes e anti-Stokes é explicada no modelo quântico do espalhamento inelástico, onde fica clara a menor probabilidade de ocorrer emissões de fótons mais energéticos que os absorvidos. Embora o espectro anti-Stokes seja de grande interesse em algumas aplicações, seu tratamento detalhado foge do escopo deste trabalho, onde foram medidos apenas espectros Stokes.

\subsection{DIFRAÇÃO DE RAIOS X (DRX)}

\subsubsection{Introdução à radiação-X}

A descoberta dos raios $\mathrm{X}$ aconteceu no ano de 1895, sendo atribuída ao físico alemão Wilhelm Röntgen (1845-1923). Suas propriedades inicialmente identificadas (alta penetrabilidade em objetos opacos, propagação em linha reta, etc) fizeram com que fosse 
posto em uso mesmo antes que se compreendesse sua natureza a fundo. Logo da descoberta de que filmes fotográficos são sensíveis a radiação X, engenheiros e físicos iniciaram estudos sobre a estrutura interna de objetos opacos, incluindo a primeira imagem negativa de um ser humano, em dezembro de 1985 (Fig. 2.3). Somente em 1912, em conjunto com a descoberta da difração de raios $\mathrm{X}$ (DRX) por cristais, foi demonstrada sua natureza ondulatória. $\mathrm{O}$ fenômeno da difração mostrara um grau de precisão imenso no estudo da estrutura da matéria, permitindo, através de observações indiretas, uma resolução de até $10^{-7} \mathrm{~mm}$.

Raios X são produzidos quando partículas carregadas são desaceleradas rapidamente. Em geral, as partículas são utilizadas na sua produção são elétrons, e a desaceleração é feita com a ajuda de um tubo de raios $\mathrm{X}$, onde há duas placas metálicas mantidas em alta diferença de potencial. O elétron é então atraído rapidamente ao anodo, atingindo-o em grande velocidade. No impacto entre o elétron e o anodo, raios X são produzidos e emitidos em todas as direções. A energia cinética dos elétrons no momento anterior a colisão é dada por

$$
K_{e}=e V=\frac{1}{2} m v^{2}
$$

Onde $V$ é a diferença de potencial entre o cátodo e o anodo, $e$ é a carga do elétron, $v$ sua velocidade e $m$ sua massa. Em um tubo com diferença de potencial de $30 \mathrm{kV}$, a velocidade do elétron gira em torno de $1 / 3$ da velocidade da luz. Apenas $1 \%$ da energia do elétron é usada na produção de raios X, sendo a maior parte perdida na produção de calor. Quando a luz produzida nos tubos de raios $\mathrm{X}$ é analisada em função da diferença de potencial que a produziu, observa-se o padrão mostrado na Fig. 2.4. 


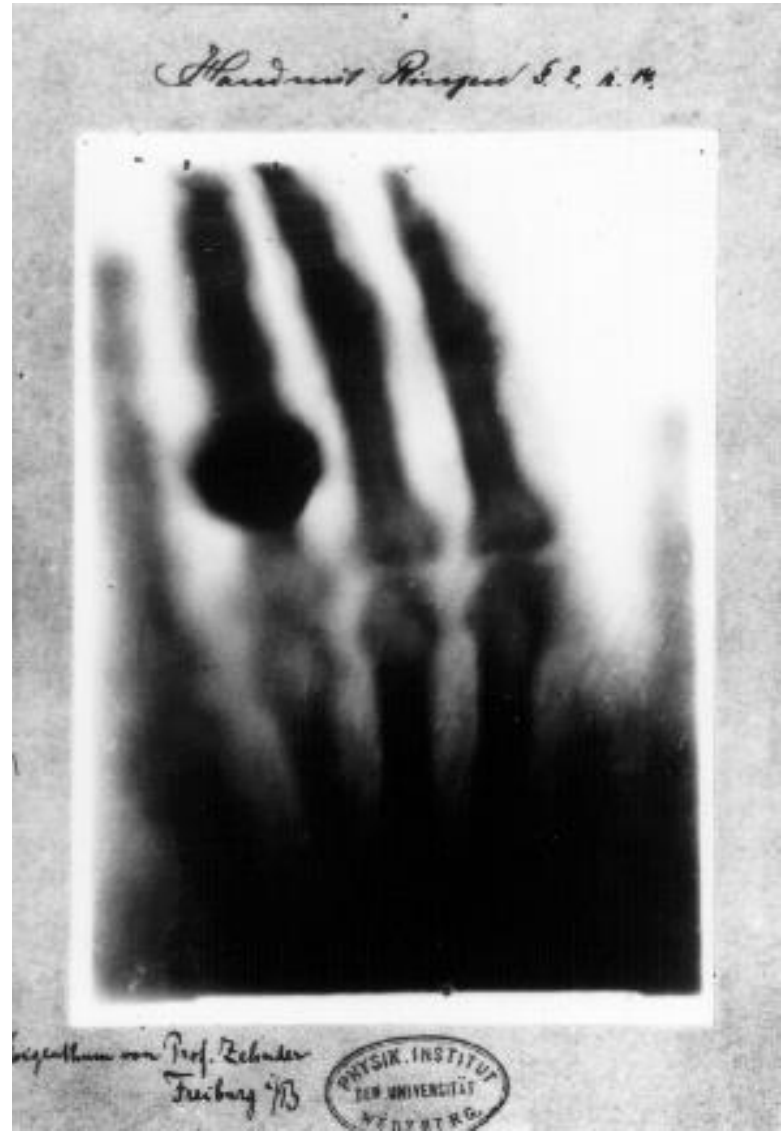

Fig. 2.3: Hand mit Ringen (Mão com aliança). Primeiro imagem negativa realizada por absorção de Raio-X da história, tirado por Wilhelm Röntgen da mão de sua esposa em dezembro de 1895.[15]. 


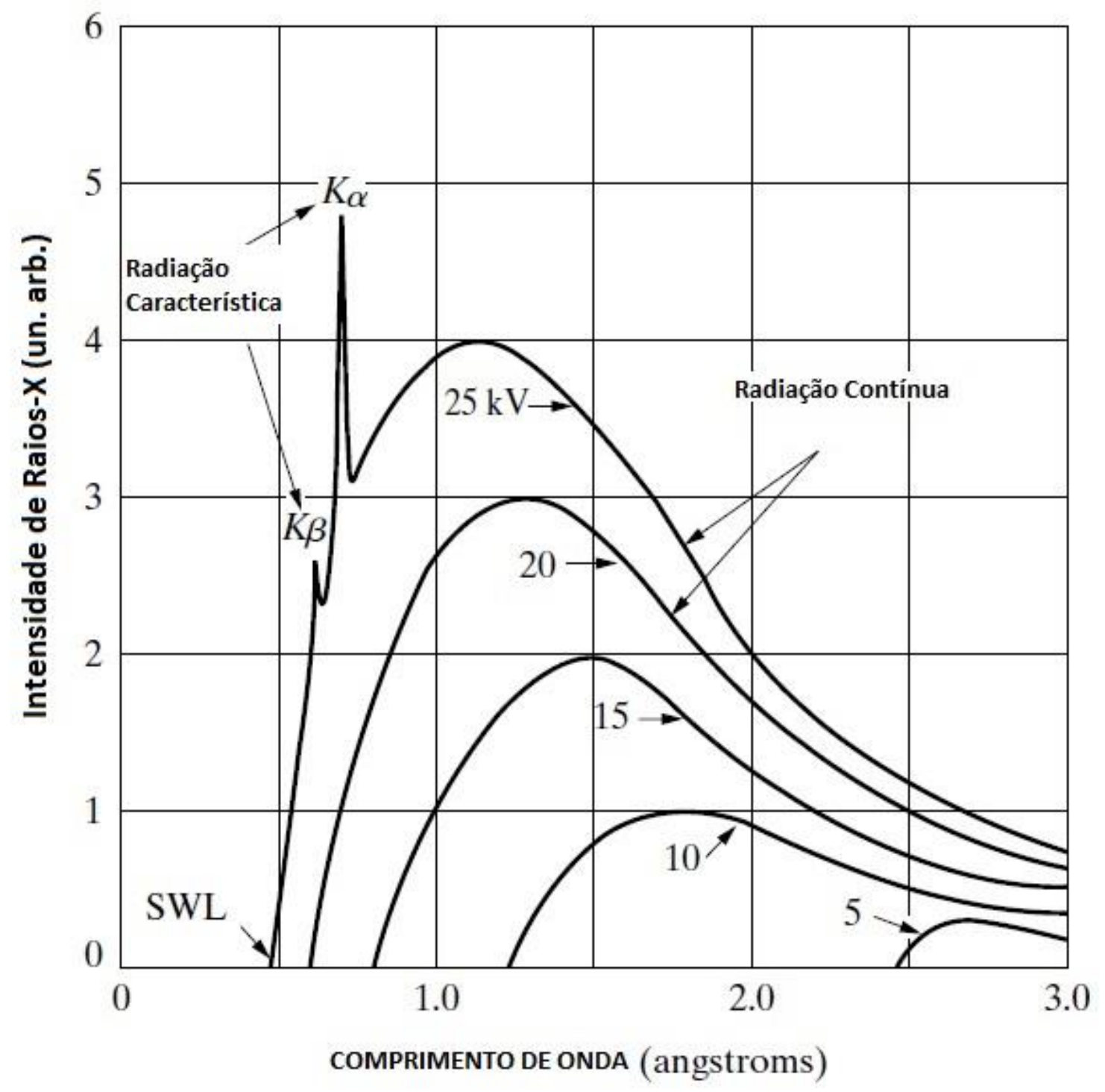

Fig. 2.4: Espectros de raios X de um anodo de molibdênio em função da voltagem aplicada. Adaptada de [16].

Os espectros de radiação contínua (Bremsstrahlung) mostrados na Fig. 2.4 devem-se a desaceleração dos elétrons no anodo. Como nem todo elétrons se desaceleram completamente quando colide com a nuvem eletrônica do primeiro átomo, fótons com diferentes energias são reemitidos, em suas colisões sucessivas, gerando assim a radiação contínua. Elétrons desacelerados totalmente no primeiro impacto geram o raio-X mais energético, com o menor comprimento de onda (SWL - short-wavelength limit). As linhas de radiação característica (chacteristic lines) como as mostradas na Fig. 2.4 têm sua origem nas transições de camadas internas dos átomos do anodo. É possível que o elétron incidente arranque um elétron de uma camada mais interna do átomo com o qual colide, induzindo assim uma transição de outro 
elétron de uma camada superior para ocupar este lugar vago, emitindo um fóton com energia característica.

\subsubsection{Difração de raios $X(D R X)$}

Apesar de todo o conhecimento acumulado por mineralogistas e geólogos sobre cristais ao longo dos anos, somente com o advento da difração de raios X (DRX) foi possível o estudo detalhado da estrutura de tais cristais. A descoberta do fenômeno de difração de raios X por cristais é atribuída ao físico alemão Max von Laue (1879-1960). Inspirado pela tese de doutorado de P. P. Ewald (espalhamento de ondas eletromagnéticas por uma sequência de osciladores harmônicos), von Laue postulou a seguinte ideia: caso raios X fossem ondas eletromagnéticas e os átomos agissem como centros espalhadores separados pela distância interatômica, então o fenômeno da difração em cristais poderia ser observado. Dessa forma, sob supervisão de von Laue, Friedrich e Kniping conduziram experimentos, validando a hipótese da difração de raios X.

Estes resultados chegaram ao conhecimento de dois físicos ingleses, W. H. Bragg (1862-1942) e seu filho W.L. Bragg (1890-1971). O filho conseguiu estabelecer as condições necessárias para a ocorrência da difração de maneira mais simples do que Laue tinha sugerido. Além disso, foi o primeiro cientista a analisar a estrutura cristalina de cristais conhecidos como NaCla, $\mathrm{KCl}$ e $\mathrm{KBr}$.

A condição para que haja um pico de radiação é dada pela chamada Lei de Bragg:

$$
\lambda n=2 d \sin \theta
$$


onde $\lambda$ é o comprimento de onda da radiação incidente, $n$ é um número inteiro, $\theta$ é o ângulo entre o feixe de radiação incidente e o plano espalhador e $d$ é a distância interplanar da rede cristalina.

Um possível arranjo experimental para obtenção do espectro DRX é obtido pela rotação da fonte de radiação incidente $(\theta)$ e do detector $(2 \theta)$, gerando assim um espectro de intensidade em função do ângulo de difração $2 \theta$. Uma análise primária dos chamados difratogramas permite a qualificação da estrutura do cristal, bem como informações sobre seus parâmetros de rede $(a, b, c, \alpha, \beta, \gamma)$.

Medidas de DRX em partículas nanométricas diferem dos padrões encontrados em cristais macroscópicos, devido ao reduzido número de planos refletores em cada partícula, causando um alargamento nos picos de difração. Este alargamento é proporcional ao diâmetro médio das partículas analisadas. Esta relação (Relação de Scherer) é dada por

$$
D=\frac{0,9 \lambda}{\beta_{D} \cos \theta}
$$

onde $D$ corresponde ao diâmetro médio das nanopartículas e $B$ à largura a meia altura (FWHM).

Outro efeito que causa alargamento do pico de difração é o estresse não homogêneo da rede cristalina. Como mostrado na Fig. 2.5, a existência de estresse no material causa diferentes variações no padrão de difração. Caso a rede sofra uma compressão homogênea $\delta d$ em toda sua extensão, o pico de difração sofre apenas um deslocamento. A lei de Bragg é reescrita então como

$$
\lambda=2(d-\delta d) \sin (\theta+\delta \theta)
$$


onde $2 d \theta$ é o deslocamento observado no difratograma. Por outro lado, o efeito causado pela existência de estresse não homogêneo causa alargamento dos picos de difração, sendo descrito pela relação

$$
\beta_{\varepsilon}=C \varepsilon \tan \theta
$$

onde $\varepsilon$ é o estresse não homogêneo médio, $\beta_{\varepsilon}$ é o alargamento gerado por este último e $C$ é uma constante ligada a natureza da deformação, tipicamente valendo 4 ou 5 .

Uma estimativa mais precisa do tamanho de nanopartículas é obtido por meio do ajuste Williamson-Hall (Williamson-Hall Plot). Ele leva em consideração que a largura dos picos de difração é devida tanto ao efeito do tamanho médio das partículas quanto do estresse não homogêneo. A largura total do pico deve ser escrita então como

$$
\beta_{\text {total }}=\beta_{D}+\beta_{\varepsilon}=C \varepsilon \tan \theta+\frac{0,9 \lambda}{D \cos \theta}
$$

Multiplicando a equação ? por $\cos \theta$ obtém-se a seguinte relação

$$
\beta_{\text {total }} \cos \theta=C \varepsilon \sin \theta+\frac{0,9 \lambda}{D}
$$

A curva acima pode ser usada para ajustar as larguras dos picos de um difratogramas, obtendo assim uma estimativa para o estresse inomogênio $\varepsilon$ e o tamanho $D$. 


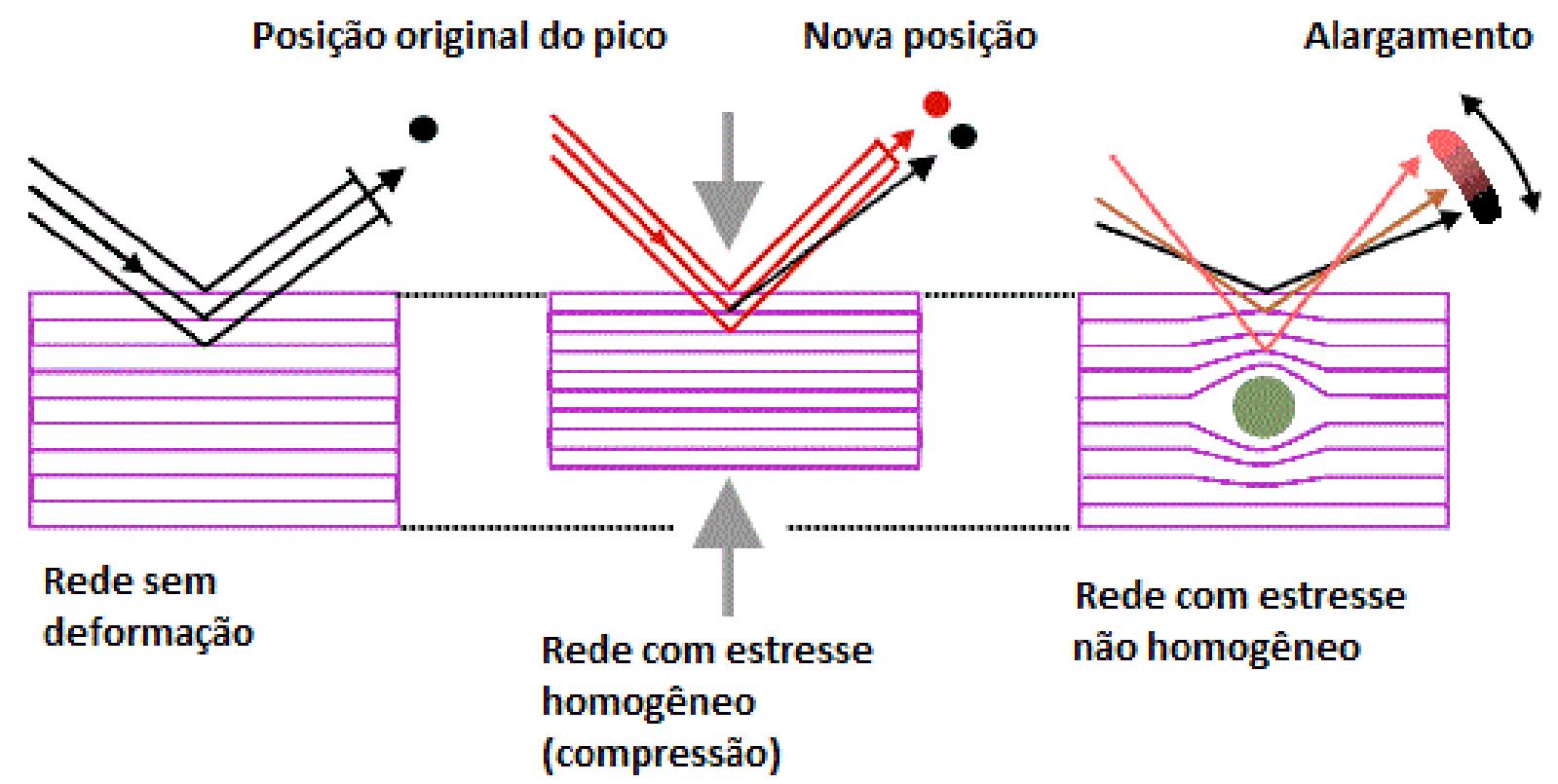

Fig. 2.5: Descrição do efeito do estresse homogêneo e não homogêneo nos picos de difração. Adaptada de [17].

\subsubsection{Método de Rietveld}

A difração de raios $\mathrm{X}$ de amostras em pó é um dos métodos mais utilizados no estudo da estrutura cristalina de materiais. Este tipo de preparação de amostras se mostra muito versátil na análise de estruturas cujo crescimento macroscópico ainda não é reproduzido, ou apresenta dificuldades em sua produção. Entretanto, a técnica de difração em pó apresenta um problema recorrente: a sobreposição de picos nos difratogramas, dificultando assim a análise de sua estrutura. O método criado por Hugo M. Rietveld (1932-2016) possibilita uma análise precisa de tais difratogramas, criando uma separação virtual dos picos sobrepostos. A técnica tem sido utilizada com sucesso no estudo de amostras em pó, com precisão similar a de amostras em cristal único, e também na determinação dos componentes de soluções sólidas, possibilitando a quantificação de fases. É utilizado por cientistas e indústrias, com na construção civil, por exemplo. 
No método de Rietveld, todo o espectrograma é analisado e comparado com um modelo teórico da estrutura cristalina. O perfil de intensidade calculado é comparado com os dados experimentais e cada parâmetro do modelo pode ser refinado até que se atinja a precisão desejada. A diferença entre o modelo e a curva experimental é avaliada pelo método dos mínimos quadrados, onde a quantidade a ser minimizada é dada por

$$
R_{y}=\sum_{i} w_{i}\left(y_{i} y_{c i}\right)^{2}
$$

onde $y_{i}$ é a intensidade observada no i-ésimo passo, $w_{i}$ é um termo de normalização e $y_{c i}$ é a intensidade calculada pelo modelo teórico.

O método de Rietveld apresenta várias vantagens em relação a outros métodos, tais como:

- Usa diretamente os pontos medidos por DRX;

- Utiliza todo o espectro, não somente os picos de difração;

- Menos sensível a erros de modelagem;

- Menos sensível a erros experimentais.

Entretanto apresenta algumas dificuldades:

- Requer um modelo teórico;

- Necessita de um espectro extenso para apresentar bons resultados;

- Os programas, em geral, são de difícil operação, necessitando de certa experiência para atingir bons resultados; 


\subsection{ESPECTROSCOPIA MÖSSBAUER}

\subsubsection{Introdução ao efeito Mössbauer}

Durante anos postulou-se que raios gama emitidos de núcleos radioativos poderiam ser absorvidos por núcleos do mesmo isótopo. Entretanto, as tentativas iniciais de detecção deste processo ressonante foram infrutíferas, graças à diferença na energia gerada pelo recuo dos núcleos. Já se sabia que, tanto no processo de emissão quanto na absorção o núcleo sofreria um recuo, obedecendo assim à conservação do momento linear. Este recuo causaria uma diferença na energia do fóton emitido, que impossibilitaria a absorção. Além disto, o fóton absorvido também teria uma parcela de sua energia gasta no recuo do núcleo absorvedor. Sendo assim, as energias relacionadas ao recuo $E_{R}$ do emissor e do absorvedor somadas gerariam uma diferença de energia de $2 E_{R}$, impossibilitando o processo ressonante.

Em 1957, Rudolf Ludwig Mössbauer (1929-2011) descobriu que um núcleo ligado a uma rede cristalina pode, por vezes, emitir e absorver radiação gama sem recuo. Quando o núcleo está incorporado na rede, é possível que a energia de recuo seja menor que a menor energia vibracional da estrutura cristalina, o que permite a emissão sem nenhuma perda de energia por recuo. A probabilidade de ocorrência da emissão/absorção sem recuo (efeito Mössbauer) depende da energia do raio gama emitido, sendo restrito a átomos com baixas estados excitados.

A primeira observação da absorção ressonante de raios gama foi feita por Mössbauer utilizando átomos de irídio ${ }^{191}$ Ir, e desde então o efeito Mössbauer já foi observado em mais de 100 diferentes isótopos [18]. 


\subsubsection{Principais propriedades dos espectros Mössbauer}

O efeito Mössbauer descreve a absorção (sem recuo) de fótons por núcleos atômicos. Como a absorção é ressonante, a fonte e a amostra devem ser do mesmo tipo. A conservação do momento linear deve ser respeitada em toda processo físico, o que se manifesta no recuo do átomo, tanto na emissão quanto na absorção dos fótons. Esse recuo pode ser minimizado quando o átomo se encontra em uma rede cristalina, pois toda a rede recua em conjunto, diminuindo assim a amplitude do movimento.

Devido ao princípio de incerteza, existe uma região de sobreposição da banda de emissão e absorção (Fig. 2.6). O efeito Mössbauer mede justamente a absorção que acontece nessa intersecção das bandas de energia. Essa região pode ser acessada induzindo uma transposição das bandas fazendo uso do efeito Doppler, deslocando a banda de emissão de sua posição original.

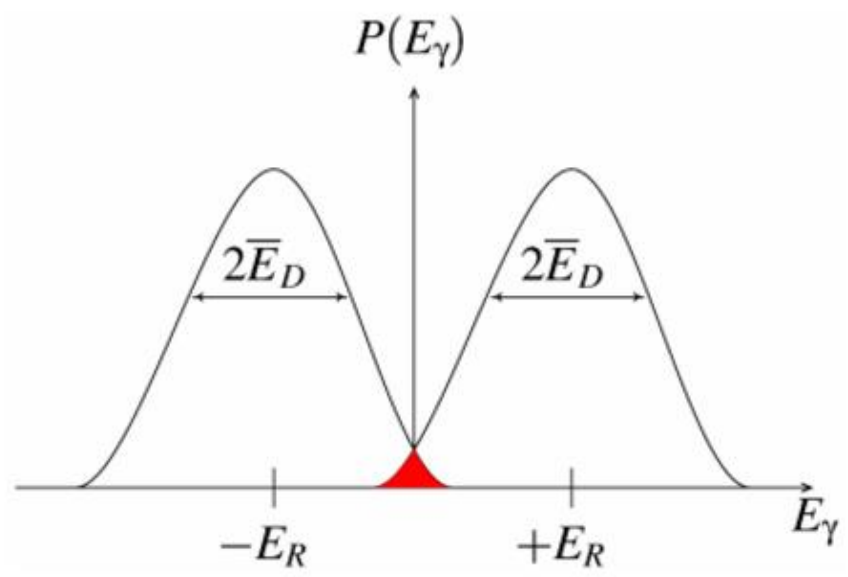

Fig. 2.6: Representação das bandas de emissão e absorção nuclear entre núcleos Mössbauer. 


\section{Intensidade, largura e área espectral do espectro Mössbauer}

Na configuração de transmissão, a intensidade do sinal é dada pela soma da intensidade relacionada à absorção ressonante (absorção sem retrocesso) e a absorção não ressonante (efeito fotoelétrico, Compton, etc). Como não é possível distinguir experimentalmente a parte do sinal devido a cada efeito diretamente, podemos fazer uma medida do sinal a velocidades baixas $I(v)$, onde ocorre ressonância, relativa ao sinal em velocidades altas $I(\infty)$, onde o sinal é predominantemente devido à absorção não ressonante. Essa medida de absorção relativa é dada por

$$
\varepsilon(v)=\frac{I(\infty)-I(v)}{I(\infty)}
$$

A Fig. 2.7 mostra espectros típicos da intensidade total $I$ e intensidade relativa $\varepsilon(v)$ em função da velocidade $v$.
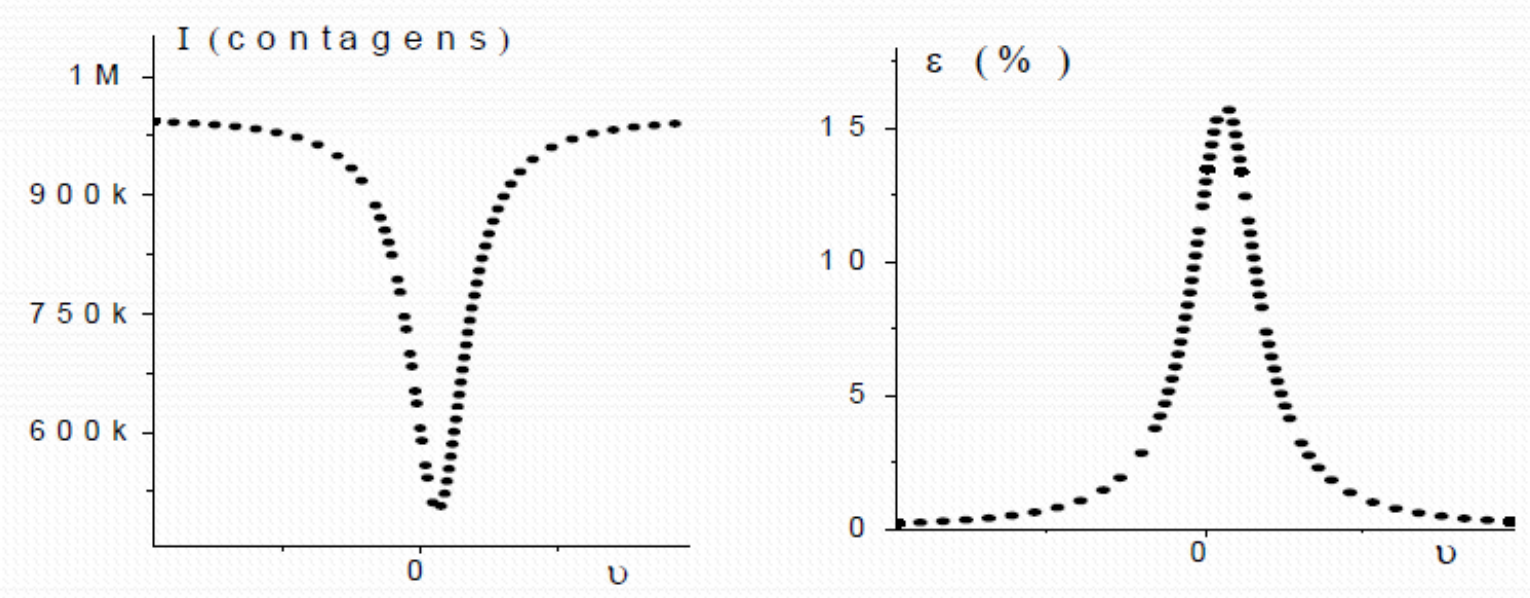

Fig. 2.7: Intensidade total e intensidade relativa em espectros Mössbauer (singleto). 
A largura da linha do espectro Mössbauer está ligada a espessura efetiva dada por

$$
t_{a}=n f_{a} \sigma_{0} d
$$

onde $n$ é o numero de núcleos por unidade de volume, $f_{a}$ é o fator de absorção, $\sigma_{0}$ é a secção de choque de absorção, e $d$ é a espessura da amostra. Quando a espessura efetiva não é muito grande, a largura da linha no espectro pode ser descrita pela equação:

$$
\Gamma_{a p}=\left(\Gamma_{a}+\Gamma_{s}\right) h\left(t_{a}\right)
$$

Onde $\Gamma_{a}$ é a largura da banda de absorção e $\Gamma_{s}$ é a largura de emissão sem recuo. A função $h\left(t_{a}\right)$ varia dependendo do valor da espessura efetiva,

$$
\begin{gathered}
h\left(t_{a}\right)=1+0,135 t_{a} \text { para } 0<t_{a}<5 \\
h\left(t_{a}\right)=1+0,145 t_{a}-0,0025 t_{a}{ }^{2} \text { para } 4<t_{a}<10
\end{gathered}
$$

Nesta aproximação, podemos ainda indicar uma relação direta entre a largura da banda de energia e a largura da velocidade, que é que efetivamente aparece no espectro:

$$
\Gamma(\mathrm{v})=\Gamma(\text { energia }) \frac{c}{E_{0}}
$$

A área espectral é definida como

$$
A=\int_{-\infty}^{\infty} \varepsilon(v) d v
$$


Que resulta em

$$
A=\frac{\pi}{2} \Gamma_{a} f_{s} t_{a}\left[1-\frac{1}{4} t_{a}+\frac{1}{16} t_{a}^{2}+\cdots\right]
$$

Onda $t_{a}$ é a espessura efetiva descrita anteriormente. Logo a área espectral é proporcional ao número de núcleos Mossbauer na amostra.

\subsubsection{Desvio Isomérico $\delta$ (isomer shift IS)}

Esse desvio do pico de absorção é ocasionado pela diferença de energia entre os estados excitado e fundamental do núcleo. O raio atômico muda dependendo do estado em que o núcleo Mössbauer se encontra. Embora não seja possível distinguir tal diferença diretamente em um único núcleo, é possível observar seu efeito na diferença energética entre o núcleo emissor e o absorvedor. Logo, a variação na energia gera um deslocamento no espectro, chamado desvio isomérico, que é descrito pela seguinte equação:

$$
\delta=c \frac{\Delta E}{E_{0}}=\frac{c Z e^{2}}{E_{0} 10 \varepsilon_{0}}\left(R_{e}^{2}-R_{g}^{2}\right)\left\{|\psi(0)|_{a}^{2}-|\psi(0)|_{s}^{2}\right\}
$$

Onde $R_{e}$ e $R_{g}$ são os raios do núcleo no estado excitado e no estado fundamental, $|\psi(0)|_{a}^{2}$ e $|\psi(0)|_{s}^{2}$ são as densidades eletrônicas nos núcleos absorvedor e emissor, respectivamente. As Fig. 2.8(a) e (b) ilustram a variação nas energias que causam o desvio isomérico no absorvedor e no emissor. 
(a)

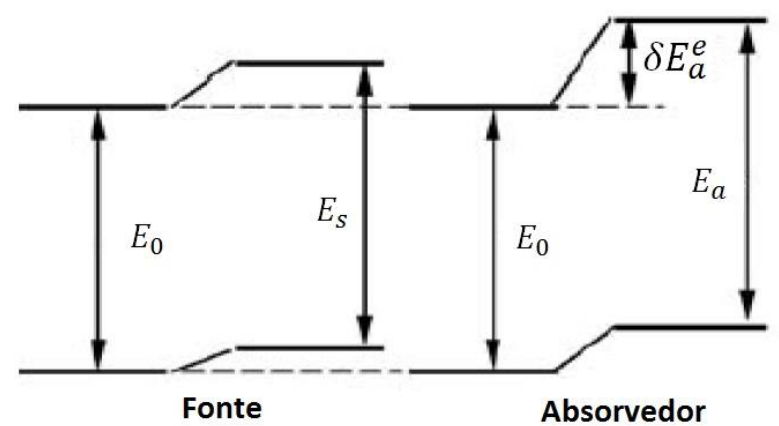

(b)

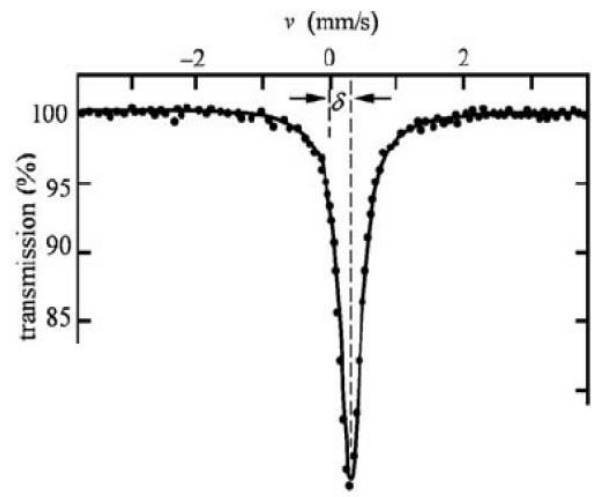

Fig. 2.8: Desvio isomérico no espectro Mössbauer (singleto). (a) Correção nas energias causada pela diferença entre o raio atômico no estado fundamental $\boldsymbol{E}_{\mathbf{0}}$ e estado excitado $\boldsymbol{E}_{\boldsymbol{S}}$, tanto para o absorvedor quanto para a fonte. (b) Desvio isomérico no espectro Mössbauer.

\subsubsection{Desdobramento quadrupolar (quadrupole spliting QS)}

Existe a possiblidade do desdobramento do sinal Mössbauer caso existe apreciável interação entre o momento quadrupolar $Q$ (obtido através da expansão do potencial elétrico nuclear) e o gradiente do campo elétrico GCE. Caso a distribuição de cargas em volta do núcleo seja simétrica, o GCE $=0$. Entretanto, para distribuições assimétricas de cargas GCE $\neq 0$, e por consequência temos o chamado desdobramento quadrupolar.

Quando o spin nuclear I é igual a 0 ou $\frac{1}{2}$, o núcleo tem simetria esférica, $\operatorname{logo} Q=0$. Somente quando $I>\frac{1}{2}$ e $Q \neq 0$ haverá interação quadrupolar. A energia dessa interação é descrita pela seguinte equação:

$$
E_{Q}=\frac{e Q V_{z z}}{4 I(2 I-1)}\left[3 m^{2}-I(I+1)\right]\left(1+\frac{\eta^{2}}{3}\right)^{1 / 2}
$$


onde $I$ é o número quântico de spin nuclear, $V_{i j}$ é o tensor de momento de quadrupolo nuclear e $Q$ é o momento de quadrupolo nuclear na direção z' (eixo de quantização). Os valores de $m$ e $\eta$ dependem de $I$ e a $V_{i j}$ da seguinte forma

$$
m=I, I-1, \ldots,-|I| \text { e } \eta=\left(V_{x x}-V_{y y}\right) / V_{z z}
$$

A diferença energética entre os níveis desdobrados pode ser calculada então como

$$
\Delta E_{Q}=\frac{e Q V_{z z}}{2}\left(1+\frac{\eta^{2}}{3}\right)^{1 / 2}
$$

\subsubsection{Interação magnética hiperfina}

Além do desdobramento energético causado pela interação entre o GCE e o momento de quadrupolo, existe a possiblidade de outra quebra de degenerescência, devido à interação magnética hiperfina entre o núcleo e o campo magnético $\mathrm{B}$ produzido por elétrons desemparelhados. Caso ocorra, a degenerescência de cada nível atômico de spin $I$ é quebrada em $(2 I+1)$ níveis. A interação hiperfina é descrita pelo Hamiltoniano

$$
H_{M}=-\vec{\mu} \cdot \vec{B}=-g \mu_{N} \vec{I} \cdot \vec{B}
$$

E os correspondentes níveis de energia são dados por

$$
E_{M}=-g m B \mu_{N}
$$


onde g é o fator nuclear, $m=I, I-1, \ldots,-I$ e $\mu_{n}$ é a magnetização nuclear. Nem todas as transições são permitidas. A regra de seleção é dada por $\Delta m= \pm 1,0$. A Fig. 2.9 ilustra todos os possíveis espectros Mössbauer considerando o desdobramento quadrupolar, a interação hiperfina magnética hiperfina, bem como o desvio isomérico.
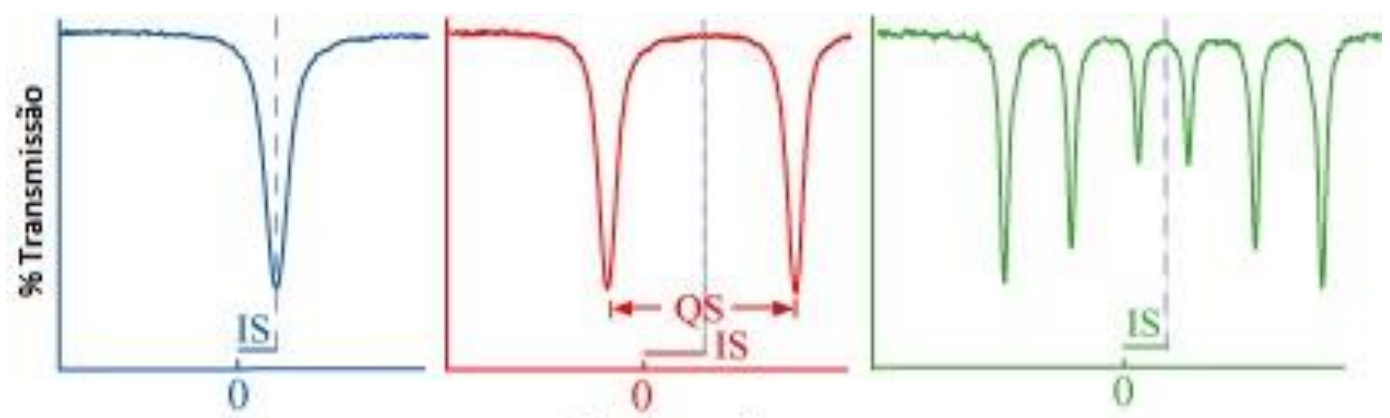

Velocidade relativa

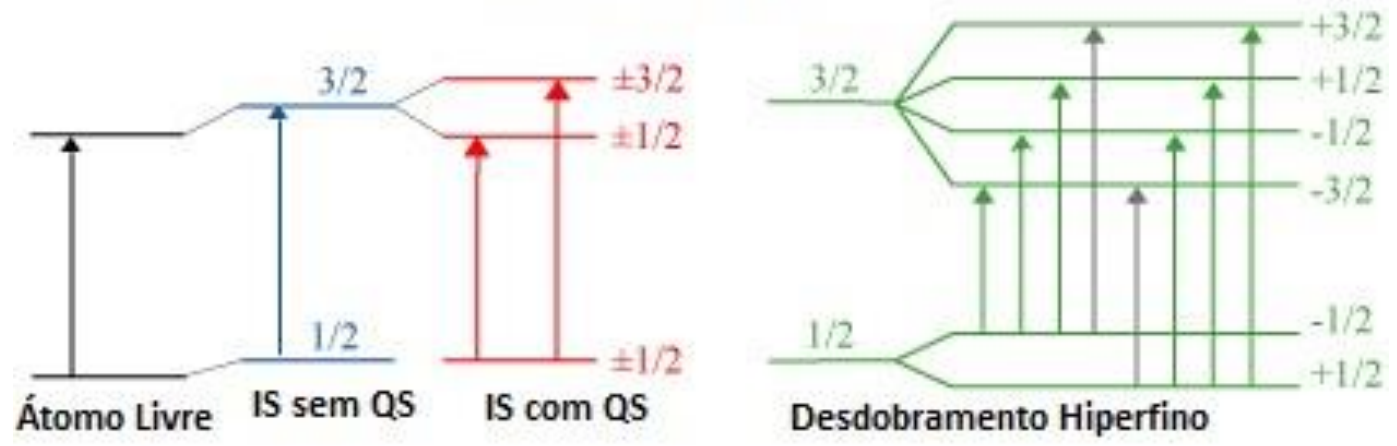

Fig. 2.9: Possíveis espectros Mössbauer e o efeito das possíveis interações nos níveis energéticos. Adaptada de [19]. 


\section{CAPÍTULO 3: REVISÃO SOBRE FERITAS ESPINÉLIO}

\subsection{ESTRUTURAS FERRIMAGNÉTICAS}

Estruturas Ferrimagnéticas, assim como os ferromagnetos, possuem magnetização espontânea abaixo da temperatura de Curie, e demonstram comportamento paramagnético a temperaturas superiores a esta temperatura. Sua magnetização é atribuída à orientação do momento magnético de átomos com elétrons desemparelhados, sendo os responsáveis pelo caráter magnético destes materiais [20]. O material mais utilizado até hoje para aplicações magnéticas a temperatura ambiente, a magnetita $\left(\mathrm{Fe}_{3} \mathrm{O}_{4}\right)$, possui ordenamento ferrimagnético, embora tenha sido incialmente classificada (erroneamente) como ferromagnética. Este comportamento é comumente encontrado em ferritas compostas por diferentes substâncias, como por exemplo, a Ferrita de Cobalto $\mathrm{CoFe}_{2} \mathrm{O}_{4}$ (ferrita dura) e a ferrita de magnésio $\mathrm{MgFe}_{2} \mathrm{O}_{4}$ (ferrita macia). Os diferentes arranjos magnéticos encontrados em cristais são mostrados na Fig. 3.1. 


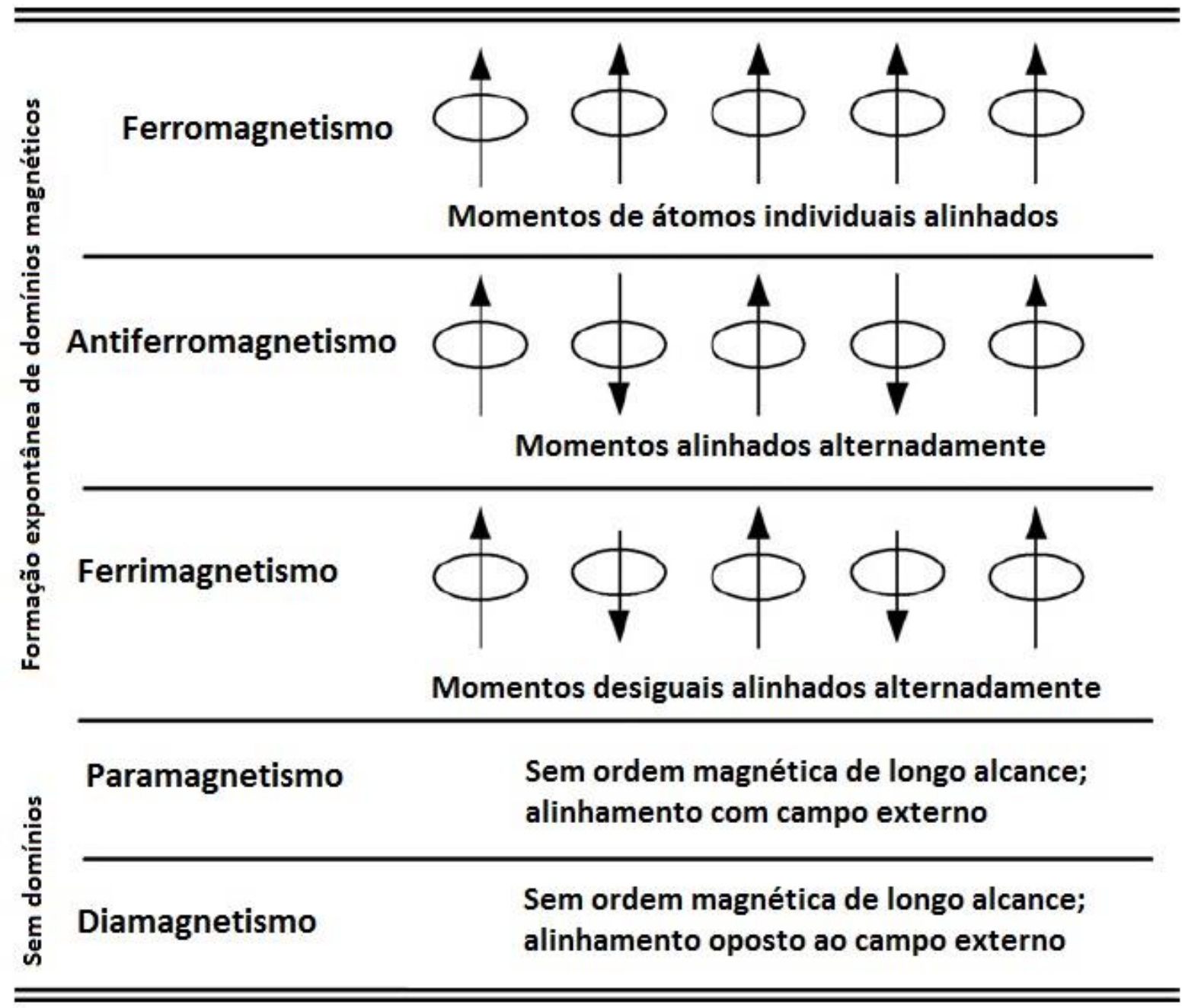

Fig. 3.1: Representação e classificação dos diferentes tipos de materiais magnéticos. Adaptada de [20]. 


\subsection{ESTRUTURA ESPINÉLIO CÚBICA}

Muitos dos óxidos a base de ferro possuem estrutura cristalina do tipo espinélio e apresentam formula química geral $\mathrm{AB}_{2} \mathrm{O}_{4}$. Uma célula unitária é composta por oito fórmulas unitárias $\left[\mathrm{MFe}_{2} \mathrm{O}_{4}\right] 8$. Nesse caso, a rede cristalina é formada por 32 oxigênios que estão em contato direto entre si, formando uma rede cúbica de face centrada de empacotamento compacto (“closed-pack face-centered cubic structure”) contendo 64 sítios tetraédricos (sítios A) e 32 sítios octaédricos (sítios B). Desses apenas 8 sítios tetraédricos e 16 octaédricos são efetivamente ocupados pelos cátions metálicos. Dependendo da distribuição dos cátions nos sítios, as ferritas podem ser classificadas em 3 categorias: (a) espinélio direta, onde os sítios A são ocupados apenas pelos metais divalentes; (b) espinélio inversa, onde todos os cátions divalentes estão presentes nos sítios B; (c) espinélio mista, onde íons divalentes estão presentes tanto em A quanto em B [21]. A Fig. 3.2 mostra a célula unitária da estrutura espinélio. As Fig. 3.3-3.5 mostram respectivamente o sítio tetraédrico, octaédrico e a vizinha dos oxigênios na rede. 


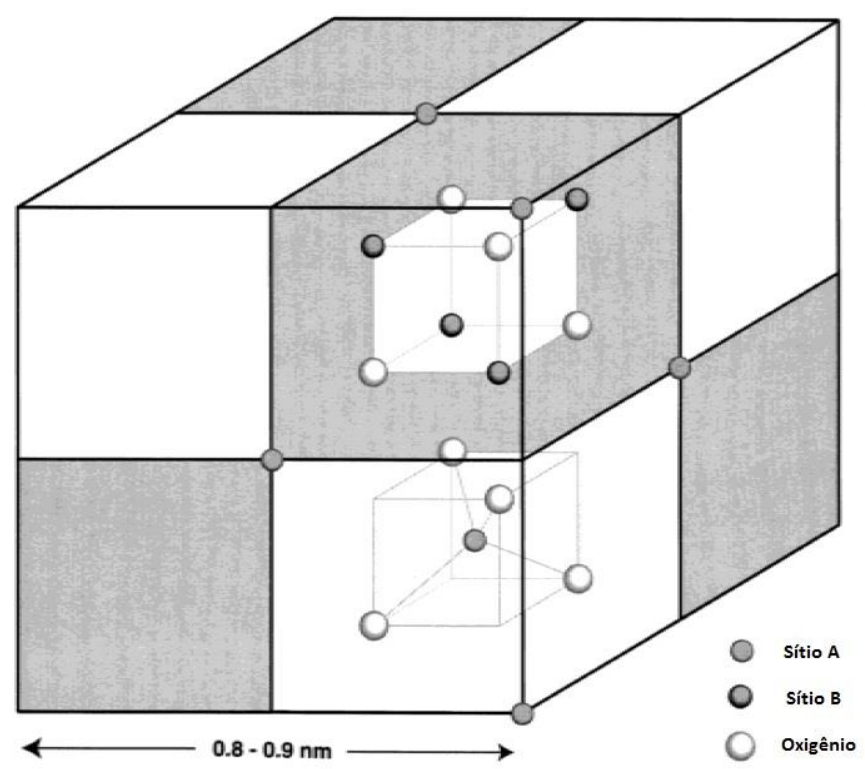

Fig. 3.2: Célula unitária da estrutura espinélio cúbica. A estrutura mostrada se repete em áreas de mesma cor. Adaptada de [22].

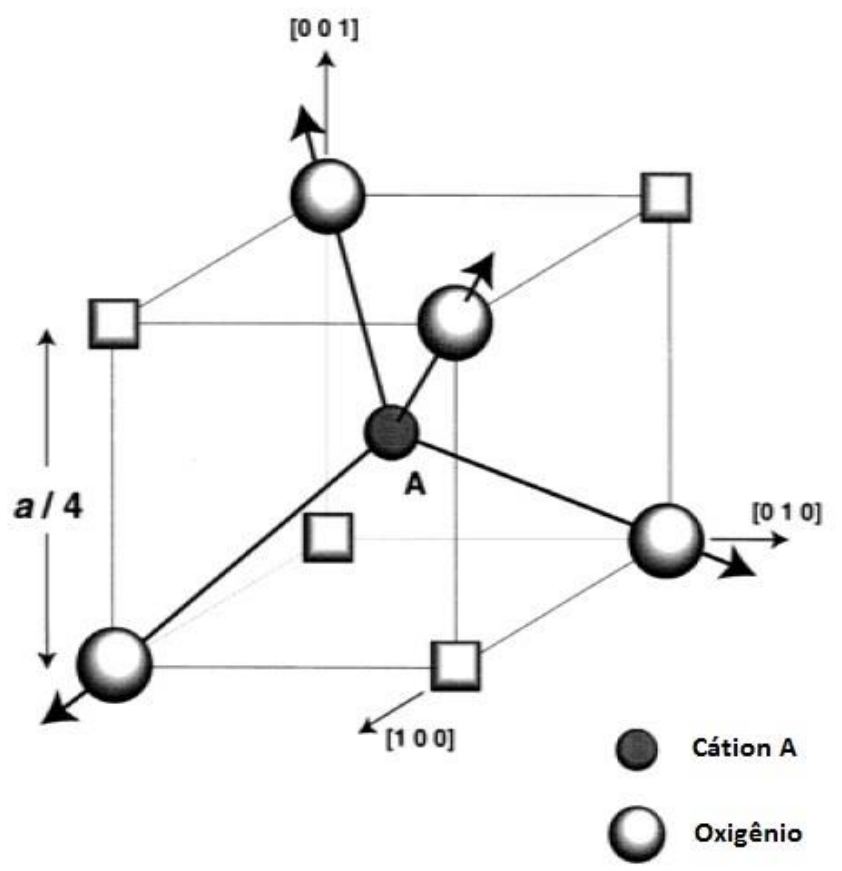

Vacância octaédrica

Fig. 3.3: Sítio de coordenação tetraédrica na estrutura espinélio cúbica. Adaptada de [22]. 


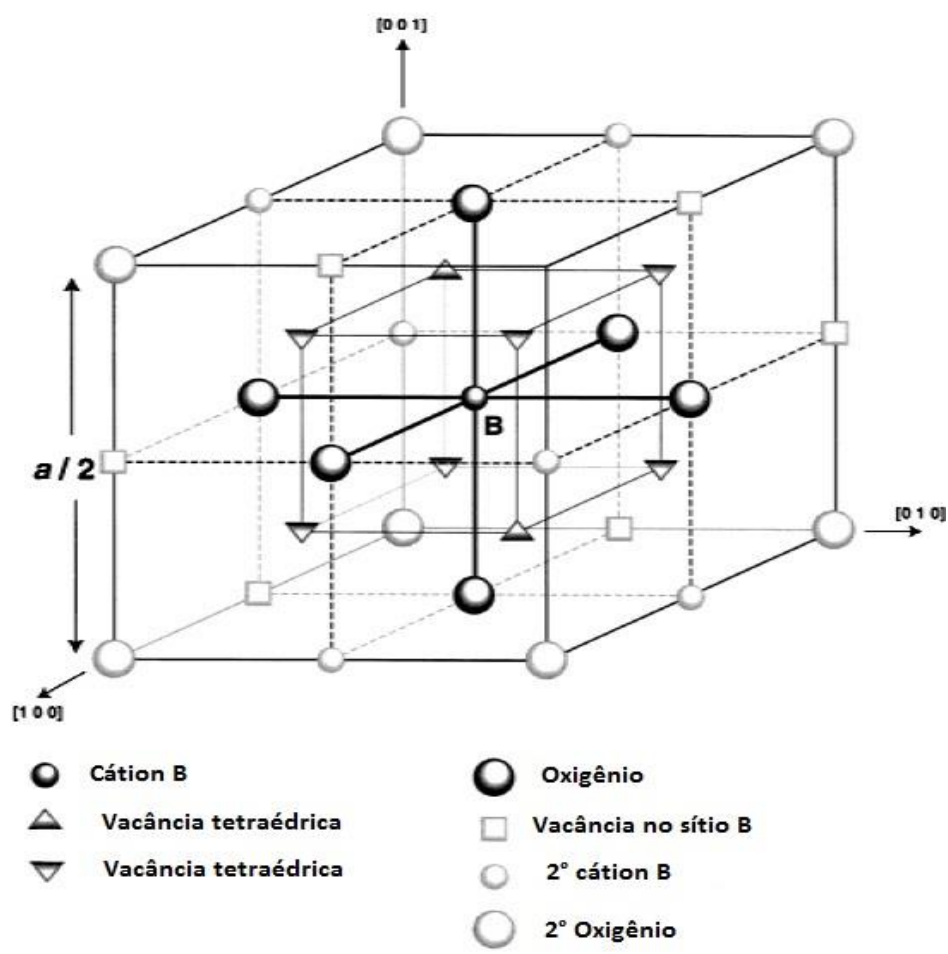

Fig. 3.4: Sítio de coordenação octaédrica na estrutura espinélio cúbica e detalhe da vizinhança. Adaptada de [22].
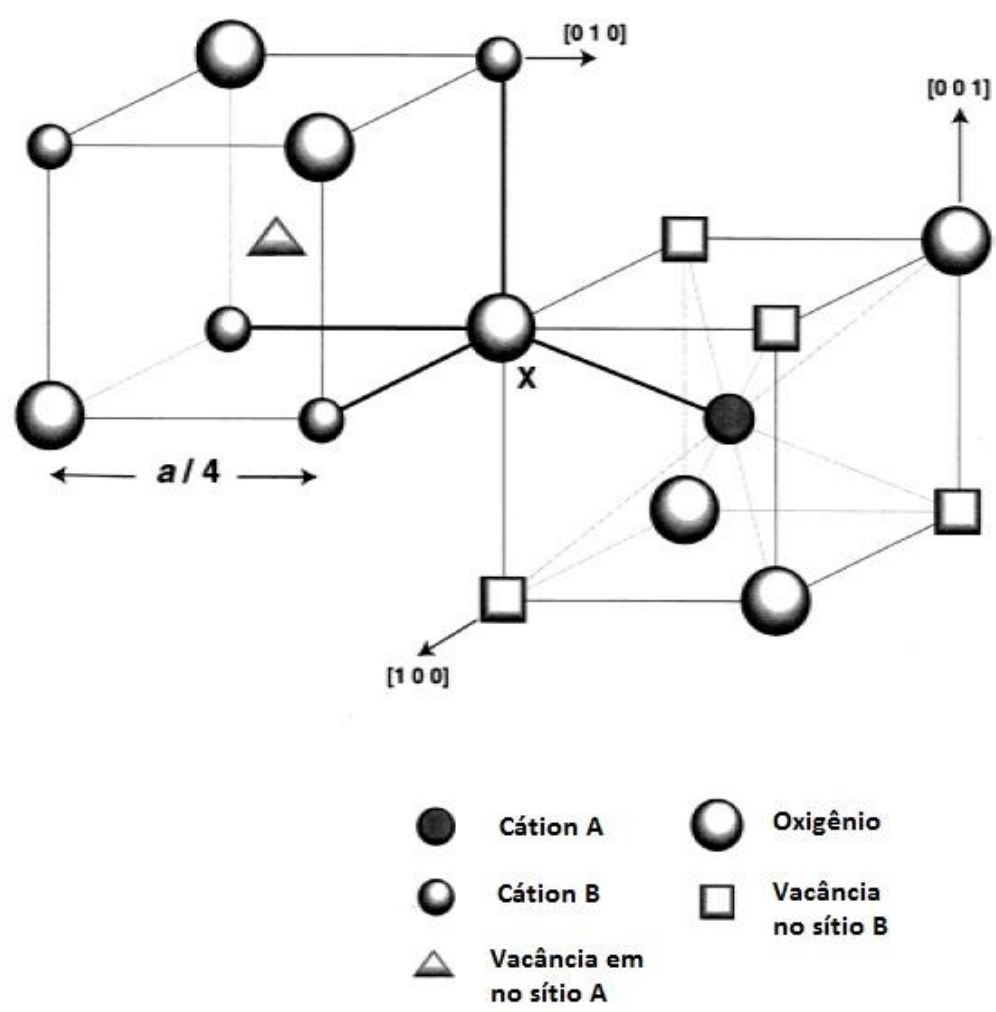

Fig. 3.5: Detalhe da vizinhança do oxigênio na estrutura espinélio cúbica. Adaptada de [22]. 


\subsection{FERRITA DE COBALTO $\left(\mathrm{CoFe}_{2} \mathrm{O}_{4}\right)$}

Diversos estudos tem sido realizados sobre nanopartículas de $\mathrm{CoFe}_{2} \mathrm{O}_{4}$. $\mathrm{O}$ grande interesse pode ser explicado por suas propriedades magnéticas e estruturais únicas que o tornam um ótimo candidato para diversas aplicações tecnológicas, tais como: carreamento de fármacos, sensores, gravação magnética, etc [23]. É uma das ferritas com estruturas espinélio mais promissoras, possuindo magnetização de saturação moderada, alto campo coercivo, alta dureza mecânica e estabilidade química [24]. Em forma "bulk" possui estrutura espinélio inversa, tendo sido reportada com estrutura espinélio mista em forma nanoparticulada.

As propriedades estruturais de amostras nanoparticuladas de $\mathrm{Co}_{\mathrm{x}} \mathrm{Fe}_{3-\mathrm{x}} \mathrm{O}_{4}$ foram estudadas por Nakagomi et al [4]. Foi observado que, no intervalo $x=(0,05-1,60)$, o tamanho cristalino médio varia linearmente de $35 \mathrm{~nm}(x=0,05)$ até $70 \mathrm{~nm}(x=1,60)$. Além disto, o parâmetro de rede varia linearmente com $x$ no intervalo $(0,05-1,00)$, permanecendo constante para $x>1,00$. Por outro lado, Toksha et al [25], em sua análise das propriedades magnéticas de nanopartículas de ferrita de cobalto, reportaram alta coercitividade $H_{c}$ e baixa magnetização de saturação $M_{s}$ à temperatura de $77 \mathrm{~K}$ para amostras de $\mathrm{CoFe}_{2} \mathrm{O}_{4}$, sintetizadas pelo processo de auto combustão (sol-gel), quando comparados aos valores em temperatura ambiente. A queda no campo coercivo $H_{c}$ foi atribuída ao aumento na anisotropia cristalina em baixas temperaturas, enquanto a baixa magnetização de saturação foi atribuída ao desordenamento de spins superficiais, importantes neste caso, já que o tamanho médio de suas partículas varia entre 11 e $40 \mathrm{~nm}$.

Diferentes resultados relacionados às propriedades de nanopartículas de ferrita de cobalto são encontrados em outras referências [8]. Isto se deve a alta sensibilidade de suas propriedades físicas ao processo de síntese utilizado. Diferentes técnicas já foram reportadas em sua produção, tais como: coprecipitação química, condensação por evaporação, reação de 
combustão, rota aerossol, etc. Apesar da variedade de técnicas, nem todas apresentam controle no tamanho das nanopartículas, propriedade crucial a várias aplicações. Dentre as técnicas apresentadas a reação de combustão (método usado neste trabalho) se destaca. Nanopartículas de $\mathrm{CoFe}_{2} \mathrm{O}_{4}$ foram sintetizadas com sucesso por Adolfo Franco Júnior et al [11] com alta cristalinidade, demonstrando assim as vantagens do referido método. 


\subsection{FERRITA COBALTO AZUL $\left(\mathrm{CoAl}_{2} \mathrm{O}_{4}\right)$}

$\mathrm{O}_{\mathrm{CoAl}} \mathrm{O}_{4}$, conhecido também como cobalto azul (Thénard blue), atraiu interesse da comunidade científica por suas propriedades particulares como pigmento azul utilizado em cerâmicas. Sua cor característica é atribuída a transições eletrônicas do cátion $\mathrm{Co}^{+2}$ no sítio tetraédrico [26]. Possui estrutura espinélio cúbica $(\mathrm{Fd}-3 \mathrm{~m}, \mathrm{Z}=8)$ e frequentemente é relatado com a estrutura espinélio direta na sua forma "bulk", onde todos os cátions $\mathrm{Al}^{+3}$ ocupam sítios octaédricos enquanto todos os cátions divalentes $\mathrm{Co}^{+2}$ ocupam os sítios tetraédricos [27]. Entretanto, existem relatos de $\mathrm{CoAl}_{2} \mathrm{O}_{4}$ com grau de inversão igual à 0.155(9) [28]. Para nanopartículas de cobalto azul sintetizadas por sol-gel com temperatura de recozimento no intervalo $\left(700-900{ }^{\circ} \mathrm{C}\right)$ e diâmetro cristalino médio entre $10.8 \mathrm{~nm}$ e $50.3 \mathrm{~nm}$, o grau de inversão relatado varia de 0.198 à 0.260 [26]. Seu parâmetro de rede e posição interna do oxigênio são teoricamente estimados em $8.092 \AA$ e 0.2621 , respectivamente [29]. Foi demonstrado por Tielens et al [29] possuir a estrutura mais estável dentre os compostos da família $\mathrm{Co}_{3-\mathrm{s}} \mathrm{Al}_{\mathrm{s}} \mathrm{O}_{4}$. Em outro estudo pelos mesmos autores [27], foi demonstrado através de simulações por DFT que distorções significativas na estrutura são observadas quando os íons de $\mathrm{Co}^{+2}$ ocupam sítios octaédricos, o que pode ser a razão deste processo de substituição ser energeticamente desfavorável. Neste mesmo estudo concluiu-se que a temperatura afeta a estabilidade relativa do $\mathrm{CoAl}_{2} \mathrm{O}_{4}$ com diferentes distribuições catiônicas, e que variações nas propriedades eletrônicas/magnéticas em amostras com alto grau de inversão são dominadas pela presença de cátions $\mathrm{Co}^{+2}$ nos sítos $\mathrm{B}$. 


\subsection{ESPECTROSCOPIA RAMAN EM FERRITAS}

Não existe consenso na literatura sobre a natureza dos modos Raman ativo nas ferritas do tipo espinélio. Em trabalhos mais antigos sobre este tipo de material, como os de Waldron et al, [30] todos os modos Raman ativos são atribuídos a movimentos do cátion localizado no sítio A e aos oxigênios em volta. As interações centradas no sítio B bem como com os sítios A vizinhos eram assumidas insignificantes e por isso eram desprezadas. Dessa forma eram previstos oito modos infravermelho ativos, diferente dos quatro modos comumente observados. White et al [31] previu corretamente os 4 modos infravermelhos e os 5 modos Raman fazendo uma analise da célula unitária por teoria de grupos. Nestes trabalhos, todas as vibrações previstas consideravam o cátion octaédrico em repouso.

Alguns trabalhos recentes contestam a ideia de que a interação dominante nas ferritas seja associada somente ao sítio tetraédrico. Trabalhos recentes como os de Kushwaha et al $[32,33]$ em que foram analisadas amostras de $\mathrm{CoCr}_{2} \mathrm{O}_{4}$ foi relatado que as interações do tipo B-O são mais importantes que as do tipo A-O. Esses resultados são apoiados por outros trabalhos como o de Gupta et al [34] sobre o espinélio $\mathrm{MnCr}_{2} \mathrm{O}_{4}$ e o de Sinha et al [35] sobre cromitas espinélio.

Outro ponto que causa discussão é a atribuição dos tipos de vibração aos modos Raman ativos observados em ferritas. Os autores que defendem uma predominância das interações A-O sobre as interações B-O. Geralmente atribuem todos os modos vibracionais ao sítio A. Esta abordagem foi introduzida no trabalho de Verble [36], o qual trata da identificação dos fônons $\mathrm{k} \cong 0$ em magnetita por meio de experimentos de espalhamento de luz. Neste trabalho, é observado os cinco modos Raman previstos para a estrutura espinélio e são feitas as seguintes atribuições: o modo $\mathrm{A}_{1 \mathrm{~g}}$, o mais enérgico do espectro, seria ligado ao modo respiração (breathing mode) do conjunto $\mathrm{AO}_{4}$, onde os oxigênios se movimentam 
simetricamente para dentro e fora ao longo da direção da ligação atômica enquanto os cátions localizados nos sítios A e B permanecem em repouso. O segundo modo mais energético previsto pela teoria de grupos, o $\mathrm{F}_{2 \mathrm{~g}}(3)$, foi atribuído ao modo respiração antissimétrico. Essa atribuição também é feita por Yamanaka et al em seu trabalho sobre as vibrações da rede do $\mathrm{Ni}_{2} \mathrm{SiO}_{4}$ [37], embora o ângulo de movimentação dos oxigênios seja diferente. O modo $\mathrm{E}_{\mathrm{g}}$ foi atribuído ao movimento de flexão simétrico (symmetric bending mode) dos oxigênios no tetraedro $\mathrm{AO}_{4}$, o que é apoiado pelos estudos mais recentes de Cynn et al [38] e Van Minh et al [39] sobre a ferrita espinélio $\mathrm{MgAl}_{2} \mathrm{O}_{4}$. O modo $\mathrm{F}_{2 \mathrm{~g}}(2)$ é atribuído ao modo de translação dos oxigênios e do cátion A em direções opostas na rede. Tanto Verble quanto a maior parte literatura é consenso na atribuição do modo $\mathrm{F}_{2 \mathrm{~g}}(1)$, o qual é divido ao movimento de translação de toda a célula $\mathrm{AO}_{4}$ dentro da rede espinélio.

A Fig. 3.6 mostra os modos vibracionais atribuídos por Verble à estrutura espinélio cúbica. Note que em toda a análise o cátion em B é assumido em repouso. Essa atribuição exclusiva dos modos vibracionais aos tetraedros $\mathrm{AO}_{4}$ é consequência direta da escolha da célula primitiva da rede espinélio sendo composta por dois tetraedros $\mathrm{AO}_{4}$ e um octaedro $\mathrm{B}_{4}$. Cada oxigênio da estrutura seria ligado a três cátions em B e a apenas um cátion em A. Vários autores apoiam esta posição [36-38]. 


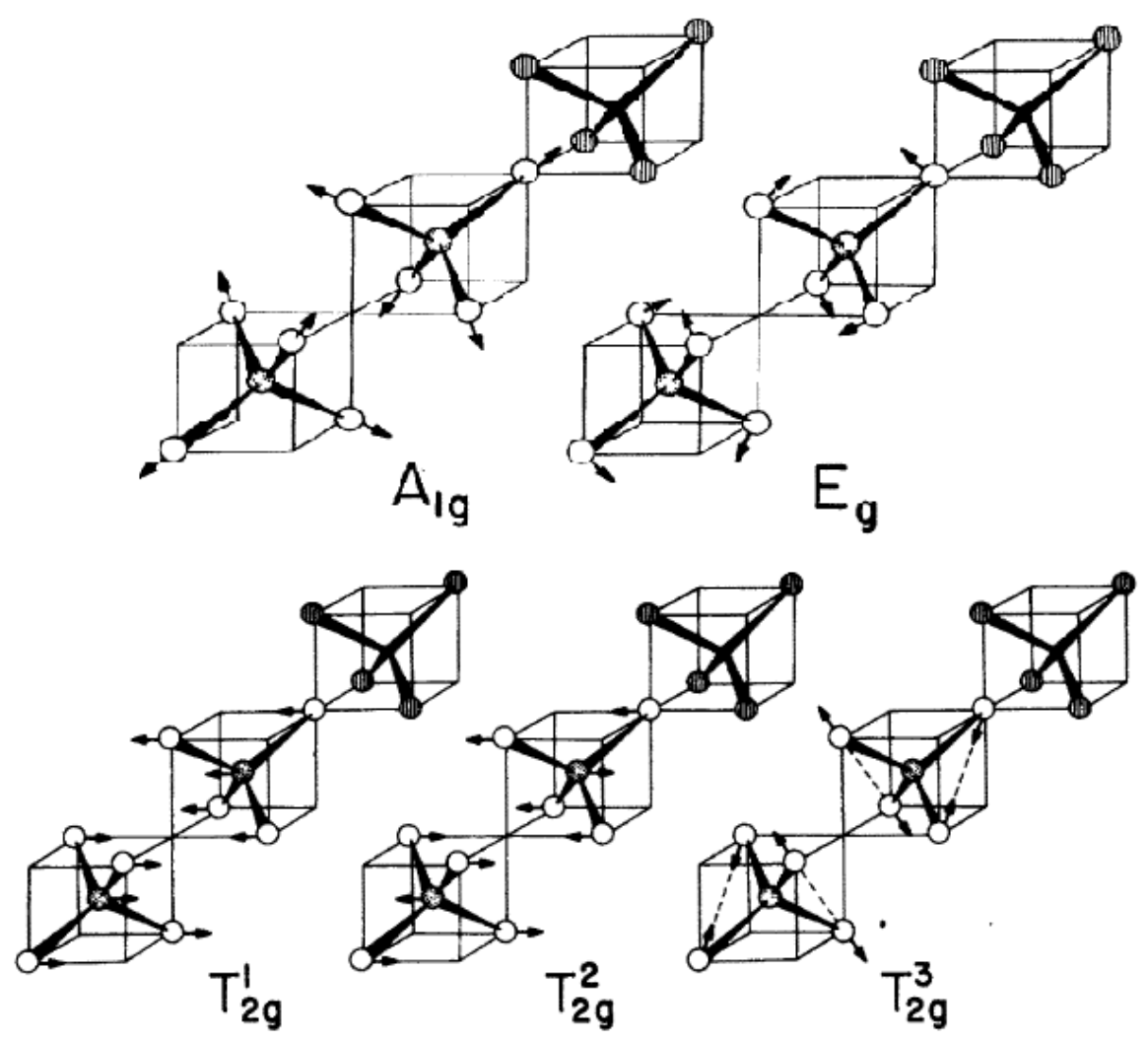

Fig. 3.6: Modos vibracionais da estrutura espinélio atribuidas por Verble [36].

Poucos autores relacionam os modos vibracionais da estrutura espinélio ao movimento dos cátions do sítio B. Em todas as atribuições acima o cátion no sítio B estaria em repouso. Essa posição é contrastada por outros trabalhos como o de Preudhomme et al [40]. Em seus estudos sobre modos infravermelho em ferritas de estrutura espinélio cúbico direto do tipo IIIII conclui-se que não seria correto assumir que os modos de mais alta energia dependam somente dos cátions tetraédricos, mas que dependeriam mais fortemente dos íons octaédricos.

Laguna-Bercero et al [41] em seu estudo sobre $\mathrm{NiAl}_{2} \mathrm{O}_{4}$ de estrutura espinélio inversa argumentam que os múltiplos modos $\mathrm{A}_{1 \mathrm{~g}}$ por eles encontrados devem-se a ocupação aleatória dos três sítios octaédricos, vizinhos a cada íon de oxigênio, por cátions $\mathrm{Ni}^{+2}$ e $\mathrm{Al}^{+3}$, onde as diferentes configurações gerariam pequenas diferenças nas energias dos modos vibracionais.

Já na análise de amostras de nanopartículas de $\mathrm{Zn}_{\mathrm{x}} \mathrm{Mg}_{1-\mathrm{x}} \mathrm{Fe}_{2} \mathrm{O}_{4}(0,0 \leq x \leq 1,0)$ feita por da Silva et al [42], um modo encontrado em torno de $650 \mathrm{~cm}^{-1}$ foi atribuído à presença de 
$\mathrm{Zn}^{2+}$ nos sítios de coordenação octaédrica, o que também foi confirmado pela análise por espectroscopia Mossbauer. Fazendo uso de técnicas complementares (espectroscopias Raman e Mossbauer), estes pesquisadores atribuiram ao sítio B modos Raman ativos encontrados em amostras de $\mathrm{Co}_{\mathrm{x}} \mathrm{Fe}_{3-\mathrm{x}} \mathrm{O}_{4}$ [4] e em amostras de nanopartículas de $\mathrm{Mg}_{\mathrm{x}} \mathrm{Fe}_{3-\mathrm{x}} \mathrm{O}_{4}$ [43] .

B. D. Hosterman [44] em seu extenso estudo sobre cromitas e ferritas argumenta que o modo $A_{1 g}$ deve depender mais do cátion octaédrico do que do tetraédrico. Um argumento sugerido por ele diz respeito a grande variação na frequência do modo $A_{1 g}$ nas ferritas, o que já não acontece nas cromitas. A maior parte das ferritas tem estrutura espinélio inversa com $\mathrm{Fe}^{+3}$ na posição tetraédrica e o cátion divalente $\mathrm{M}^{+2}$ preferencialmente na posição octaédrica. Com isso, se o modo citado dependesse apenas do grupo $\mathrm{AO}_{4}$, sua frequência deveria ser praticamente a mesma em todas as ferritas, o que não é observado. Outro fato que sustenta a dependência do modo $\mathrm{A}_{1 \mathrm{~g}}$ dos cátions $\mathrm{B}$ é deduzido da comparação entre várias cromitas $\mathrm{M}^{2+} \mathrm{Cr}_{2}^{3+} \mathrm{O}^{2-}$, onde foram variados os cátions divalentes $\mathrm{M}^{2+}$. Todas elas apresentam estruturas predominantemente do tipo espinélio direto II-III, e variam apenas no cátion divalente ocupando o sítio A. Analisando espectros Raman destas cromitas, B. D. Hosterman verificou que o modo $A_{1 g}$ varia significativamente menos que todos os outros modos Raman ativos, o que sugeriria a independência deste modo vibracional com relação ao tipo do cátion divalente. Apesar de toda controvérsia sobre a atribuição dos modos associados aos sítios A e B, a literatura demonstra boa concordância sobre os modos mais energéticos $\left(>650 \mathrm{~cm}^{-1}\right)$ estarem ligados ao sítio tetraédrico.

Preudhomme et al argumentam que, para sistemas mistos como o aqui estudado, os modos vibracionais podem variar de três maneiras distintas [45]. As variações podem ser "características", "complexas", ou uma combinação destas duas. A primeira descreve vibrações com a origem restrita a apenas um tipo de cátion ou grupo coordenado. Já as 
variações complexas envolveriam simultaneamente a participação de dois cátions ou grupos coordenados. Preudhomme argumenta que é possível atribuir, com certa segurança, modos vibracionais em estruturas mistas onde os cátions possuem massas bem diferentes, como por exemplo, o $\mathrm{MoNa}_{2} \mathrm{O}_{4}$. Entretanto, toda atribuição feita em soluções sólidas formadas por cátions de massas próximas deve ser considerada apenas uma aproximação, já que grupos coordenados com energias vibracionais próximas devem interagir significativamente. $\mathrm{O}$ trabalho de Preudhomme também descreve as interações entre os grupos coordenados $\mathrm{AO}_{4} \mathrm{e}$ $\mathrm{AO}_{4}, \mathrm{AO}_{4}$ e $\mathrm{BO}_{6}$ e também entre $\mathrm{BO}_{6}$ e $\mathrm{BO}_{6}$, além de citar atribuições de modos vibracionais a grupos $\mathrm{BO}_{6}$.

Chang et al. [46] define os termos "comportamento de um modo" (one mode behavior) e "comportamento de dois modos" (two-modes behavior) para descrever as variações anteriormente descritas por Preudhomme. Nesse trabalho os autores dividem os materiais mistos em duas classes, cada um com um comportamento característico. O comportamento de um modo descreve a existência de fônons com $\mathrm{k} \cong 0$ correspondentes a cada um dos modos variando continuamente com o teor $x$ das substâncias substitucionais, de um extremo ao outro. Por outro lado, o comportamento de dois modos descreve a existência de dois modos vibracionais distintos, próximos das frequências características das substâncias de cada extremidade, com intensidades proporcionais a fração de cada membro puro pertencente à substância mista. Os dois tipos de comportamento podem ser encontrados em um mesmo conjunto de amostras mistas, cada um em determinado intervalo de $x$. Ferritas dos grupos III$\mathrm{V}$ comumente apresentam os 2 tipos de comportamento. O comportamento de dois modos ainda pode ser indício de fases puras dos dois extremos do sistema misto, em escala suficientemente pequena para não ser detectada pela difração de raios X. Além disso, podemse encontrar deslocamentos na frequência dos modos devido à substituição catiônica. 
Além dos modos principais, deformações locais na rede cristalina podem produzir modos vibracionais detectáveis por espectroscopia Raman, mas que passam despercebidos pela Difração de raios X. Estes modos extras devidos a deformações da rede são comumente chamados de modos locais. 


\section{CAPÍTULO 4: PROCEDIMENTOS EXPERIMENTAIS}

\subsection{PREPARAÇÃO DAS AMOSTRAS}

As amostras utilizadas nesse trabalho são partículas de ferrita de cobalto-alumínio $\mathrm{CoAl}_{\mathrm{x}} \mathrm{Fe}_{2-\mathrm{x}} \mathrm{O}_{4}(x=0,00-2,00)$, sintetizadas pelo método de reação de combustão [11]. Para $x=0,00$ tem-se a já extensivamente estudada ferrita de cobalto [4, 23, 25]. No outro extremo tem-se o aluminato de cobalto, material conhecido como cobalto azul (cobalt blue), assim chamado devido a sua coloração azul e extensivo uso na fabricação de pigmentos usados no campo da arte, por exemplo, em porcelanas chinesas do século XVII [47].

$\mathrm{O}$ processo de síntese utiliza nitrato de ferro $\mathrm{Fe}\left(\mathrm{NO}_{3}\right)_{3} \cdot 9 \mathrm{H}_{2} \mathrm{O}$, nitrato de cobalto $\mathrm{Co}\left(\mathrm{NO}_{3}\right)_{2} \cdot 6 \mathrm{H}_{2} \mathrm{O}$, nitrato de alumínio $\mathrm{Al}\left(\mathrm{NO}_{3}\right)_{3} \cdot 9 \mathrm{H}_{2} \mathrm{O}$ como reagentes e ureia $\mathrm{CO}\left(\mathrm{NH}_{2}\right)_{2}$ como combustível orgânico. As reações ocorreram ao ar livre, sem nenhuma condição atmosférica especial. A composição estequiométrica de cada amostra foi estimada baseando-se nas valências totais de oxidação e redução dos nitratos e do combustível. Quando o número total de oxidação é igual ao de redução, a razão de equivalência é igual a um, i.e. $\phi_{e}=O / F=1$, gerando assim a maior liberação de energia possível. Em química dos propelentes, as espécies $\mathrm{M}^{2+}, \mathrm{M}^{3+}, \mathrm{M}^{4+}, \mathrm{C}$ e $\mathrm{H}$ são considerados elementos redutores, enquanto o oxigênio é considerado espécie oxidante e a valência do nitrogênio é considerada zero [48]. Dessa forma, os elementos $\mathrm{H}, \mathrm{Co}, \mathrm{Al}, \mathrm{Fe}$ e $\mathrm{C}$ têm valências iguais a $+1,+2,+3,+3$ e +4 respectivamente, enquanto o oxigênio tem valência igual a -2. Levando estes valores em consideração, os valores totais de valência dos nitratos metálicos $\mathrm{Fe}\left(\mathrm{NO}_{3}\right)_{3} \cdot 9 \mathrm{H}_{2} \mathrm{O}, \mathrm{Al}\left(\mathrm{NO}_{3}\right)_{3} \cdot 9 \mathrm{H}_{2} \mathrm{O}$ e $\mathrm{Co}\left(\mathrm{NO}_{3}\right)_{2} \cdot 6 \mathrm{H}_{2} \mathrm{O}$ são iguais a $-15,-15$ e -10 , respectivamente. Por outro lado, a valência total da ureia é igual a +6 . Logo, a reação estequiométrica para que tenhamos a maior liberação de energia possível requer que $-15(2-x)-15 x-10+6 n=0$, o que resulta em $n=6,67$ 
mol de ureia. Os reagentes devem ser combinados na proporção molar de $1: 2-x: x: 6,67$ de $\mathrm{Co}\left(\mathrm{NO}_{3}\right)_{2} \cdot 6 \mathrm{H}_{2} \mathrm{O}, \mathrm{Fe}\left(\mathrm{NO}_{3}\right)_{3} \cdot 9 \mathrm{H}_{2} \mathrm{O}, \mathrm{Al}\left(\mathrm{NO}_{3}\right)_{3} \cdot 9 \mathrm{H}_{2} \mathrm{O}$ e $\mathrm{CO}\left(\mathrm{NH}_{2}\right)_{2}$, respectivamente, onde $x$ é a quantidade de alumínio.

A síntese das partículas $\mathrm{CoAl}_{\mathrm{x}} \mathrm{Fe}_{2-\mathrm{x}} \mathrm{O}_{4}$ foi realizada na Universidade Federal do Goiás pela equipe do Prof. Dr. Adolfo Franco Júnior, utilizando compostos com alto grau de pureza. As proporções estequiométricas de cada amostra foram calculadas como descrito anteriormente. Os reagentes e o combustível foram pesados, colocados em uma cápsula de porcelana e aquecidos em uma placa aquecedora até a temperatura de ignição, de cerca de 400 ${ }^{\circ} \mathrm{C}$. Nesta temperatura se inicia uma reação exotérmica, autossustentável que se mantém por alguns segundos (Fig. 4.1), produzindo assim as partículas.

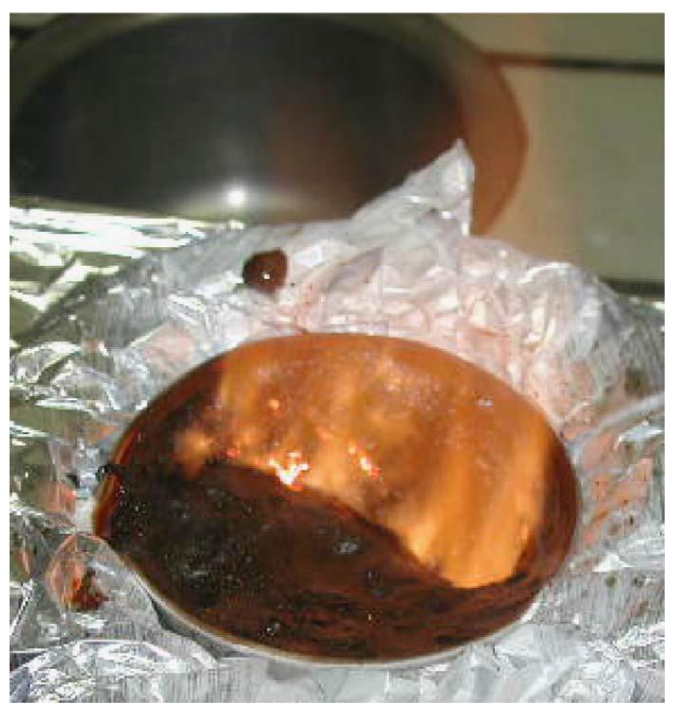

Fig. 4.1: Chamas produzidas durante reação de combustão [11]. 


\subsection{ESPECTROSCOPIA RAMAN}

Os espectros Raman foram realizados em um espectrômetro triplo Jobin-Yvon, modelo T64000, em configuração subtrativa. O sinal Raman foi detectado por um detector CCD refrigerado a nitrogênio líquido. A excitação das amostras foi realizada por um laser VERDI ® sintonizado na linha $532 \mathrm{~nm}$ e focalizando na amostra com uma lente cilíndrica, com densidade de potência de $0,1 \mathrm{~W} / \mathrm{cm}^{2}$. Os espectros foram obtidos na região entre $100 \mathrm{e}$ $900 \mathrm{~cm}^{-1}$.

\subsection{ESPECTROSCOPIA MÖSSBAUER}

Os espectros Mössbauer foram obtidos na geometria de transmissão, usando uma fonte de ${ }^{57}$ Co em matriz de Ródio, a temperatura de 77 K. O sistema de velocidade foi calibrado com uma folha fina de Fe. Os espectros foram ajustados por combinação de Lorentizianas usando os critérios de mínimos quadrados.

\subsection{DIFRAÇÃO DE RAIOS X (DRX)}

As medidas de difração de raios $\mathrm{X}$ foram realizadas no Laboratório de Difratometria de raios $\mathrm{X}$ do Instituto de Geociências da Universidade de Brasília. Utilizou-se um difratrômetro modelo Rigaku (Ultima IV) na configuração $\theta-2 \theta$. A fonte de radiação utilizada foi um tubo de cobre, $\mathrm{K}_{\alpha}$ (médio)=1,5418 $\mathrm{A}$. As medidas foram feitas no intervalo de $20^{\circ}$ a $80^{\circ}$, com um passo de $0,05^{\circ}$ e com uma velocidade de varredura de $0,5^{\circ}$ por minuto. 


\subsection{REFINAMENTO RIETVELD}

Os dados de difração de raios X foram refinados via Método de Rietveld. Para isso, uma amostra de silício cristalino foi utilizada como padrão (NIST 640d). Usou-se o Programa GSAS e a interface gráfica EXPGUI. Para o ajuste do background, utilizou-se a função polinomial de primeiro tipo de Chebyschev. A função de perfil utilizada foi a de número 4 . Foram refinados os parâmetros de rede de ambas as fases, as frações de fase, trns, shft, GW, GV, GU, GP, ptec, U, X (oxigênio).

\subsection{MEDIDAS DE MAGNETIZAÇÃO}

Todas as medidas de magnetização (curvas de histerese $M v s H$ e ZFC-FC) foram realisadas em um Magnetômetro SQUID da Quantum Desing, com campos magnéticos variando de 0 a 7 T. A temperatura de 5 a $380 \mathrm{~K}$. As medidas foram realizadas no Laboratório de Caracterização Magnética do NFA do Instituto de Física da Universidade de Brasília. 


\section{CAPÍTULO 5: RESULTADOS E DISCUSSÕES}

\subsection{ESPECTROSCOPIA MÖSSBAUER}

Os espectros Mössbauer das amostras de $\mathrm{CoAl}_{\mathrm{x}} \mathrm{Fe}_{2-\mathrm{x}} \mathrm{O}_{4}$ obtidos a $77 \mathrm{~K}$ são mostrados na Fig. 5.1. Não foi possível obter espectros para $x=1,50$ e $x=2,00$ a está temperatura devido ao baixo/inexistente teor de alumínio destas amostras. No intervalo $0,00 \leq x \leq 1,00$ pode-se observar nos espectros uma contínua redução na separação dos sextetos em função do teor $A l(x)$ substitucional. Para investigar este comportamento os espectros Mössbauer foram ajustados com uma combinação de dois sextetos, associados à presença de íons de ferro $\mathrm{Fe}^{3+}$ nas duas diferentes coordenações, tetraédrica e octaédrica, respectivamente. A redução na posição dos sextetos indica uma queda no campo magnético hiperfino dos sítios A e B. Este fato se deve ao momento magnético nulo do alumínio, que quando incorporado na estrutura cristalina da ferrita, causa uma diminuição na intensidade da interação de troca entre os sítios A e B, que por sua vez se relaciona a magnitude dos campos hiperfinos (HF) que geram o desdobramento dos espectros [49]. A redução de HF nos sítios tetraédricos e octaédricos é mostrada na Fig. 5.2 (a).

As amostras com teor de $A l(x)$ entre 0,00 e 0,25 e a amostra 1,00 mostram valores de desvio isométrico (IS) praticamente constante, em torno de $0,27 \mathrm{~mm} / \mathrm{s}$ para a coordenação tetraédrica e 0,17 para a coordenação octaédrica (Fig. 5.2 (b)). Este resultado indica uma maior densidade dos elétrons $s$ nos núcleos de $\mathrm{Fe}^{3+}$ localizados nos sítios octaédricos em relação aos elétrons $s$ dos íons $\mathrm{Fe}^{3+}$ localizados nos sítios tetraédricos. Os valores de desvio quadrupolar (QS) para os sítios tetraédricos e octaédricos são mostrados na Fig. 5.2 (c). Para amostras com teor de $A l(x)$ entre 0,00 e 0,25 os valores do QS mostram pouca variação com o conteúdo de $\mathrm{Al}^{3+}$ nos sítios A e B. Nota-se, entretanto uma mudança mais substancial nas 
amostras $x=0,30$ e $x=1,00$, onde os sítios tetraédricos são ligeiramente mais afetados que os octaédricos.

A Fig. 5.2 (d) mostra a variação das áreas integradas dos sub-espectros Mössbauer em função do teor de $A l(x)$. Os resultados mostraram que a incorporação do alumínio na estrutura cristalina das nanopartículas induz pequenas variações na proporção de $\mathrm{Fe}^{3+}$ nos diferentes sítios, não maior do que 5\% nas amostras com teor de $A l(x)$ com $x<0,25$, e abaixo de $10 \%$ para as demais amostras. Como já foi citado, a estrutura do $\mathrm{CoFe}_{2} \mathrm{O}_{4}$ é preferencialmente espinélio inversa, com o $\mathrm{Fe}^{3+}$ ocupando igualmente os sítios A e B. No extremo oposto, o $\mathrm{CoAl}_{2} \mathrm{O}_{4}$ possui estrutura espinélio direta, com o alumínio ocupando preferencialmente o sítio $\mathrm{B}$, deixando o sítio A ocupado principalmente por $\mathrm{Co}^{2+}$. Dos dados aqui apresentados é possível concluir que na transição da estrutura espinélio inversa para a espinélio direta, ocorre uma redistribuição quase homogênea dos íons $\mathrm{Fe}^{3+}$ remanescentes entre os sítios A e B.

Não é possível determinar por espectroscopia Mössbauer uma distribuição catiônica completa de uma solução sólida quaternária. Uma vez que esta técnica é sensível apenas aos íons ${ }^{57} \mathrm{Fe}$, não diferenciando a presença de $\mathrm{Al}^{3+}$ de $\mathrm{Co}^{2+}$ na estrutura cristalina. Por essa razão, distribuições catiônicas parciais, obtidas para as amostras $\mathrm{CoAl}_{\mathrm{x}} \mathrm{Fe}_{2-\mathrm{x}} \mathrm{O}_{4}$, considerando apenas a espectroscopia Mössbauer, são mostradas na Tabela 5.3. Uma análise completa da distribuição de cátions para as mesmas amostras será realizada na próxima seção. 


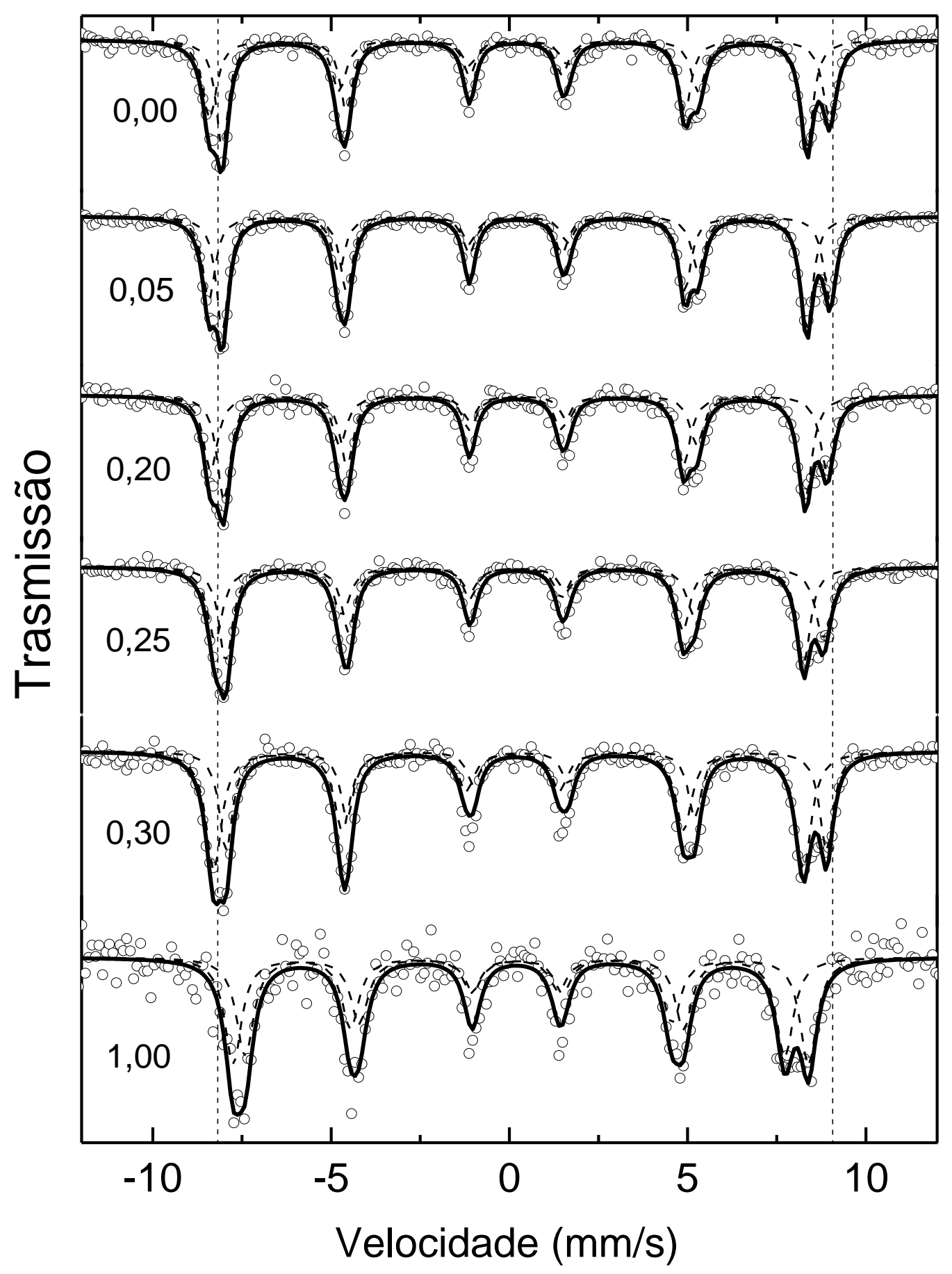

Fig. 5.1: Espectros Mössbauer das amostras de $\mathrm{CoAl}_{\mathrm{x}} \mathrm{Fe}_{2-\mathrm{x}} \mathrm{O}_{4}$ obtidos à temperatura de $77 \mathrm{~K}$ em geometria de transmissão. As linhas verticais pontilhadas são apenas guia para os olhos. 


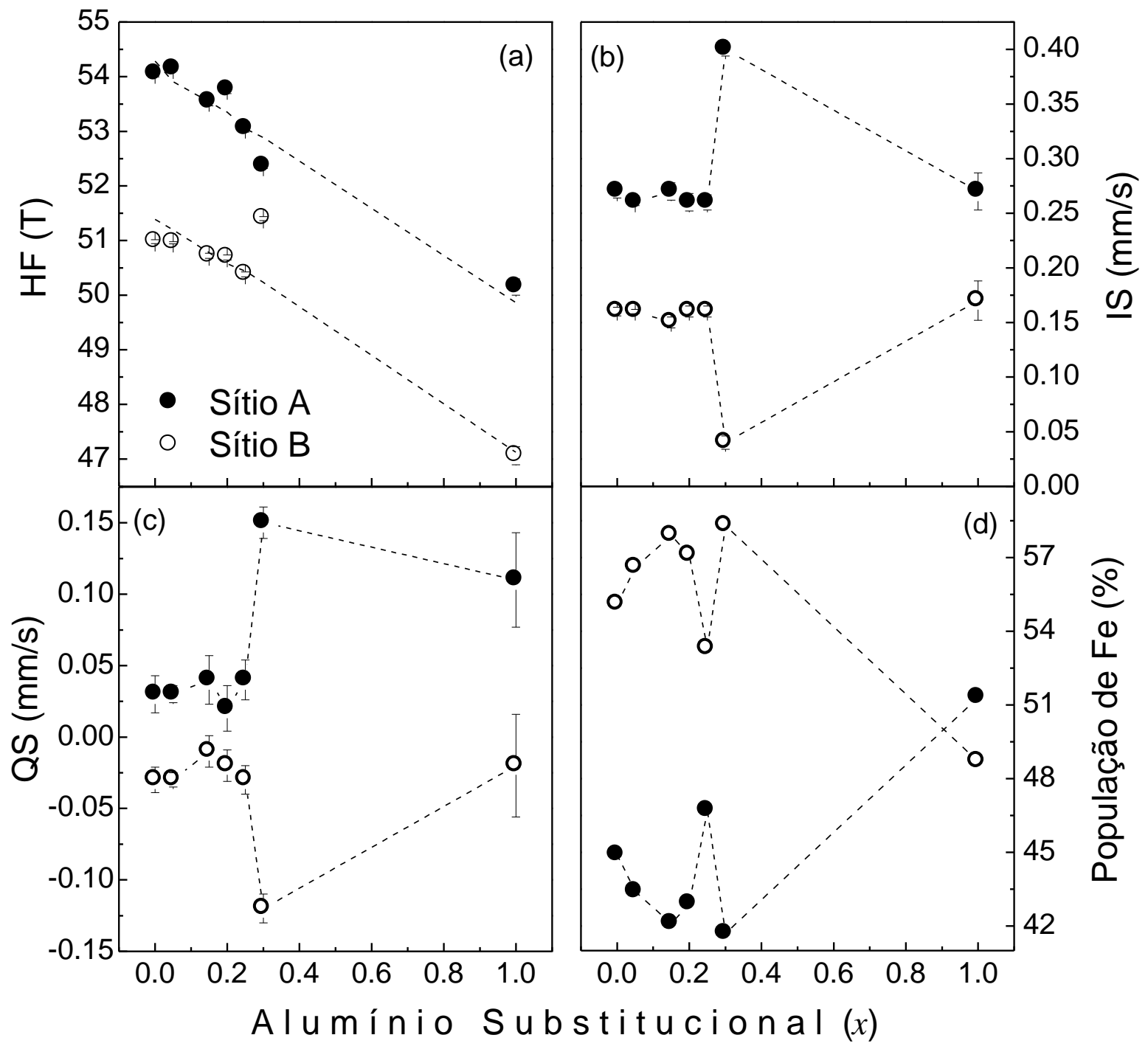

Fig. 5.2: Dependência dos Parâmetros hiperfinos em função do teor de Al substitucional, obtidos para as amostras de $\mathrm{CoAl}_{\mathrm{x}} \mathrm{Fe}_{2-\mathrm{x}} \mathrm{O}_{4}$ : (a) Campo Hiperfino HF, (b) Desvio Isométrico IS, (c) Desvio Quadrupolar QS e (d) população percentual de Fe nos sítios A e B. Os círculos cheios estão relacionados aos sítios tetraédricos, enquanto os vazios aos sítios octaédricos. As linhas pontilhadas são apenas guia para os olhos. 


\subsection{DIFRAÇÃO DE RAIOS X}

\subsubsection{Dados Experimentais}

São mostrados na Fig. 5.3 (a) os difratogramas de DRX das amostras de $\mathrm{CoAl}_{\mathrm{x}} \mathrm{Fe}_{2-\mathrm{x}} \mathrm{O}_{4}$ para $x=0,00-2,00$. Todos os picos observados são bem indexados como a estrutura espinélio cúbica, pertencendo assim ao mesmo grupo cristalográfico que a ferrita de cobalto (JCPDS card $N^{\circ}$ 22-1086). O fato de não se verificar reflexões extras nos padrões de difração sugere ausências de fases extras.

A Fig. 5.3 (b) mostra uma ampliação da região em torno do pico mais intenso (311) de todas as amostras. Observa-se claramente que esta reflexão sofre um deslocamento contínuo para maiores valores de $\theta$ à medida que o teor nominal de alumínio aumenta. O mesmo ocorre para os demais picos de difração. Para entender melhor este comportamento, todos os padrões de DRX foram analisados usando o Método de Rietveld. Para isso foi utilizado o programa GSAS [50] e a interface gráfica EXPGUI [51]. A Fig. 5.4 (a) mostra em detalhe o resultado do ajuste para a amostra com $x=0.20$. A inserção na Fig. 5.4 (a) mostra uma ampliação da região em torno do pico mais intenso (311). Por meio do refinamento Rietveld, observou-se uma redução contínua (e linear) do parâmetro de rede com o aumento do teor de $\operatorname{Al}(x)$ (Fig. 5.4 (b)). Esta redução evidencia que o alumínio é satisfatoriamente inserido na estrutura espinélio. Devido aos raios iônicos do $\mathrm{Fe}^{+3}$ e do $\mathrm{Al}^{+3}$ serem iguais a $0.49 \AA$ e $0.39 \AA$ para o sítio tetraédrico e $0.645 \AA$ e $0.53 \AA$ para o sítio octaédrico, respectivamente [52], verifica-se que a substituição de ferro por alumínio leva à diminuição do parâmetro de rede. Verifica-se ainda que a variação no parâmetro de rede segue satisfatoriamente a lei de Vegard, cujo parâmetro de rede da solução sólida é dado por 


$$
a=\frac{(2-x) a_{A}+x a_{B}}{2}
$$

onde $a_{A}$ é o parâmetro de rede da ferrita de colbato pura, e $a_{B}$ o parâmetro do colbato azul. Comportamento similar foi encontrado nos trabalhos de Anantharamaiah et al [3] e Aghav et al [7], onde as nanopartículas foram sintetizadas pelos métodos citrato-gel e sol-gel, respectivamente.

O diâmetro médio das nanopartículas foi obtido utilizando-se Williamson-Hall plot [53] e estão listados na Tabela 5.1. Os dados mostram que a síntese produziu partículas com diâmetros entre $108 \mathrm{~nm}$ e $146 \mathrm{~nm}$. Além disso, também estão listados na Tabela 5.1 outros parâmetros obtidos pelo refinamento dos dados de DRX, tais como: parâmetro de rede da estrutura $(a)$, posição do oxigênio $(u)$ na célula unitária e incerteza do ajuste Rietveld $\left(\chi^{2}\right)$. A incerteza $\chi^{2}$ mede a dispersão dos dados experimentais em relação a curva do ajuste, onde um $\chi^{2}=1,00$ representa um ajuste perfeito. Como se pode observar na Tabela 5.1, os valores obtidos de $\chi^{2}$ são próximos a 1,00, o que demonstra a alta qualidade do ajuste. 


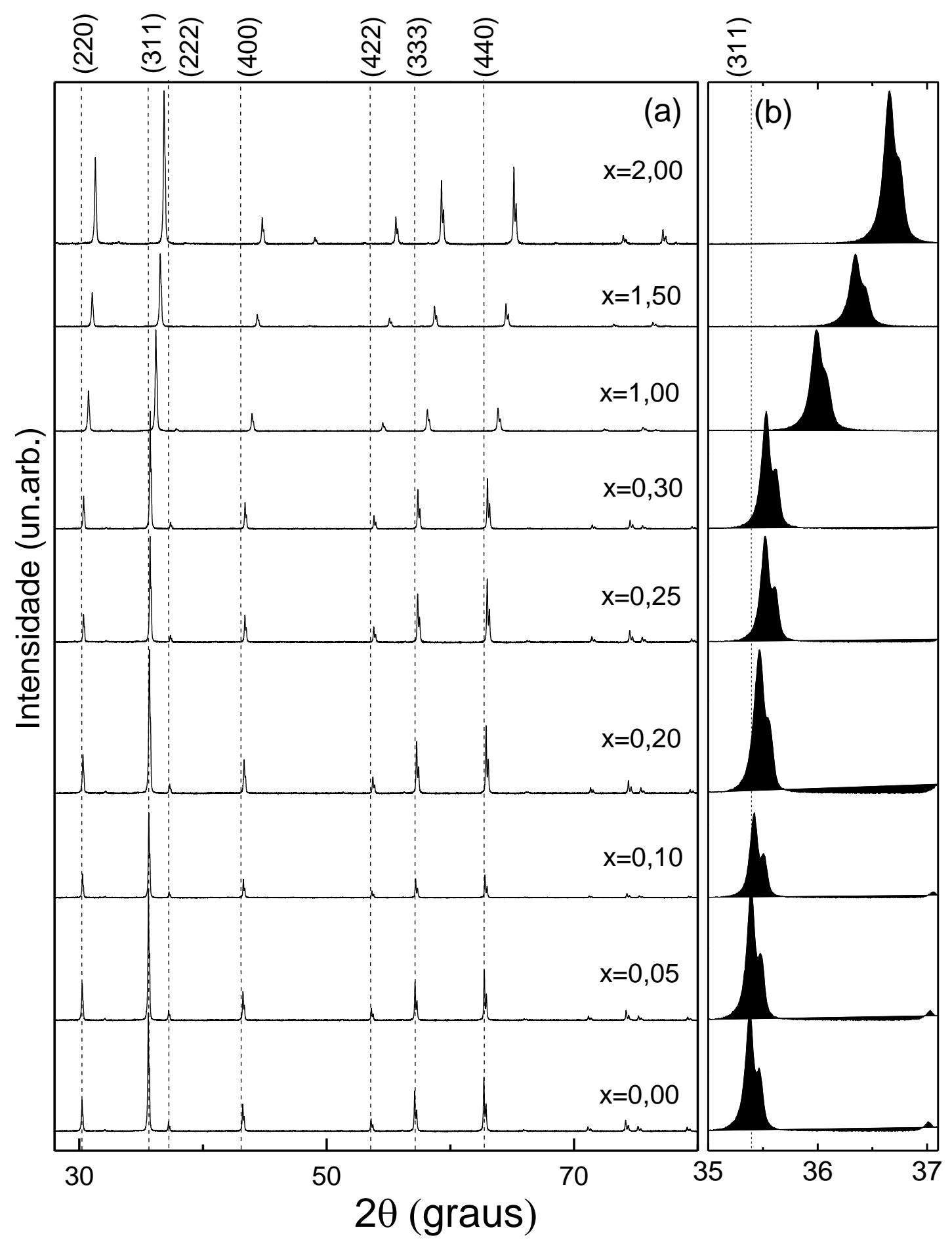

Fig. 5.3: (a) Padrões de difração de raios $X$ das amostras de $\mathrm{CoAl}_{\mathrm{x}} \mathrm{Fe}_{2-\mathrm{x}} \mathrm{O}_{4} \operatorname{com} x=0,0 \quad$ 2,0. (b) Detalhes dos Padrões de DRX da região em torno do pico (311) das mesmas amostras. 


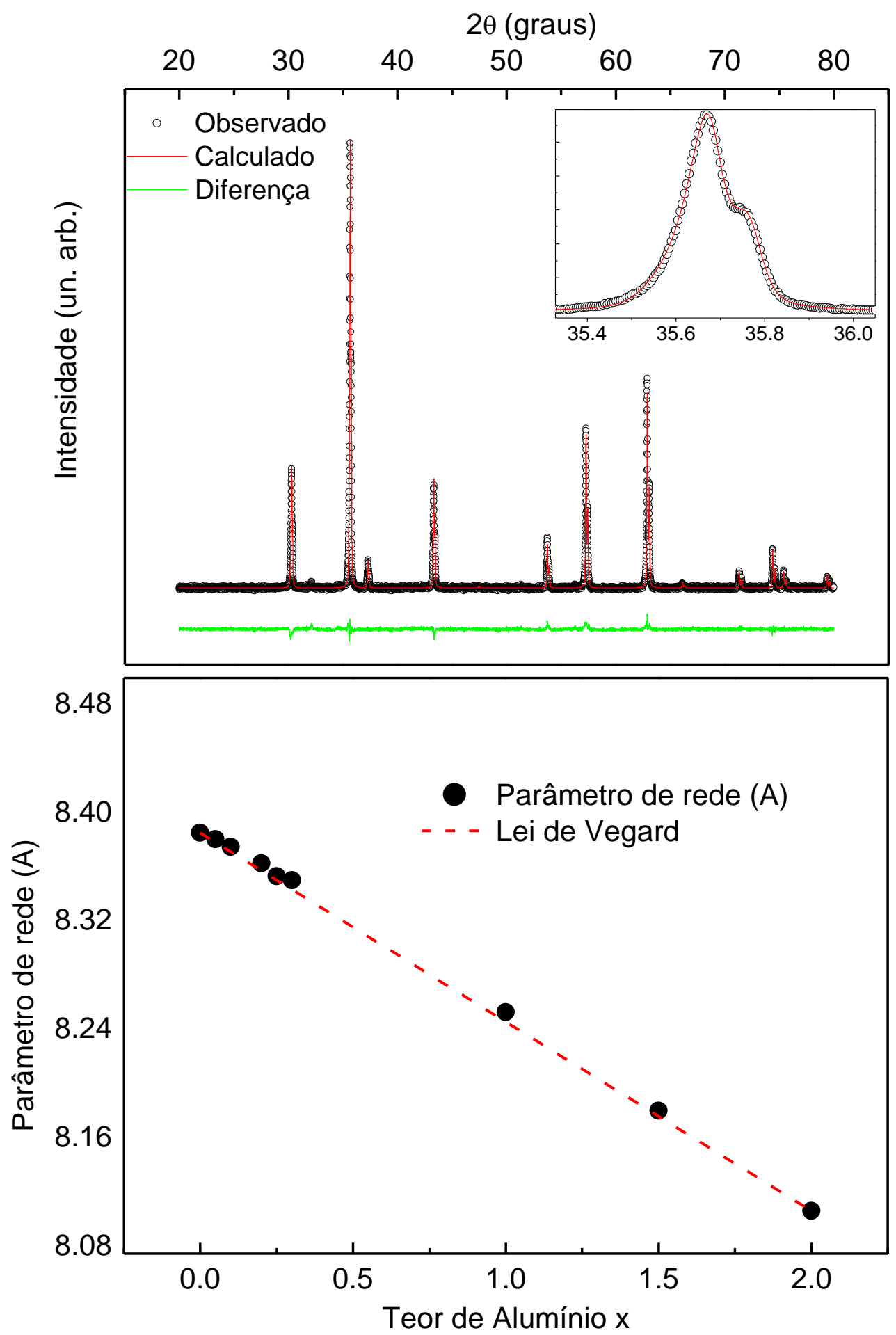

Fig. 5.4: (a) Refinamento Rietveld do padrão de DRX da amostra $\operatorname{com} x=0,20$. A inserção mostra detalhes do ajuste em torno do pico (311). (b) Parâmetro de rede das amostras de $\mathrm{CoAl}_{\mathrm{x}} \mathrm{Fe}_{2-\mathrm{x}} \mathrm{O}_{4} \operatorname{com} x=0,0-2,0$ obtido por meio do refinamento Rietveld. 
Tabela 5.1: Parâmetros obtidos por meio do refinamento Rietveld dos espectrogramas de DRX das amostras de $\mathrm{CoAl}_{\mathrm{x}} \mathrm{Fe}_{2-\mathrm{x}} \mathrm{O}_{4}$.

\begin{tabular}{ccccc}
\hline$A l(x)$ & Parâmetro de rede a & Posição do & Incerteza do ajuste & Diâmetro WH- \\
& $(\AA)$ & oxigênio $u$ & Rietveld $\chi^{2}$ & plot $(n m)$ \\
\hline 0,00 & 8,385 & 0,257 & 1,67 & 108 \\
0,05 & 8,380 & 0,256 & 1,32 & 132 \\
0,10 & 8,375 & 0,254 & 1,38 & 124 \\
0,20 & 8,363 & 0,258 & 1,30 & 121 \\
0,25 & 8,353 & 0,262 & 4,23 & 146 \\
0,30 & 8,350 & 0,258 & 1,36 & 146 \\
1,00 & 8,253 & 0,233 & 1,59 & 128 \\
1,50 & 8,180 & 0,256 & 1,15 & 114 \\
2,00 & 8,106 & 0,263 & 1,23 & \\
\hline
\end{tabular}

\subsubsection{Distribuição catiônica das amostras de $\mathrm{CoAl}_{x} \mathrm{Fe}_{2-x} \mathrm{O}_{4}$}

A espectroscopia Mössbauer pode ser usada com sucesso na determinação da distribuição de cátions em ferritas terciárias, uma vez que esta técnica é sensível ao teor de $\mathrm{Fe}^{3+}$ existente em cada uma das coordenações da estrutura espinélio. Neste caso, basta completar o balanço estequiométrico com o cátion restante. Esta estratégia foi adotada por Nakagomi e al [43] no estudo das propriedades estruturais e magnéticas da ferrita de magnésio $\mathrm{Mg}_{\mathrm{x}} \mathrm{Fe}_{3-\mathrm{x}} \mathrm{O}_{4}$. Contudo, na investigação de ferritas quaternárias como as estudadas neste trabalho, faz-se necessário o uso de outras técnicas para a diferenciação entre os outros dois cátions além do $\mathrm{Fe}^{3+}$. Levando-se em consideração os fatores de espalhamento (medida 
da eficiência do espalhamento por determinado átomo) das substâncias presentes nas amostras (Tabela 5.2), observa-se uma grande diferença entre os valores encontrados para o alumínio em relação aos encontrados para o ferro e cobalto. Estes dados sugerem que apesar de não ser possível diferenciar os átomos de ferro dos átomos de cobalto é possível diferenciá-los dos átomos de alumínio.

Tabela 5.2: Fatores de espalhamento atômico dos íons constituintes da ferrita de $\mathbf{C o A l}_{\mathbf{x}} \mathbf{F} \mathbf{e}_{2-\mathbf{x}} \mathbf{O}_{4}$.

\begin{tabular}{ccccc}
\hline $\begin{array}{c}\text { Fator de } \\
\text { espalhamento }\end{array}$ & $\mathrm{Fe}^{3+}$ & $\mathrm{Co}^{2+}$ & $\mathrm{Al}^{3+}$ & $\mathrm{O}^{2-}$ \\
\hline $\mathrm{f}^{\prime+}$ & $-1,135$ & $-2,417$ & 0,213 & 0,050 \\
$\mathrm{f}^{\prime}$ & 3,154 & 3,622 & 0,246 & 0,032 \\
\hline
\end{tabular}

Os difratogramas de DRX foram analisados com o programa GSAS na plataforma gráfica EXPGUI como já descrito anteriormente. Vários parâmetros são passíveis de refinamento, como por exemplo, o parâmetro de rede $(a)$, posição dos oxigênios na rede $(u)$ e o tamanho médio das partículas (LX). Também é possível determinar a distribuição dos elementos nos sítios tetraédricos e octaédricos da estrutura. Neste último caso, a proximidade dos fatores de espalhamento do ferro e do cobalto se torna um problema, já que a substituição de um pelo outro não causa mudanças significativas no fator $\xi^{2}$, erro da curva teórica calculada pelo programa em relação ao espectrograma experimental. Por outro lado, a troca dos íons de ferro/cobalto por íons de alumínio na estrutura cristalina gera mudanças significativas no fator $\xi^{2}$.

Assim, com o objetivo de verificar o efeito do teor de $A l(x)$ nos padrões de DRX, simulações com diferentes distribuições de $\mathrm{Al}^{3+}$ nos sítios $\mathrm{A}$ e $\mathrm{B}$ foram realizados para todos 
os valores as amostras. As simulações foram realizadas com o programa GSAS e durante todo o processo, além da distribuição, também foram refinados os valores de parâmetro de rede das amostras, embora este último não gerasse modificação significativas em $\xi^{2}$.

Embora os difratogramas variem para cada possível distribuição catiônica, a área total do espectro deve ser proporcional à quantidade de núcleos espalhadores, o que se mantém constante para um teor de $A l(x)$ fixo. Baseando-se neste princípio, todos os espectrogramas DRX gerados na simulação foram normalizados a unidade para possibilitar a comparação entre os difratogramas.

Alguns planos de difração, como por exemplo, o (311) parece não ter relação especial com a distribuição do $\mathrm{Al}^{3+}$, uma vez que suas intensidades praticamente não variam com o teor de $A l(x)$. Entretanto, foi verificada uma correlação entre as intensidades dos picos de difração (220), (400), (422), (331), e (222) e o teor de alumínio substitucional nos sítios A e B. Por exemplo, é mostrado na Fig. 5.5 (a) e (b) uma ampliação em torno dos picos (220) e (400) dos difratogramas de DRX simulados, para diferentes teores de $\mathrm{Al}^{3+}$ no sítio tetraédrico, obtido para uma amostra de $\mathrm{CoAl}_{\mathrm{x}} \mathrm{Fe}_{2-\mathrm{x}} \mathrm{O}_{4} \operatorname{com} x=0,30$. Note que quando o sítio A está totalmente preenchido por íons de $\mathrm{Al}^{3+}$, a intensidade do pico (220) é da ordem de $30 \%$ da intensidade do pico (400). Essa relação de intensidade se inverte quando a totalidade dos íons de alumínio está inserida no sítio B. Este comportamento, assim como o comportamento do pico (422) se estende a todos os valores de $x$ estudado.

Por outro lado, a intensidade dos picos de difração (222) e (331) apresentam comportamentos mais complexos em comparação com os planos cristalinos anteriormente descritos (ver Fig. 5.5 (c) - (f)). Por exemplo, é verificado que para $x=2,00$ a intensidade dos picos (222) e (331) é máxima quando a totalidade de Al está no sítio A ou no sítio B e mínima quando os íons de Al estão divididos entre estes sítios (Fig. 5.5 (c) e (d)). Contudo, para menores valores de $x$ é observado que as intensidades destes picos decrescem com o teor 
de alumino no sítio A com relação ao sítio B. É interessante notar que apesar do parâmetro de rede ter sido refinado em todas as simulações, não foram observados deslocamentos dos picos de difração em função da distribuição dos cátions de alumínio Al(sítio A). Estas observações nos levam a concluir que, apesar de existir uma variação no raio iônico do $\mathrm{Al}^{3+}$ em função do sítio que ocupa, esta diferença não causa deslocamento visível nos difratogramas das amostras de $\mathrm{CoAl}_{\mathrm{x}} \mathrm{Fe}_{2-\mathrm{x}} \mathrm{O}_{4}$.

A partir das simulações descritas acima, foram construídas curvas das razões de intensidades $I(220) / I(400)$ em função do teor de $A l(x)$ no sítio tetraédrico (ver Fig. 5.6). Estes picos foram escolhidos em função da melhor relação sinal/ruído destas reflexões nos difratogramas.

Fazendo uso destas curvas, foram estimados os teores de $\mathrm{Al}^{3+}$ substitucional nos sítios tetraédricos e octaédricos para as diferentes amostras estudadas. Assim, de posse da distribuição dos íons de $\mathrm{Al}^{3+}$, estimados por $\mathrm{DRX}$, e dos íons de $\mathrm{Fe}^{3+}$, estimados por espectroscopia Mössbauer, foi possível determinar a distribuição catiônicas de todas as amostras de $\mathrm{CoAl}_{\mathrm{x}} \mathrm{Fe}_{2-\mathrm{x}} \mathrm{O}_{4}$. Estes distribuições podem ser encontradas na Tabela 5.3. Além do mais, foi constatado que as distribuição catiônicas obtidas como descrito acima levaram aos menores fatores $\xi^{2}$ para todas as amostras, demonstrando assim a efetividade do método utilizado. 


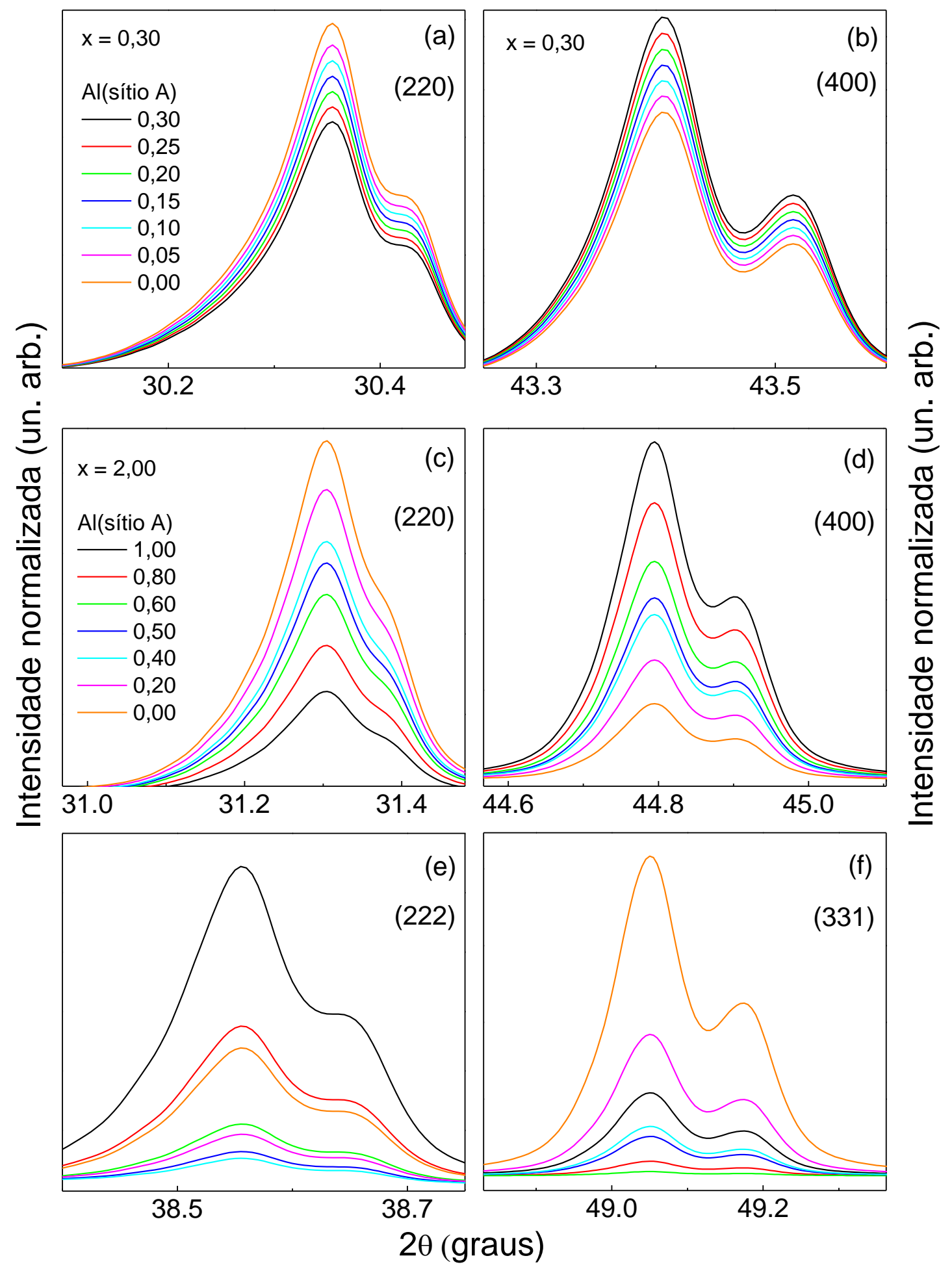

Fig. 5.5: Variação das intensidades dos planos (220) (a) e (c), (400) (b) e (d), (222) (e) e (331) (f) em função do teor de Alumínio substitucional no sítio tetraédrico Al(sítio A). As áreas de todos os difratogramas foram normalizadas a unidade. 


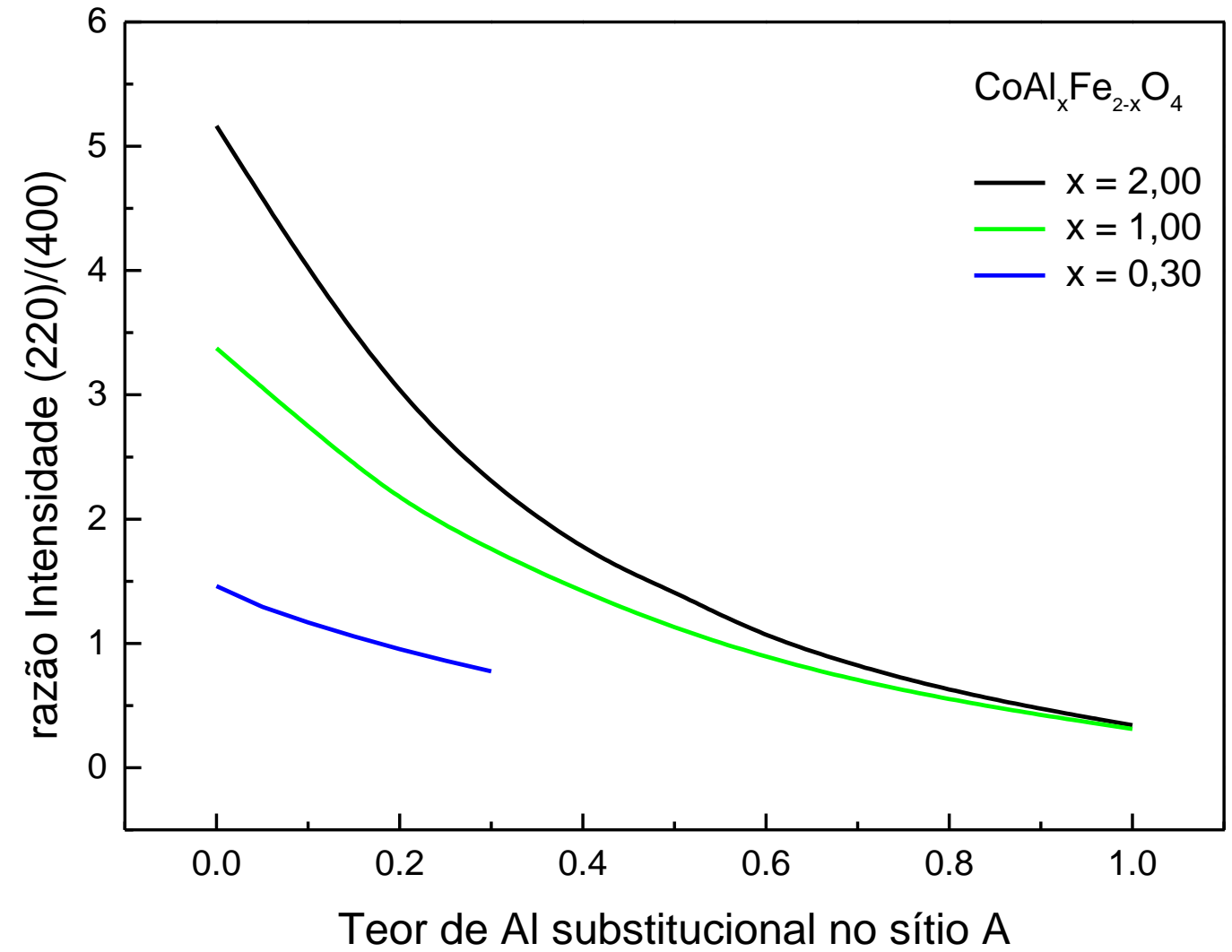

Fig. 5.6: Simulação: razão entre as intensidades dos picos (220) e (400) obtidos para a ferrita de $\mathrm{CoAl}_{\mathrm{x}} \mathrm{Fe}_{2-\mathrm{x}} \mathrm{O}_{4}$ com $x=0,30,1,00$ e 2,00 em função do teor de Alumínio substitucional no sítio tetraédrico $A l(s i ́ t i o ~ A)$. 
Tabela 5.3: Distribuição de cátions obtidas por meio das técnicas de espectroscopias Mössbauer e DRX (Refinamento de Rietiveld). M representa o íon $\mathrm{Co} / \mathrm{Al}$ não diferenciados na espectroscopia Mössbauer. A medida de erro $\xi^{2}$ foi obtido por meio do refinamento dos padrões de DRX pelo método o de Rietveld.

\begin{tabular}{|c|c|c|c|}
\hline $\operatorname{Al}(x)$ & Técnica & Distribuição de Cátions & $\xi^{2}$ \\
\hline \multirow{2}{*}{0,00} & Mössbauer & {$\left[\mathrm{Fe}_{0,90}^{3+} \mathrm{Co}_{0,10}^{2+}\right]^{A}\left[\mathrm{Fe}_{1,10}^{3+} \mathrm{Co}_{0,90}^{2+}\right]^{B} \mathrm{O}_{4}^{2-}$} & \\
\hline & DRX (Rietveld) & {$\left[\mathrm{Fe}_{0,90}^{3+} \mathrm{Co}_{0,10}^{2+}\right]^{A}\left[\mathrm{Fe}_{1,10}^{3+} \mathrm{Co}_{0,90}^{2+}\right]^{B} \mathrm{O}_{4}^{2-}$} & 1,66 \\
\hline \multirow{2}{*}{0,05} & Mössbauer & {$\left[F e_{0,85}^{3+} M_{0,15}\right]^{A}\left[F e_{1,10}^{3+} M_{0,90}\right]^{B} O_{4}^{2-}$} & \\
\hline & DRX (Rietveld) & {$\left[\mathrm{Fe}_{0,85}^{3+} \mathrm{Co}_{0,10}^{2+} A l_{0,05}^{3+}\right]^{A}\left[\mathrm{Fe}_{1,10}^{3+} \mathrm{Co}_{0,90}^{2+}\right]^{B} \mathrm{O}_{4}^{2-}$} & 1,35 \\
\hline \multirow{2}{*}{0,10} & Mössbauer & {$\left[F e_{0,90}^{3+} M_{0,10}\right]^{A}\left[F e_{1,00}^{3+} M_{1,00}\right]^{B} O_{4}^{2-}$} & \\
\hline & DRX (Rietveld) & {$\left[\mathrm{Fe}_{0,90}^{3+} \mathrm{Co}_{0,10}^{2+}\right]^{A}\left[\mathrm{Fe}_{1,00}^{3+} \mathrm{Co}_{0,90}^{2+} A l_{0,10}^{3+}\right]^{B} \mathrm{O}_{4}^{2-}$} & 1,43 \\
\hline \multirow{2}{*}{0,20} & Mössbauer & {$\left[F e_{0,85}^{3+} M_{0,15}\right]^{A}\left[F e_{1,10}^{3+} M_{0,9}\right]^{B} O_{4}^{2-}$} & \\
\hline & DRX (Rietveld) & {$\left[\mathrm{Fe}_{0,75}^{3+} \mathrm{Co}_{0,25}^{2+}\right]^{A}\left[\mathrm{Fe}_{1,00}^{3+} \mathrm{Co}_{0,80}^{2+} \mathrm{Al}_{0,2}^{3+}\right]^{B} \mathrm{O}_{4}^{2-}$} & 1,61 \\
\hline \multirow{2}{*}{0,25} & Mössbauer & {$\left[F e_{0,80}^{3+} M_{0,20}\right]^{A}\left[F e_{0,95}^{3+} M_{1,05}\right]^{B} O_{4}^{2-}$} & \\
\hline & DRX (Rietveld) & {$\left[\mathrm{Fe}_{0,80}^{3+} \mathrm{Co}_{0,05}^{2+} A l_{0,15}^{3+}\right]^{A}\left[\mathrm{Fe}_{0,95}^{3+} \mathrm{Co}_{0,95}^{2+} A l_{0,10}^{3+}\right]^{B} \mathrm{O}_{4}^{2-}$} & 4,07 \\
\hline \multirow{2}{*}{0,30} & Mössbauer & {$\left[F e_{0,70}^{3+} M_{0,30}\right]^{A}\left[F e_{1,00}^{3+} M_{1,00}\right]^{B} O_{4}^{2-}$} & \\
\hline & DRX (Rietveld) & {$\left[\mathrm{Fe}_{0,70}^{3+} \mathrm{Co}_{0,25}^{2+} A l_{0,05}^{3+}\right]^{A}\left[\mathrm{Fe}_{1,00}^{3+} \mathrm{Co}_{0,75}^{2+} A l_{0,25}^{3+}\right]^{B} \mathrm{O}_{4}^{2-}$} & 1,42 \\
\hline \multirow{2}{*}{1,00} & Mössbauer & {$\left[F e_{0,50}^{3+} M_{0,50}\right]^{A}\left[F e_{0,50}^{3+} M_{1,50}\right]^{B} O_{4}^{2-}$} & \\
\hline & DRX (Rietveld) & {$\left[\mathrm{Fe}_{0,50}^{3+} \mathrm{Co}_{0,35}^{2+} A l_{0,15}^{3+}\right]^{A}\left[\mathrm{Fe}_{0,50}^{3+} \mathrm{Co}_{0,65}^{2+} A l_{0,85}^{3+}\right]^{B} \mathrm{O}_{4}^{2-}$} & 1,58 \\
\hline \multirow{2}{*}{1,50} & Mössbauer & -------------- & \\
\hline & DRX (Rietveld) & {$\left[\mathrm{Fe}_{0,50}^{3+} \mathrm{Co}_{0,40}^{2+} A l_{0,10}^{3+}\right]^{A}\left[\mathrm{Co}_{0,60}^{2+} A l_{1,40}^{3+}\right]^{B} \mathrm{O}_{4}^{2-}$} & 1,12 \\
\hline \multirow[b]{2}{*}{2,00} & Mössbauer & ------------- & \\
\hline & DRX (Rietveld) & {$\left[\mathrm{Co}_{0,85}^{2+} A l_{0,15}^{3+}\right]^{A}\left[\mathrm{Co}_{0,15}^{2+} A l_{1,85}^{3+}\right]^{B} \mathrm{O}_{4}^{2-}$} & 1,51 \\
\hline
\end{tabular}




\subsection{ESPECTROSCOPIA RAMAN}

A Fig. 5.7 mostra os espectros Raman, obtidos a temperatura ambiente para as amostras de $\mathrm{CoAl}_{\mathrm{x}} \mathrm{Fe}_{2-\mathrm{x}} \mathrm{O}_{4}$ com $x=0,05-2,00$. Os modos Raman característicos da ferrita de cobalto pura $(x=0,00)$ e do cobalto azul $(x=2,00)$ são indicados na Fig. 5.7 por linhas verticais tracejadas e pontilhadas, respectivamente [54, 55]. A fim de analisar os espectros com maior precisão, ajustes com o programa Fityk [56] utilizando curvas do tipo Lorenztiana foram realizados.

Como descrito anteriormente, a estrutura espinélio cúbica pertence ao grupo espacial Fd-3m, e seus modos Raman ativos são derivados das seguintes representações irredutíveis:

$$
\Gamma=A_{1 g}(R)+E_{g}(R)+F_{1 g}+3 F_{2 g}(R)+2 A_{2 u}+2 E_{u}+5 F_{1 u}(I R)+2 F_{2 u}
$$

onde (R) e (IR) representam respectivamente os modos Raman e Infravermelho ativos. Como o grupo cristalográfico Fd-3m possui centro de inversão, os modos Raman e infravermelho são mutuamente excludentes. Com isto, são previstos cinco modos Raman ativos para cristais com estrutura espinélio cúbica: três modos vibracionais com simetria $\mathrm{F}_{2 \mathrm{~g}}$ (os diferentes modos $F_{2 g}$ foram diferenciados como 1, 2 e 3 ), um modo vibracional com simetria $E_{g}$ e um modo vibracional com simetria $A_{1 g}$. Os modos previstos pela teoria de grupo foram identificados de acordo com a literatura $[54,55,57]$ confirmando assim a estrutura espinélio cúbica para todas as amostras.

As Fig. 5.8 (a) e (b) mostram de forma ampliada os ajustes com curvas lorentzianas dos espectros Raman das amostras de ferrita de cobalto (a) e do cobalto azul (b). O deslocamento dos modos vibracionais previstos pela teoria de grupo em função do teor de $A l(x)$ são mostrados nas Fig. 5.8 ((c) - (f)). O modo vibracional $\mathrm{F}_{2 \mathrm{~g}}(3)$ (azul - Fig. 5.7) 
apresenta comportamento misto [46], deslocando-se para energias mais altas até se dividir em dois modos vibracionais $\mathrm{F}_{2 \mathrm{~g}}(3)$ (Fig.5.8 (d)). Da mesma forma, o comportamento do modo $\mathrm{A}_{1 \mathrm{~g}}$ (discutido em detalhe abaixo) também segue a mesma tendência, dividindo-se em dois modos vibracionais, $A_{1 g}(1)$ (preto - Fig. 5.7) e $A_{1 g}(2)$ (cinza - Fig. 5.7). Os demais modos, com energias abaixo de $650 \mathrm{~cm}^{-1}$, demonstram comportamento de um modo único [46], com deslocamentos energéticos proporcionais ao teor de $A l(x)$ substitucional.

Além dos modos inicialmente previstos pela teoria de grupo, modos vibracionais ainda não identificados (ombros) foram encontrados em todas as amostras. Embora frequentemente relatados na literatura, ainda não há uma explicação clara sobre suas origens.

Por outro lado, é consenso que os modos vibracionais acima de $650 \mathrm{~cm}^{-1}$ estão associados a vibrações do sítio tetraédrico. Sendo assim, uma possível explicação para os modos extras encontrados acima de $650 \mathrm{~cm}^{-1}$ observados em todas as amostras, seria a existência de diferentes configurações dos sítios octaédricos, vizinhos aos sítios tetraédricos [41].

A hipótese de que os diferentes modos vibracionais de mais alta energia (acima de 650 $\mathrm{cm}^{-1}$ ) estão relacionadas a diferentes configurações de ocupação do sitio octaédrico é defendida nos trabalhos de Laguna-Bercero et al. [41] e de B. D. Hosterman [44] (ver discussão na sessão 2.4). A análise dos espectros Raman das amostras aqui estudadas e de suas distribuições catiônicas (Tabela 5.3) apoia esta hipótese. Os dois modos vibracionais de mais altas energias atribuídos à simetria $\mathrm{A}_{1 \mathrm{~g}}$, podem ser subdivididos da seguinte forma: nas amostras $x=(0,00-0,30)$ o modo $A_{1 g}(1)$ seria atribuído principalmente a vibrações do tipo $(\mathrm{Fe})^{A}-\mathrm{O}-(\mathrm{Fe})_{3}^{B}$ enquanto o modo $\mathrm{A}_{1 \mathrm{~g}}(2)$ corresponderia predominantemente à vibrações do tipo $(F e)^{A}-O-(C o)_{3}^{B}$. Já nas amostras $\operatorname{com} x=1,00-2,00$ o modo $\mathrm{A}_{1 \mathrm{~g}}(1)$ seria gerado principalmente por vibrações do tipo $(\mathrm{Fe} / \mathrm{Co})^{A}-O-(A l)_{3}^{B}$ (mais energéticos) e o modo $\mathrm{A}_{1 \mathrm{~g}}(2)$ estaria associado a vibrações do tipo $(\mathrm{Fe} / \mathrm{Co})^{A}-\mathrm{O}-(\mathrm{Fe} / \mathrm{Co})_{3}^{B}$. 
Além do mais, o deslocamento dos modos $\mathrm{A}_{1 \mathrm{~g}}$ para maiores energias com o aumento no teor de $A l(x)$ substitucional observado em todas as amostras seria atribuído ao aumento do número de ligações do tipo $(M)^{A}-O-(A l)^{B}$, onde $(M)^{A}$ corresponde aos cátions que ocupam o sítio tetraédrico. No presente caso: $\mathrm{Fe}, \mathrm{Co}$ ou $\mathrm{Al}$. 


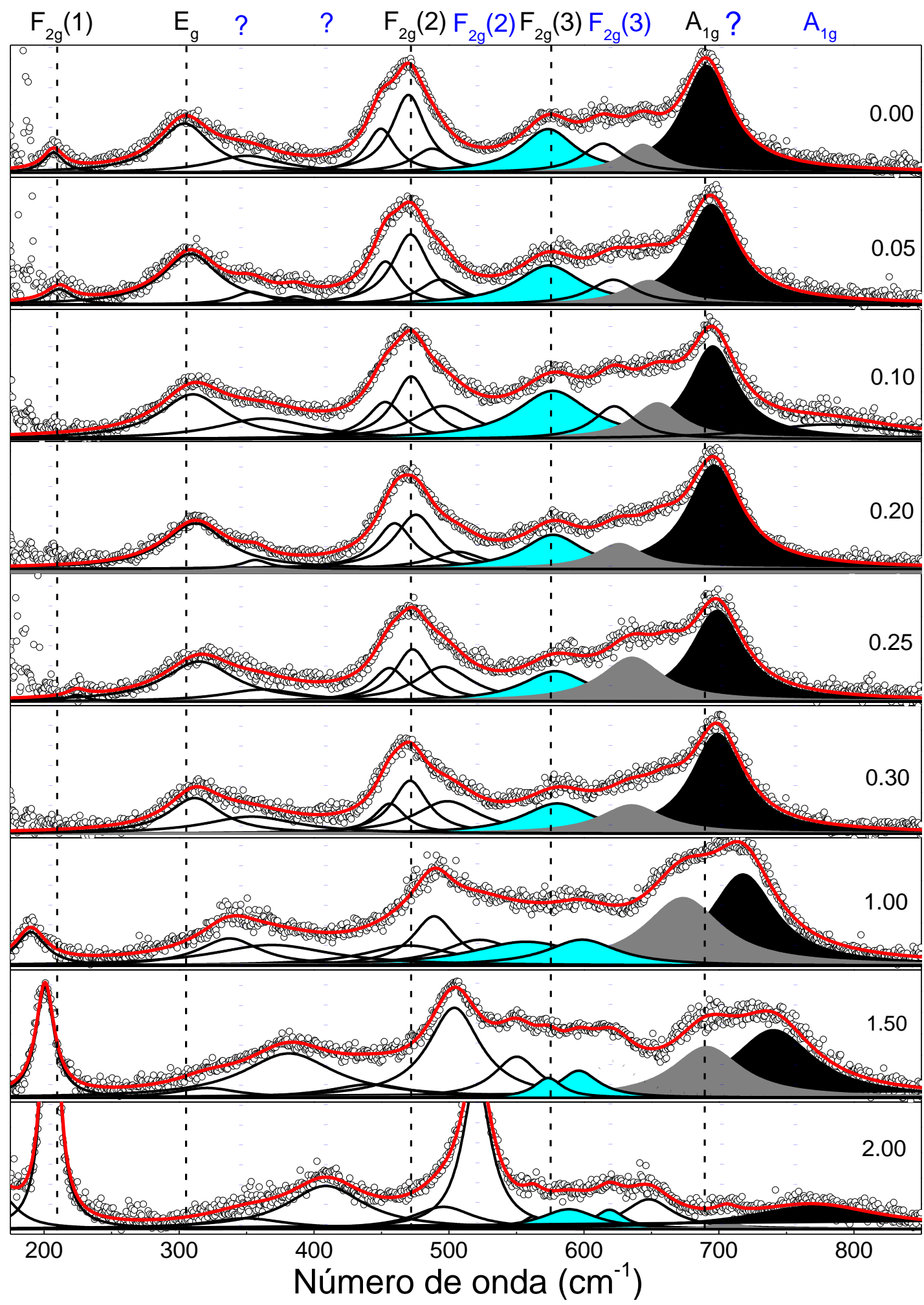

Fig. 5.7: Espectros Raman das amostras de $\mathrm{CoAl}_{x} \mathrm{Fe}_{2-\mathrm{x}} \mathrm{O}_{4} \operatorname{com} x=0,00$ - 2,00. Os principais modos vibracionais previstos para as ferrita de Cobalto $(x=0,00)$ e Cobalto Azul $(x=2,00)$ estão indicados por retas tracejadas $\mathrm{e}$ pontilhadas, respectivamente. As curvas vermelhas representam o melhor ajuste. 


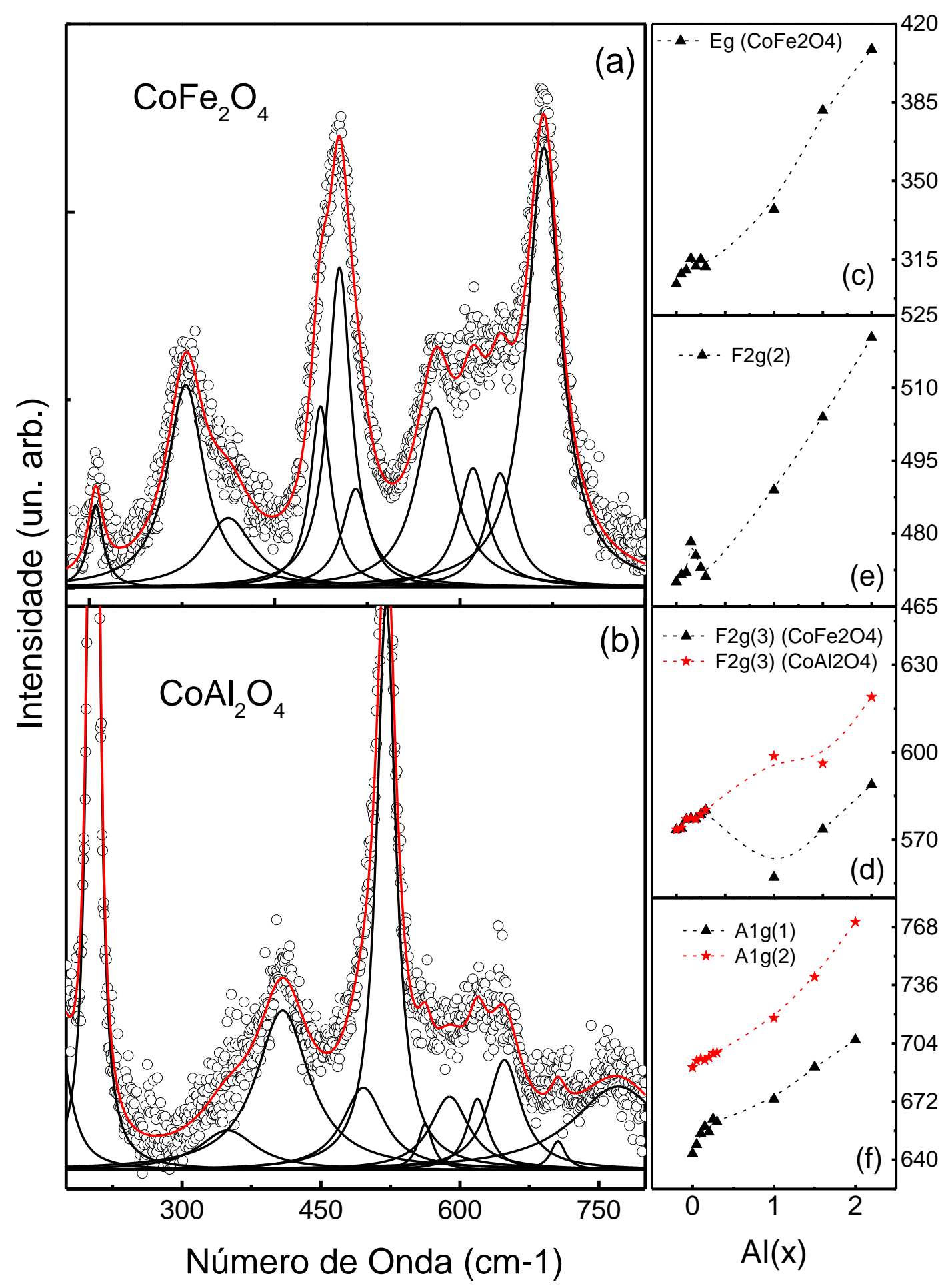

Fig. 5.8: Detalhes dos espectros Raman das amostras de. $\mathrm{CoFe}_{2} \mathrm{O}_{4}$ (a) e $\mathrm{CoAl}_{2} \mathrm{O}_{4}$. (b) Deslocamentos dos modos vibracionais (c) $\mathrm{E}_{\mathrm{g}}$, (d) $\mathrm{F}_{2 \mathrm{~g}}(3),(\mathrm{e}) \mathrm{F}_{2 \mathrm{~g}}(2)$ e (f) $\mathrm{A}_{1 \mathrm{~g}}$ em função do teor de $A l(x)$ substitucional. 


\subsection{MEDIDAS DE MAGNETIZAÇÃO}

A Fig. 5.9 mostra as curvas de magnetização $M$ vs $H$ realizadas a 300K para as amostras de $\mathrm{CoAl}_{\mathrm{x}} \mathrm{Fe}_{2-\mathrm{x}} \mathrm{O}_{4}$ com $x=0,00-2,00$. As curvas de histerese mostram comportamento típico de materiais magneticamente ordenados para amostras com teor de $A l(x)$ no intervalo $0,00-1,00$ e comportamento típico de materiais magneticamente desordenados para as amostras $\operatorname{com} x=1,50$ e 2,00. Os valores de magnetização de saturação, $M_{s}$, obtidas por meio da estrapolação do gráfico de $M$ vs $1 / H$ para $1 / H \rightarrow 0$, em função do teor de $A l(x)$ são mostrados na Fig. 5.10 (símbolos em vermelho) e na Tabela 5.4. Observa-se que os valores de $M_{s}$ decrescem de forma não homogênea com o teor de $\operatorname{Al}(x)$, onde o maior valor foi encontrado para a amostra $x=0,05$. Para comparação, os valores teóricos de $M_{S}$ obtidos a partir da distribuição de cátions descrita na Tabela 5.3 também são mostrados na Fig. 5.10 (símbolos em preto). Para a obtenção destes valores não foram levados em consideração possíveis efeitos como "spin-canting" ou defeitos na rede. Neste cálculo foi utilizada a aproximação de Nèel, dada por:

$$
\mu=\mu_{B}-\mu_{A}
$$

onde $\mu_{\mathrm{A}}$ e $\mu_{\mathrm{B}}$ correspondem respectivamente aos momentos magnéticos totais dos sítios tetraédrico e octaédrico [58]. Os valores de momento magnético atômico dependem tanto dos elétrons desemparelhados quanto do sítio por eles ocupados. Nesta análise foram utilizados os valores de momentos magnéticos atômicos obtidos por Kim et al [59] para amostras de $\mathrm{CoAl}_{\mathrm{x}} \mathrm{Fe}_{2-\mathrm{x}} \mathrm{O}_{4}$. Estas foram sintetizadas pelo método sol-gel e analisadas por meio de difração de nêutrons e espectroscopia Mössbauer. 
Em nosso estudo foram constatados valores de magnetização experimentais consideravelmente abaixo dos valores previstos teoricamente, em torno de $30 \%$ menores que o esperado para amostras com $x \leq 0,30$. Contudo, o comportamento da curva experimental de $M_{S} v S A l(x)$ segue o mesmo padrão obtido pelos valores teóricos, reafirmando assim a validade do método utilizado no cálculo da distribuição de cátions. 


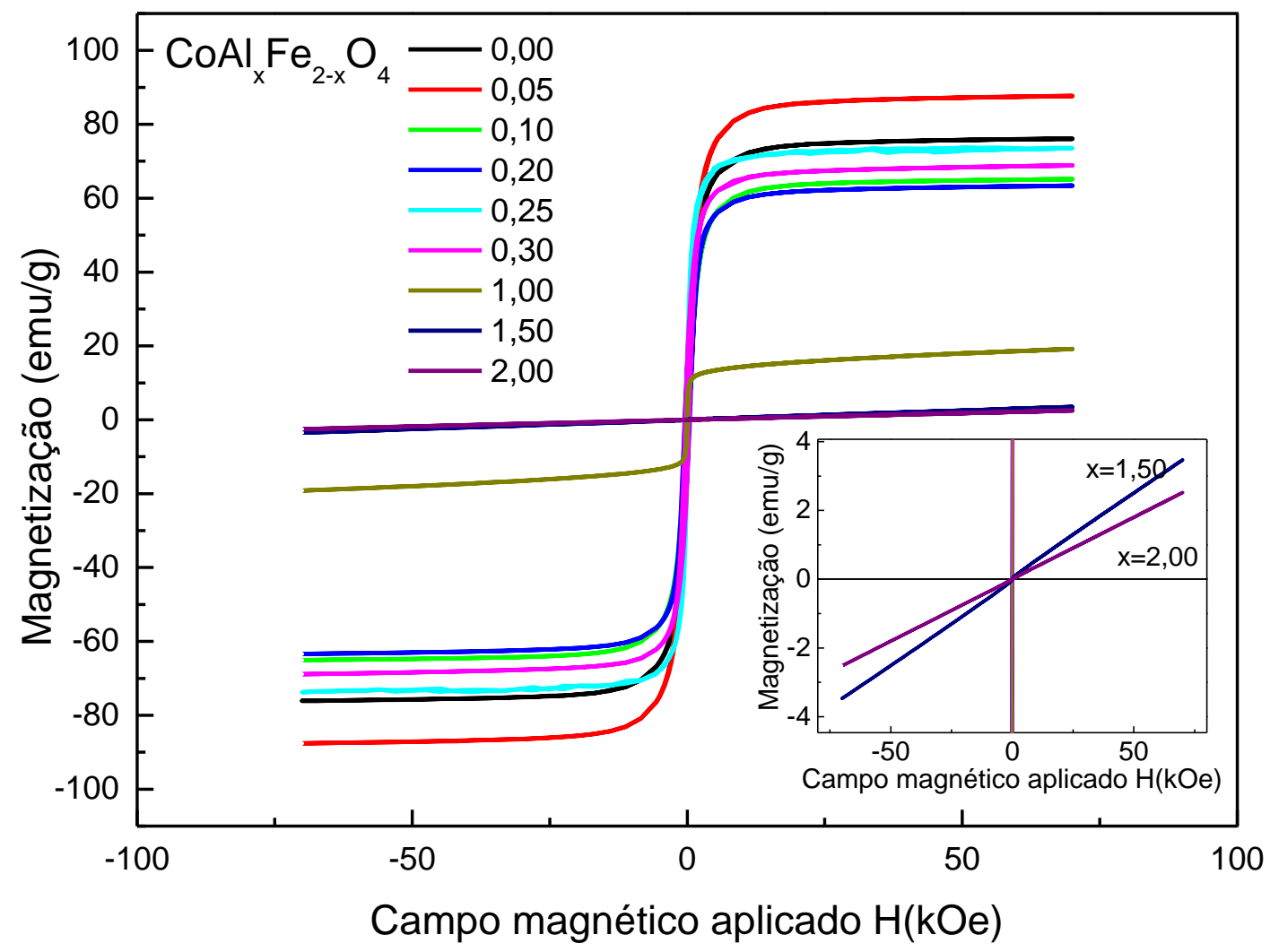

Fig. 5.9: Curvas de histerese, $M$ vs $H$, das amostras de $\mathrm{CoAl}_{\mathrm{x}} \mathrm{Fe}_{2-\mathrm{x}} \mathrm{O}_{4}$ com teor de $A l(x)$ no intervalo $0,00-$ 2,00. Detalhe das curvas $x=1,50$ e $x=2,00$. 


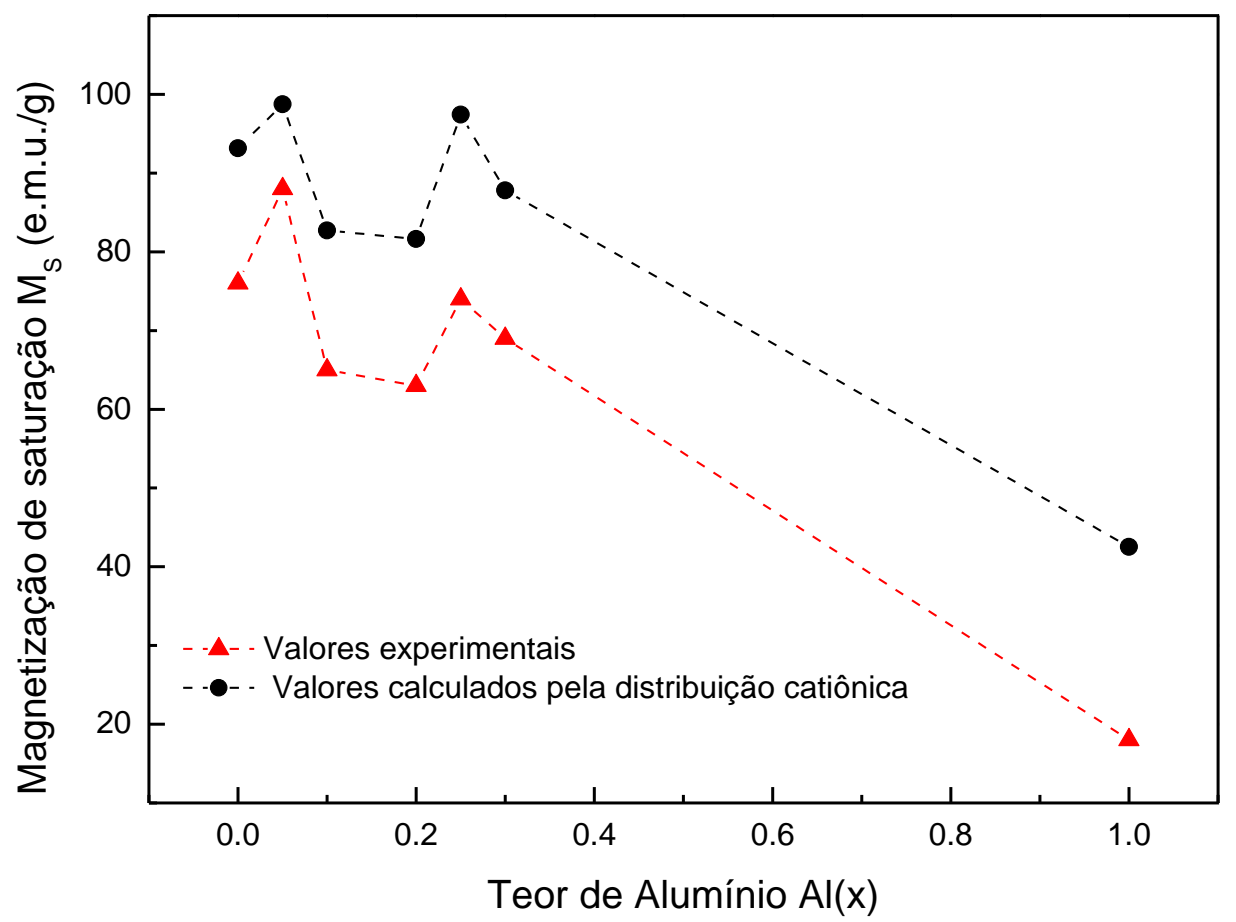

Fig. 5.10: Comparação entre os valores de magnetização de saturação $M_{s}$ experimentais, obtidos para as amostras de $\mathrm{CoAl}_{x} \mathrm{Fe}_{2-\mathrm{x}} \mathrm{O}_{4}$ (em vermelho) e teóricos, obtidos por meio da equação (5.2) e da distribuição de cátions mostradas na Tabela 5.3 (em preto). As linhas pontilhadas servem apenas como guia para os olhos. 
A discrepância entre os valores de $M_{S}$ experimentais e teóricos (ver Fig. 5.10) podem ser atribuídas a diferentes fatores, tais como: defeitos na estrutura cristalina (amorfização e/ou vacâncias), efeitos de vidros de spin, efeitos de "spin-canting", e/ou a formação de uma estrutura núcleo-casca (“core-shell”) com diferentes distribuições de cátions [60], [61].

Šepelák et al. [60] mostraram, por meio de medidas de espectroscopia Mössbauer com campo magnético aplicado, que a presença de uma estrutura núcleo-casca poderia explicar a discrepância entre os valores de $M s$ esperados e os observados. Os autores mostraram que as nanopartículas por eles estudadas eram formadas por um núcleo homogêneo, com distribuição similar ao $\mathrm{MgFe}_{2} \mathrm{O}_{4}$ bulk (com fator de inversão $\lambda=0,90$ ), recoberta por uma casca com distribuição mista (com fator de inversão $\lambda=0,69$ ). Embora seja plausível a existência desta estrutura para altos teores de alumínio nas amostras de $\mathrm{CoAl}_{\mathrm{x}} \mathrm{Fe}_{2-\mathrm{x}} \mathrm{O}_{4}$, este modelo não se mostrou suficientemente adequado para descrever os resultados para as amostras com pequenos valores de $A l(x)$, já que mesmo para uma troca total dos cátions numa casca correspondendo a metade do volume total não seria suficiente para justificar a discrepância entre os valores teóricos e experimentais.

No caso do efeito de "spin-canting", as interações de troca e supertroca são enfraquecidas na superfície das nanopartículas devido à quebra da simetria de translação. $\mathrm{O}$ que leva formação de uma camada não magnética na superfície das mesmas. Embora este efeito possa estar presente nas amostras aqui estudadas, sua magnitude não seria suficiente para explicar a considerável discrepância nos valores de $M_{S}$ encontrados, uma vez que o tamanho médio das nanopartículas é superior a $100 \mathrm{~nm}$ e a espessura da camada não magnética não seria superior a uma monocamada atômica [61].

Por último, as discrepâncias entre valores de $M_{S}$ experimentais e teóricos podem ser explicadas levando-se em conta a presença de uma fase de vidro de spin (“spin-glass") recobrindo um núcleo homogêneo. Como reportado por [57] a existência de uma camada de 
spins não ordenados (vidro de spin) pode causar diminuições significativas na magnetização de saturação em nanopartículas magnéticas. Um dos principais indícios da presença de uma fase do tipo vidro de spin é a existência de irreversibilidade (curvas de histerese abertas) em curvas $M$ vs $H$ abaixo da temperatura de congelamento, mesmo para campos da ordem de vários kOe [63].

A Fig. 5.11 mostra o primeiro quadrante das curvas de $M$ vs $H$ para as amostras $\mathrm{CoAl}_{0.20} \mathrm{Fe}_{1,80} \mathrm{O}_{4}$ e $\mathrm{CoAl}_{1,50} \mathrm{Fe}_{0,50} \mathrm{O}_{4}$ obtidas nas temperaturas de 5 e $300 \mathrm{~K}$. Pode-se observar que a $5 \mathrm{~K}$ ainda existe irreversibilidade para campos de aproximadamente $40 \mathrm{kOe}$ para $x=0,20$ (Fig. 5.11 (a)) e em campos de até 60 kOe para $x=1,50$ (Fig. 5.11 (c)). Este comportamento indica que dentro da estrutura não ordenada de spins, presente na camada que recobre o núcleo da nanopartícula, são necessários campos magnéticos superiores a 40 kOe para que os spins se alinhem com o campo aplicado. Este efeito não é observado nas medidas feitas a $300 \mathrm{~K}$, provavelmente por terem sido realizadas em temperatura acima da temperatura de congelamento dos spins. É importante ressaltar que foi observada irreversibilidade em altos campos magnéticos em todas as amostras com comportamento ferrimagnético a $5 \mathrm{~K}$. 


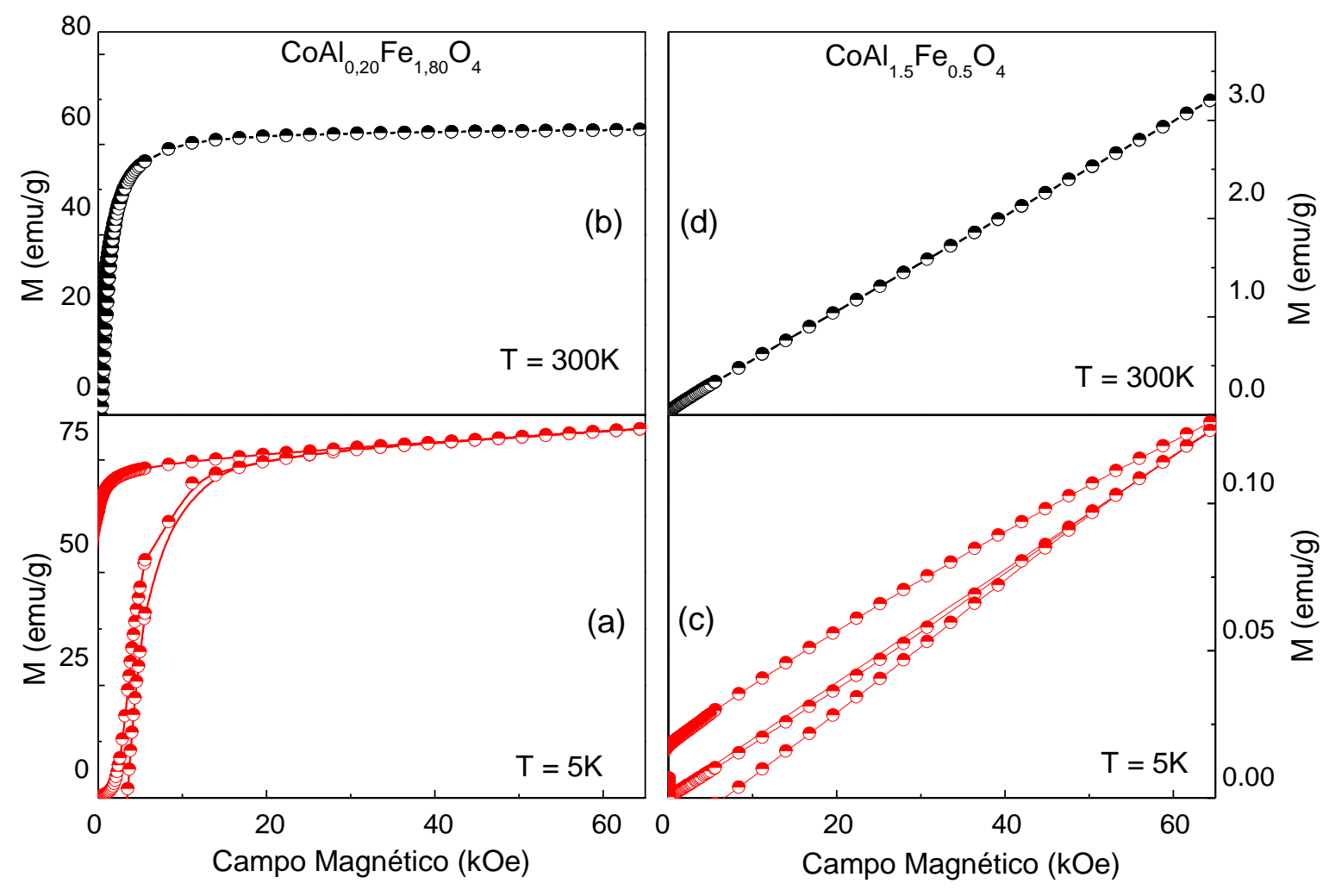

Fig. 5.11: Primeiro quadrante da curva $M v s H$ para as amostras $x=0,20$ e $\mathrm{x}=1,50$ a $5 \mathrm{~K}$ (vermelho) e a $300 \mathrm{~K}$ (preto). 
A Fig. 5.12 mostra as curvas ZFC-FC ("zero field cooled - field cooled") das amostras de $\mathrm{CoAl}_{\mathrm{x}} \mathrm{Fe}_{2-\mathrm{x}} \mathrm{O}_{4} \operatorname{com} x=0,00,0,02,1,00$ e 1,50. Para obtenção da curva ZFC a amostra é resfriada até a temperatura de $5 \mathrm{~K}$, e então é aplicado um campo magnético de 100 Oe. Em seguida a amostra é aquecida lentamente para obtenção da magnetização em função da temperatura. Após alcançar a temperatura de $380 \mathrm{~K}$ a amostra é novamente resfriada até 5 $\mathrm{K}$, com a presença do campo magnético, e aquecida lentamente, obtendo assim a curva FC.

A amostra $x=2,00$ apresenta uma curva $M v s T$ tipicamente paramagnética (Fig. 5.12 (a)). Por outro lado, a presença de um pico na curva ZFC nas amostras $x=1,00$ e $x=1,50$ pode ser atribuída a um mecanismo de transição de fase induzido pela competição entre a energia térmica e a energia anisotrópica magnética (Fig. 5.12 (b) e (c)) [63]. O máximo deste pico marca a temperatura de Curie $T_{C}$ destas amostras $(\sim 300 \mathrm{~K}$ para $x=1,00 \mathrm{e}$ $\sim 100 \mathrm{~K}$ para $x=1,50$ ), possuindo comportamento paramagnético para temperaturas acima de $T_{C}$ e comportamento ferrimagnético para temperaturas abaixo de $T_{C}$. As amostras $x=$ 0,00 e 0,20 (Fig 5.12 (d)) não mostra tal comportamento na curva $M$ vs $T$ no intervalo de temperatura estudado, indicando uma temperatura de Curie superior a $380 \mathrm{~K}$.

Evidências da fase vidro de spin também são encontradas nas curvas ZFC - FC das amostras $x=0,00,0,20,1,00$ e 1,50. Observa-se uma queda da magnetização nas curvas FC com a redução da temperatura, sugerindo a passagem do estado descongelado para o estado congelado dos spins. A queda da energia térmica faz com que os spins voltem ao seu estado de menor energia, que corresponde ao arranjo desordenado (estado vidro de spin) [64]. Embora as curvas FC sejam obtidas com campo magnético aplicado de 100 Oe, este campo não é suficiente para alinhar os spins.

Comportamento anômalo foi encontrado na curva $\mathrm{FC}$ da amostra $\mathrm{CoAl}_{1,50} \mathrm{Fe}_{0,50} \mathrm{O}_{4}$, onde foi observada a presença de magnetização negativa. Este comportamento é conhecido como "reversão magnética", e embora incomum, tem sido encontrado em algumas estruturas 
com ordenamento antiferromagnético, ferri- e ferromagnético [65], [66]. Em materiais com ordenamento antiferromagnético, a reversão magnética é comumente explicada pela criação de campos magnéticos internos, criados pelas distorções na subrede principal. Por exemplo, no caso do $\mathrm{GdCrO}_{3}$ (estrutura perovskita) [65], a subrede principal, formada pelos $\mathrm{Cr}^{3+}$, cria um campo efetivo interno nos sítios ocupados pelo $\mathrm{Gd}^{3+}$, que por sua vez se alinha de forma antiparalela ao $\mathrm{Cr}$ [67]. Os valores de magnetização negativa estariam então relacionados ao alinhamento antiparalelo do $\mathrm{Gd}^{3+}$ em relação ao $\mathrm{Cr}^{3+}$. Por outro lado, em amostras de $\mathrm{Co}_{2} \mathrm{VO}_{4}$ (estrutura espinélio), foi sugerido que a reversão magnética está relacionada a diferentes dependências térmicas das interações encontradas na rede [66]. Menyuk et al argumentam que interações (A-B) do tipo $\mathrm{Co}^{2+}-\mathrm{O}^{2-}-\mathrm{Co}^{2+}$, sendo as mais fortes da estrutura $\mathrm{Co}_{2} \mathrm{VO}_{4}$, gerariam um momento magnético alinhado ao campo. Além disso, interações do tipo $\mathrm{Co}^{2+}-\mathrm{O}^{2-}-\mathrm{V}^{4+}(\mathrm{A}-$ B) $\mathrm{e}^{4+}-\mathrm{O}^{2-}-\mathrm{V}^{4+}(\mathrm{B}-\mathrm{B})$, mais fracas que as descritas anteriormente, contribuiriam para o alinhamento do $\mathrm{V}^{4+}$ na direção oposta ao campo aplicado. Dessa forma, o efeito de reversão magnética estaria ligado as diferentes dependências térmicas destas interações, influenciando o ordenamento total dos spins.

Em nossa amostra, o efeito parece estar ligado a diferentes dependências térmicas das interações de supertroca que alinham os spins em cada sítio. Nossa distribuição catiônica sugere fortes interações (A-B) do tipo $\left(\mathrm{Co}^{3+} / \mathrm{Fe}^{3+}\right)-\mathrm{O}^{2-} \mathrm{Co}^{3+}$, além de interações mais fracas (AA) do tipo $\mathrm{Fe}^{3+}-\mathrm{O}^{2-} \mathrm{Co}^{3+}$ e (B-B) do tipo $\mathrm{Co}^{3+}-\mathrm{O}^{2-} \mathrm{Co}^{3+}$. Diferentes dependências térmicas destas interações podem ter causado o efeito de reversão magnética [66]. Entretanto, são necessários estudos mais detalhados para uma investigação mais profunda sobre a origem da reversão magnética encontrada na amostra $x=1,50$. 

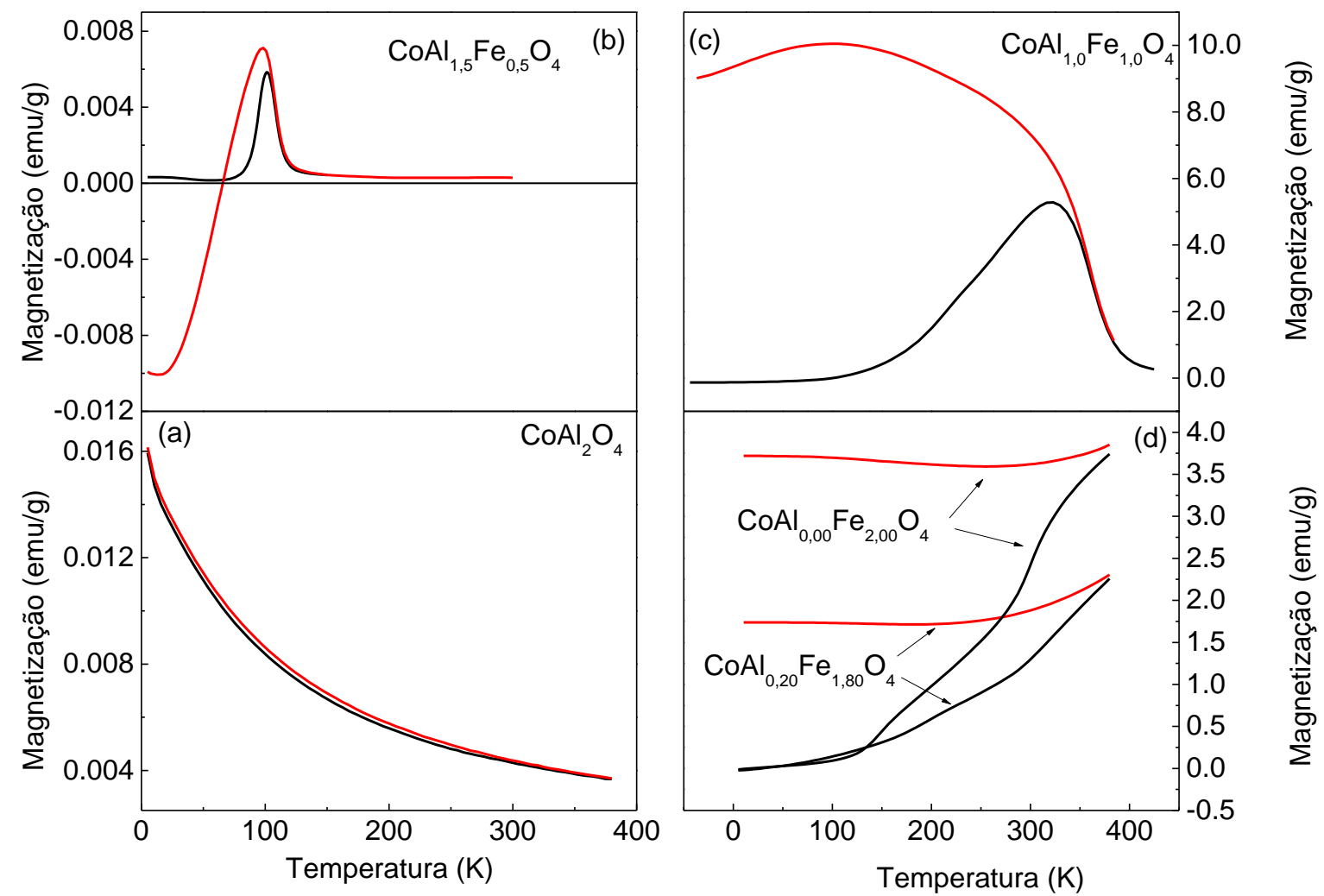

Fig. 5.12: Curvas ZFC(preto)-FC(vermelho) das amostras de $\mathrm{CoAl}_{x} \mathrm{Fe}_{2-\mathrm{x}} \mathrm{O}_{4}$ para $x=0,00,0,20,1,50$ e 2,00. 
Estimativas do valor da anisotropia magnética das amostras podem ser obtidas através da lei de aproximação à saturação, que para medidas a temperatura ambiente (abaixo da temperatura de Curie) é dada por:

$$
M(H)=M_{S}\left[1-\frac{b}{H^{2}}\right]
$$

onde, $M_{S}$ é a magnetização de saturação e $b$ é uma constante relacionada a anisotropia magnetocristalina. Para um sistema cúbico seu valor é dado por $b=\frac{4 K_{e f f}^{2}}{15 M_{S}^{2}}$, onde $K_{e f f}$ corresponde a constante de anisotropia efetiva. Fazendo o ajuste para campos magnéticos $H \gg H_{c}$, obtiveram-se os valores de $K_{\text {eff }}$ listados na Tabela 5.4. Além deste, foram listados os valores de magnetização de saturação $M_{s}$ e campo coercivo $H_{c}$ para as amostras de $\mathrm{CoAl}_{\mathrm{x}} \mathrm{Fe}_{2-\mathrm{x}} \mathrm{O}_{4}$.

Os valores encontrados para magnetização de saturação $M_{S}$ são maiores que os encontrados em trabalhos anteriores sobre o $\mathrm{CoAl}_{\mathrm{x}} \mathrm{Fe}_{2-\mathrm{x}} \mathrm{O}_{4}$, enquanto os valores para a constante de anisotropia efetiva $K_{\text {eff }}$ e campo coercivo $H_{c}$ são consideravelmente menores, da ordem de 300 Oe e $10^{5} \mathrm{erg} / \mathrm{cm}^{3}$, respectivamente $[7,9,10]$.

Em complemento, materiais com altos valores de magnetização e baixos valores $K_{\text {eff }}$ demonstram alta sensibilidade magnetostrictiva $d \lambda / d H$ (magnetostriction strain sensitivity). Magnetorestrição é uma propriedade característica de materiais ferri e ferromagnéticos, que quando submetidos a um campo magnético, variam sua forma e dimensões. Quanto maior $d \lambda / d H$, maior a deformação do material para determinado campo aplicado [62]. A relação entre sensibilidade magnetostrictiva, anisotropia magnética e magnetização é dada pela equação [69]: 


$$
\frac{d \lambda}{d H}=\frac{2 \mu_{0} \lambda_{S} M}{N K_{e f f}}
$$

onde $\lambda$ é a deformação magnetostrictiva, $H$ é o campo magnético aplicado, $\mu_{0}$ é a permeabilidade magnética, $M$ é a magnetização, $K_{e f f}$ é a constante de anisotropia magnética, $\lambda_{S}$ é a magnetorestrição de saturação e $N$ é uma constante que depende da anisotropia do material. Anantharamaiah et al [3] fizeram medidas de sensibilidade magnetostrictiva para amostras de $\mathrm{CoAl}_{0,1} \mathrm{Fe}_{1,9} \mathrm{O}_{4}$ e encontraram $(d \lambda / d H)_{\text {máx }}=-2,47 \cdot 10^{-9} \mathrm{~m} / A \operatorname{com} K_{\text {eff }}=$ $2,00.10^{6} \mathrm{erg} / \mathrm{cm}^{3}$. Considerando apenas variações a diferença na constante de anisotropia efetiva, podemos estimar uma sensibilidade magnetostrictiva máxima aproximadamente três vezes maior do que a encontrada em [3]. Dessa forma, podemos presumir que ferritas de cobalto-alumínio sintetizadas por reação de combustão constituem bons candidatos à aplicação em sensores baseados em torque e estresse, devido à alta sensibilidade magnetocristalina e magnetização de saturação [68]. 
Tabela 5.4: Parâmetros obtidos através de histerese magnética das amostras de $\mathbf{C o A l}_{\mathbf{x}} \mathbf{F e}_{2-\mathbf{x}} \mathbf{O}_{\mathbf{4}}$ a temperatura ambiente. $\left(\boldsymbol{M}_{\boldsymbol{S}}=\right.$ magnetização de saturação, $\boldsymbol{H}_{\boldsymbol{C}}=$ campo coercivo, $\boldsymbol{K}_{\boldsymbol{e f f}}=$ anisotropia magnetocristalina efetiva).

\begin{tabular}{cccc}
\hline $\boldsymbol{A l}(\boldsymbol{x})$ & $\boldsymbol{M}_{\boldsymbol{S}}(\mathbf{e . m . u} . \mathbf{g})$ & $\boldsymbol{H}_{\boldsymbol{C}}(\mathbf{O e})$ & $\boldsymbol{K}_{\boldsymbol{e f f}}\left(\mathbf{e r g} / \mathbf{c m}^{\mathbf{3}}\right)$ \\
0,00 & 76,34 & 350 & \\
0,05 & 88,11 & 324 & $8.69 \mathrm{E}+05$ \\
0,10 & 65,46 & 324 & $6.46 \mathrm{E}+05$ \\
0,20 & 63,76 & 465 & $6.76 \mathrm{E}+05$ \\
0,25 & 73,75 & 146 & $4.15 \mathrm{E}+05$ \\
0,30 & 69,26 & 360 & $7.49 \mathrm{E}+05$ \\
1,00 & 20,26 & 0 & - \\
1,50 & - & - & - \\
2,00 & - & - & - \\
\hline
\end{tabular}




\section{CAPÍTULO 6: CONCLUSÕES E PERSPECTIVAS FUTURAS}

Neste trabalho foram estudadas amostras de $\mathrm{CoAl}_{\mathrm{x}} \mathrm{Fe}_{2-\mathrm{x}} \mathrm{O}_{4} \quad$ com $x=(0,00,0,05,0,10,0,20,0,25,0,30,1,00,1,50$ e 2,00) sintetizadas pelo método de reação de combustão. Suas propriedades estruturais e magnéticas foram analisadas por meio das seguintes técnicas de espectroscopia Mössbauer e Raman, Difração de raios X (DRX) e magnetização.

A análise dos parâmetros hiperfinos obtidos por meio da espectroscopia Mössbauer mostrou uma redução do campo magnético hiperfino (HF) com o aumento no teor de alumínio $A l(x)$ tanto nos sítios tetraédricos quanto nos octaédricos. Os valores de desvio isomérico (IS) nas amostras $x=(0,00-1,00)$ se mantêm praticamente constantes em $0,27 \mathrm{~mm} / \mathrm{s}$ para o sítio A e em $0,17 \mathrm{~mm} / \mathrm{s}$ para o sítio $\mathrm{B}$, indicando uma maior concentração dos elétrons $\mathrm{S}$ nos núcleos de $\mathrm{Fe}^{3+}$ localizados nos sítios de coordenação tetraédrica. Os valores de desvio quadrupolar (QS) indicam pequenos desvios da simetria nos dois sítios nas amostras com $x \leq 0,25$. Além disto, a análise das áreas dos espectros Mössbauer permitiu a quantificação do teor de $\mathrm{Fe}^{3+}$ nos sítios A e B.

Os dados obtidos pelo método da Difração de raios $\mathrm{X}$ foram analisados por meio do método de Rietveld, utilizando o programa GSAS. Foi observado que as nanopartículas têm diâmetro médio de 100 nm, e que o parâmetro de rede reduz linearmente com o aumento no teor de alumínio substitucional. Além disto, foram realizadas simulações dos padrões de DRX para investigar a variação dos difratogramas com o teor de alumínio nos sítios A e B. Foi verificada uma forte correlação entre os picos (220), (400) e a distribuição catiônica dos íons de $\mathrm{Al}^{3+}$. Por meio dos dados obtidos pela simulação, em conjunto com a análise dos Mössbauer, foi determinada a distribuição catiônica das amostras de $\mathrm{CoAl}_{\mathrm{x}} \mathrm{Fe}_{2-\mathrm{x}} \mathrm{O}_{4}$. 
Todos os modos vibracionais previstos pela teoria de grupos foram identificados nos espectros Raman. Foi verificado comportamento de modo único para os modos vibracionais $F_{2 g}(1), F_{2 g}(2)$ e $E_{g}$, com deslocamentos energéticos proporcionais ao teor de alumínio substitucional. Por outro lado, os modos $\mathrm{F}_{2 \mathrm{~g}}(3)$ e o modo $\mathrm{A}_{1 \mathrm{~g}}$ demonstram comportamento de dois modos nas amostras com $x>0,30$. A separação em dois modos foi atribuída a diferentes configurações de vizinhança (sítios octaédrico) dos sítios tetraédricos.

As curvas de $M$ vs $H$ revelaram comportamento típico de materiais magneticamente ordenados para as amostras $x=(0,00-1,50)$ e comportamento típico de materiais magneticamente desordenados para a amostra $x=2,00$ no intervalo de temperatura aqui investigado. Também foi verificado que a magnetização de saturação experimental é da ordem de $30 \%$ menor que a prevista teoricamente. Esta discrepância foi atribuída à existência de um núcleo homogêneo, recoberto por uma casca de spins desordenados, estado conhecido como vidro de spin. Indícios deste estado são evidenciados tanto na existência de irreversibilidade das curvas $\mathrm{M}$ vs $\mathrm{H}$ para altos campos, quanto nas curvas ZFC-FC. Nestas últimas, pode-se observar uma queda na magnetização com a temperatura (curvas FC), demostrando assim a predominância de um estado desordenado de spins. Foram também estimados os valores de constante anisotrópica efetiva $K_{e f f}$, sendo esta consideravelmente menor do que as encontradas em trabalhos anteriores. A combinação de baixa anisotropia efetiva e moderada magnetização de saturação contribui para uma alta sensibilidade magnetostrictiva, fazendo com que as amostras de $\mathrm{CoAl}_{x} \mathrm{Fe}_{2-\mathrm{x}} \mathrm{O}_{4}$ sejam bons candidatos na construção de sensores magnéticos baseados em torque e estresse.

Em trabalhos futuros pretende-se avaliar a extensão dos resultados obtidos pelas simulações de DRX para outros tipos de ferritas, principalmente as quaternárias, onde a obtenção da distribuição catiônica se mostra mais complexa. Também serão realizados mais estudos sobre a razão do desdobramento do modo vibracional $A_{1 \mathrm{~g}}$, e sua relação com a 
distribuição catiônica, problema este que está aberto desde o início do estudo dos modos Raman pela teoria de grupos. Além disso, com a obtenção de mais amostras de $\mathrm{CoAl}_{\mathrm{x}} \mathrm{Fe}_{2-\mathrm{x}} \mathrm{O}_{4}$ na vizinhança de $x=1,50$ poderemos avaliar a dependência do fenômeno de reversão magnética com o teor de alumínio substitucional, além de realizar mais medidas de magnetização em função da temperatura, já que está parece estar relacionada intrinsicamente com o fenômeno. 


\section{REFERÊNCIAS}

[1] SHARIFI, I.; SHOKROLLAHI, H.; AMIRI, S. Ferrite-based magnetic nanofluids used in hyperthermia applications. Journal of Magnetism and Magnetic Materials, v. 324, n. 6, p. 903-915, 2012.

[2] GUBIN, Sergei Pavlovich et al. Magnetic nanoparticles: preparation, structure and properties. Russian Chemical Reviews, v. 74, n. 6, p. 489-520, 2005.

[3] ANANTHARAMAIAH, P. N.; JOY, P. A. Magnetic and magnetostrictive properties of aluminium substituted cobalt ferrite synthesized by citrate-gel method. Journal of Materials Science, v. 50, n. 19, p. 6510$6517,2015$.

[4] NAKAGOMI, F. et al. The influence of cobalt population on the structural properties of CoxFe3-xO4. Journal of applied physics, v. 101, n. 9, p. 9M514, 2007.

[5] SAWATZKY, G. A.; WOUDE, F. VAN DER; MORRISH, A. H. Cation distributions in octahedral and tetrahedral sites of the ferrimagnetic spinel CoFe2O4. Journal of Applied Physics, v. 39, n. 2, p. 1204-1205, 1968.

[6] SAWATZKY, G. A.; VAN DER WOUDE, F.; MORRISH, A. H. Mössbauer study of several ferrimagnetic spinels. Physical Review, v. 187, n. 2, p. 747, 1969.

[7] AGHAV, P. S. et al. Effect of aluminum substitution on the structural and magnetic properties of cobalt ferrite synthesized by sol-gel auto combustion process. Physica B: Condensed Matter, v. 406, n. 23, p. 43504354, 2011.

[8] KUMAR, Lawrence; KUMAR, Pawan; KAR, Manoranjan. Effect of non-magnetic substitution on the structural and magnetic properties of spinel cobalt ferrite ( $\mathrm{CoFe} 2-\mathrm{xAlxO} 4)$ ceramics. Journal of Materials Science: Materials in Electronics, v. 24, n. 8, p. 2706-2715, 2013. 
[9] KUMAR, Lawrence; KAR, Manoranjan. Influence of Al 3+ ion concentration on the crystal structure and magnetic anisotropy of nanocrystalline spinel cobalt ferrite. Journal of Magnetism and Magnetic Materials, v. 323, n. 15, p. 2042-2048, 2011.

[10] SINGHAL, Sonal; BARTHWAL, S. K.; CHANDRA, Kailash. XRD, magnetic and Mössbauer spectral studies of nano size aluminum substituted cobalt ferrites (CoAlxFe 2- $\mathrm{xO} 4)$. Journal of magnetism and magnetic materials, v. 306, n. 2, p. 233-240, 2006.

[11] FRANCO, Adolfo et al. Synthesis of nanoparticles of CoxFe (3- x) O 4 by combustion reaction method. Journal of magnetism and magnetic materials, v. 308, n. 2, p. 198-202, 2007.

[12] ALVES, Annelise Kopp; BERGMANN, Carlos P.; BERUTTI, Felipe Amorim. Novel synthesis and characterization of nanostructured materials. Springer, 2013.

[13] SALA, Oswaldo. Fundamentos da espectroscopia Raman e no infravermelho. Unesp, 1996.

[14] Fundamentals \& Technology of Raman Spectroscopy, Introduction. Königswinter, Germany, 2016; http://www.raman.de/ (acessado em setembro de 2016).

[15] KEVLES, Bettyann. Naked to the bone: medical imaging in the twentieth century. Basic Books, 1998.

[16] CULLITY, Bernard Dennis. Elements of X-ray Diffraction. 2001.

[17] Powder Diffraction on the WEB, Crystallite Size and Strain. Birkbeck College, University of London. Copyright 1997-2006; http://pd.chem.ucl.ac.uk/pdnn/peaks/size.htm (acessado em setembro de 2016).

[18] DICKSON, Dominic PE; BERRY, Frank J. (Ed.). Mossbauer spectroscopy. Cambridge, UK: Cambridge University Press, 1986. 
[19] DYAR, M. Darby et al. Mössbauer spectroscopy of earth and planetary materials. Annu. Rev. Earth Planet. Sci., v. 34, p. 83-125, 2006.

[20] MATHEW, Daliya S.; JUANG, Ruey-Shin. An overview of the structure and magnetism of spinel ferrite nanoparticles and their synthesis in microemulsions. Chemical Engineering Journal, v. 129, n. 1, p. 51-65, 2007.

[21] HAMMOND, Christopher. The basics of crystallography and diffraction. Oxford: Oxford University Press, 2009.

[22] SICKAFUS, Kurt E.; WILLS, John M.; GRIMES, Norman W. Structure of spinel. Journal of the American Ceramic Society, v. 82, n. 12, p. 3279-3292, 1999.

[23] MOHAPATRA, Sasmita et al. Monodisperse mesoporous cobalt ferrite nanoparticles: synthesis and application in targeted delivery of antitumor drugs. Journal of Materials Chemistry, v. 21, n. 25, p. 9185-9193, 2011 .

[24] LIMAYE, Mukta V. et al. High coercivity of oleic acid capped CoFe2O4 nanoparticles at room temperature. The Journal of Physical Chemistry B, v. 113, n. 27, p. 9070-9076, 2009.

[25] TOKSHA, B. G. et al. Structural investigations and magnetic properties of cobalt ferrite nanoparticles prepared by sol-gel auto combustion method. Solid State Communications, v. 147, n. 11, p. 479-483, 2008.

[26] KURAJICA, Stanislav et al. The effect of annealing temperature on the structure and optical properties of sol-gel derived nanocrystalline cobalt aluminate spinel. Materials Chemistry and Physics, v. 135, n. 2 , p. $587-$ 593,2012

[27] TIELENS, F. et al. Periodic DFT study of the structural and electronic properties of bulk CoAl2O4 spinel. The Journal of Physical Chemistry B, v. 110, n. 2, p. 988-995, 2006.

[28] TORIUMI, K. et al. Electron-density distribution in crystals of CoAl2O4. Acta Crystallographica Section B: Structural Crystallography and Crystal Chemistry, v. 34, n. 4, p. 1093-1096, 1978. 
[29] TIELENS, Frederik et al. Theoretical investigation of the inversion parameter in $\mathrm{Co} 3-\mathrm{s} \mathrm{Al} \mathrm{s} \mathrm{O} 4$ (s=0-3) spinel structures. Solid State Ionics, v. 180, n. 14, p. 1011-1016, 2009.

[30] WALDRON, R. D. Infrared spectra of ferrites. Physical review, v. 99, n. 6, p. 1727, 1955.

[31] WHITE, W. B.; DEANGELIS, B. A. Interpretation of the vibrational spectra of spinels. Spectrochimica Acta Part A: Molecular Spectroscopy, v. 23, n. 4, p. 985-995, 1967.

[32] KUSHWAHA, A. K. Study of interatomic interactions in chromite spinel CoCr2O4. Chinese Journal of Physics, v. 47, n. 3, p. 355-360, 2009.

[33] KUSHWAHA, A. K.; KUSHWAHA, S. S. Zone-centre phonon frequencies of oxide spinels. Chinese Journal of Physics, v. 45, n. 3, p. 363-373, 2007.

[34] GUPTA, H. C. et al. A study of the interatomic interaction in oxide spinel $\mathrm{MnCr} 2 \mathrm{O}$ 4. Physica B: Condensed Matter, v. 192, n. 4, p. 343-344, 1993.

[35] SINHA, M. M. Vibrational analysis of optical phonons in mixed chromite spinels. Nuclear Instruments and Methods in Physics Research Section B: Beam Interactions with Materials and Atoms, v. 153, n. 1, p. 183-185, 1999.

[36] VERBLE, J. Larry. Temperature-dependent light-scattering studies of the Verwey transition and electronic disorder in magnetite. Physical Review B, v. 9, n. 12, p. 5236, 1974.

[37] YAMANAKA, Takamitsu; ISHII, Motohiko. Raman scattering and lattice vibrations of Ni2SiO4 spinel at elevated temperature. Physics and Chemistry of Minerals, v. 13, n. 3, p. 156-160, 1986.

[38] CYNN, H. et al. High-temperature Raman investigation of order-disorder behavior in the MgAl $2 \mathrm{O} 4$ spinel. Physical Review B, v. 45, n. 1, p. 500, 1992. 
[39] VAN MINH, Nguyen; YANG, In-Sang. A Raman study of cation-disorder transition temperature of natural MgAl 2 O 4 spinel. Vibrational spectroscopy, v. 35, n. 1, p. 93-96, 2004.

[40] PREUDHOMME, J.; TARTE, P. Infrared studies of spinels-III: the normal II-III spinels. Spectrochimica Acta Part A: Molecular Spectroscopy, v. 27, n. 9, p. 1817-1835, 1971.

[41] LAGUNA-BERCERO, M. A.; SANJUAN, M. L.; MERINO, R. I. Raman spectroscopic study of cation disorder in poly-and single crystals of the nickel aluminate spinel. Journal of Physics: Condensed Matter, v. 19, n. 18, p. $186217,2007$.

[42] DA SILVA, S. W. et al. Raman study of cations' distribution in Zn x Mg1- x Fe2O4 nanoparticles. Journal of Nanoparticle Research, v. 14, n. 4, p. 1-10, 2012.

[43] NAKAGOMI, F. et al. Influence of the Mg-content on the cation distribution in cubic MgxFe 3- xO 4 nanoparticles. Journal of Solid State Chemistry, v. 182, n. 9, p. 2423-2429, 2009.

[44] HOSTERMAN, Brian D. Raman spectroscopic study of solid solution spinel oxides. 2011.

[45] PREUDHOMME, J.; TARTE, P. Infrared studies of spinels-II: The experimental bases for solving the assignment problem. Spectrochimica Acta Part A: Molecular Spectroscopy, v. 27, n. 6, p. 845-851, 1971.

[46] CHANG, I. F.; MITRA, S. S. Long wavelength optical phonons in mixed crystals. Advances in Physics, v. 20, n. 85 , p. $359-404,1971$.

[47] BOUCHARD, Michel; GAMBARDELLA, Alessa. Raman microscopy study of synthetic cobalt blue spinels used in the field of art. Journal of Raman Spectroscopy, v. 41, n. 11, p. 1477-1485, 2010.

[48] PATIL, K. C. Advanced ceramics: combustion synthesis and properties.Bulletin of Materials Science, v. 16, n. 6, p. 533-541, 1993. 
[49] KIM, Sam Jin; JUNG, Kwang-Deog; KIM, Chul Sung. Mössbauer and Neutron Diffraction Studies on CoAl Ferrite. Hyperfine interactions, v. 156, n. 1-4, p. 113-122, 2004.

[50] LARSON, A. C.; VON DREELE, R. B. General Structure Analysis System (GSAS); Report LAUR 86-748; Los Alamos National Laboratory: Los Alamos, NM, 2000.

[51] TOBY, Brian H. EXPGUI, a graphical user interface for GSAS. Journal of applied crystallography, v. 34, n. 2, p. 210-213, 2001 .

[52] SHANNON, RD T.; PREWITT, C. Tfc. Effective ionic radii in oxides and fluorides. Acta Crystallographica Section B: Structural Crystallography and Crystal Chemistry, v. 25, n. 5, p. 925-946, 1969.

[53] WILliAMSON, G. K.; HALL, W. H. X-ray line broadening from filed aluminium and wolfram. Acta metallurgica, v. 1, n. 1, p. 22-31, 1953.

[54] SHIRAI, Hiroshi; MORIOKA, Yoshiyuki; NAKAGAWA, Ichiro. Infrared and Raman spectra and lattice vibrations of some oxide spinels. Journal of the Physical Society of Japan, v. 51, n. 2, p. 592-597, 1982.

[55] JONGSOMJIT, Bunjerd; PANPRANOT, Joongjai; GOODWIN, James G. Co-support compound formation in alumina-supported cobalt catalysts. Journal of Catalysis, v. 204, n. 1, p. 98-109, 2001.

[56] WOJDYR, Marcin. Fityk: a general-purpose peak fitting program. Journal of Applied Crystallography, v. 43, n. 5, p. 1126-1128, 2010.

[57] CHANDRAMOHAN, P. et al. Cation distribution and particle size effect on Raman spectrum of CoFe $2 \mathrm{O}$ 4. Journal of Solid State Chemistry, v. 184, n. 1, p. 89-96, 2011.

[58] LEE, Dong Hoon et al. Characterization of the magnetic properties and transport mechanisms of Co x Fe 3x O 4 spinel. Solid state communications, v. 96, n. 7, p. 445-449, 1995. 
[59] KIM, Sam Jin; MYOUNG, Bo Ra; KIM, Chul Sung. Neutron diffraction and exchange interaction on CoAlxFe2- xO4 ( $\mathrm{x}=0.1,0.2)$. Journal of magnetism and magnetic materials, v. 272, p. 2161-2162, 2004.

[60] ŠEPELÁK, Vladimir et al. Nonequilibrium cation distribution, canted spin arrangement, and enhanced magnetization in nanosized $\mathrm{MgFe} 2 \mathrm{O} 4$ prepared by a one-step mechanochemical route. Chemistry of materials, v. 18, n. 13, p. 3057-3067, 2006.

[61] KODAMA, R. H. et al. Surface spin disorder in ferrite nanoparticles. Journal of Applied Physics, v. 81, n. 8, p. 5552-5557, 1997.

[62] RECHENBERG, Hercilio Rodolfo et al. Surface spin disorder in nickel ferrite nanomagnets studied by infield Mössbauer spectroscopy. In: ICAME 2007. Springer Berlin Heidelberg, 2008. p. 423-428.

[63] ZHANG, Q. et al. Magnetic properties and spin-glass-like behavior in stoichiometric Mn3In compound. Journal of Applied Physics, v. 106, n. 11, 2009.

[64] SONG, Hyon-Min; ZINK, Jeffrey I.; KHASHAB, Niveen M. Seeded growth of ferrite nanoparticles from Mn oxides: observation of anomalies in magnetic transitions. Physical Chemistry Chemical Physics, v. 17, n. 28, p. $18825-18833,2015$.

[65] YOSHII, K. Magnetic properties of perovskite GdCrO 3. Journal of Solid State Chemistry, v. 159, n. 1, p. 204-208, 2001.

[66] MENYUK, N.; DWIGHT, K.; WICKHAM, D. G. Magnetization reversal and asymmetry in cobalt vanadate (IV). Physical Review Letters, v. 4, n. 3, p. 119, 1960.

[67] COOKE, A. H.; MARTIN, D. M.; WELLS, M. R. Magnetic interactions in gadolinium orthochromite, GdCrO3. Journal of Physics C: Solid State Physics, v. 7, n. 17, p. 3133, 1974. 
[68] RANVAH, Naresh. Investigation of chemically substituted cobalt ferrite for high magnetostriction based sensor and actuator applications. 2010. Tese de Doutorado. CARDIFF UNIVERSITY (UNITED KINGDOM).

[69] CHEN, Y. et al. Magnetomechanical effects under torsional strain in iron, cobalt and nickel. Journal of Magnetism and Magnetic materials, v. 236, n. 1, p. 131-138, 2001. 